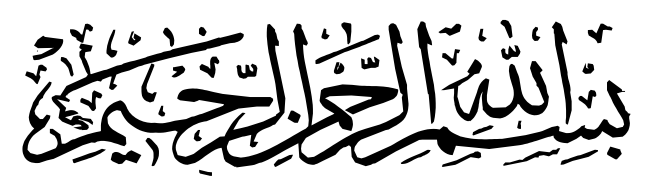

دراسة للفروق بين الأطفال الذين يعانون صعوبات تعلم الرياضيات

$$
\begin{aligned}
& \text { والأطفال الأسوياء في الأداء على بعض الاطفال المتغيرات الانفعالية } \\
& \text { /الاجتماعية }
\end{aligned}
$$

إعداد

ككتمر / خالك السيد هحمد زيادة إعداد

قسم علم النفس - كلية الآداب جامعة المنوفية 


\title{
دراسة للفروق بين الأطفال الذين يعانون صعوبات تعلم الرياضيات والأطفال الأسوياء في الأداء على الألي بعض المتغيرات الانفعالية / الاجتماعية
}

\author{
إعداد الدكتور/ خالد السيد زيادة \\ قسم علم النفس- كلية الآداب-جامعة المنوفية السيد
}

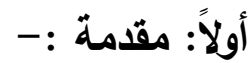

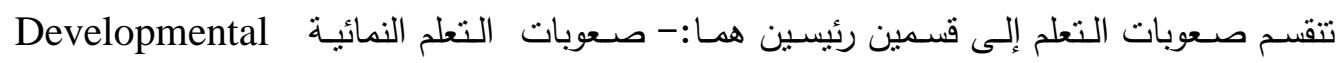

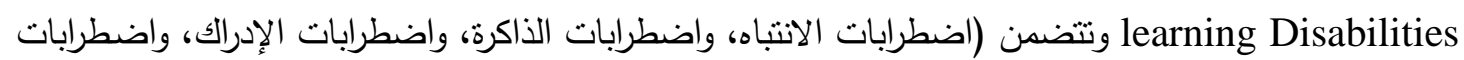

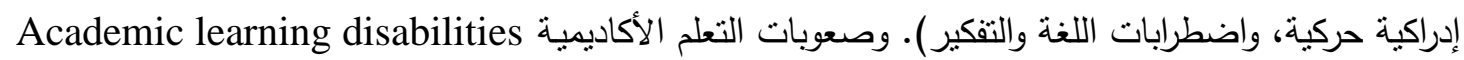

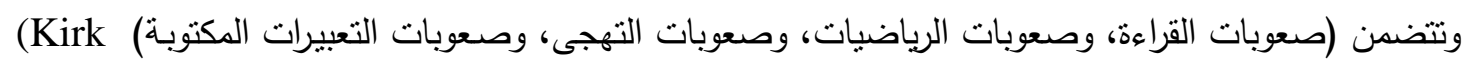
.\& Gallagher, 1989)

وتعد صعوبات تعلم الرياضيات من الصـوبات الأكاديميـة الأكثر انتشـارا بين الأطفال في مرحلـة

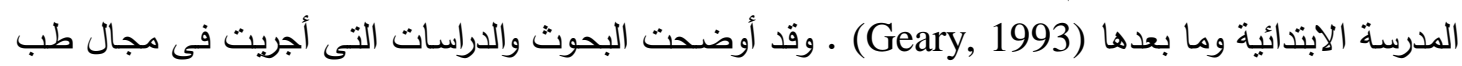

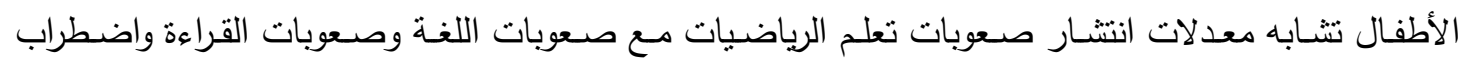

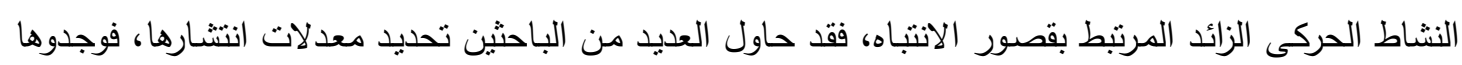

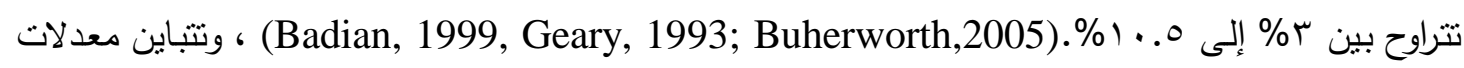

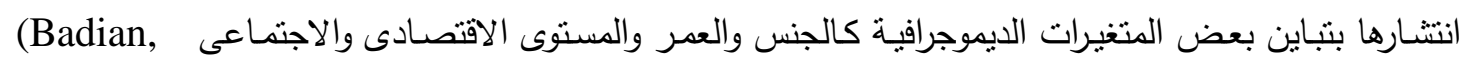

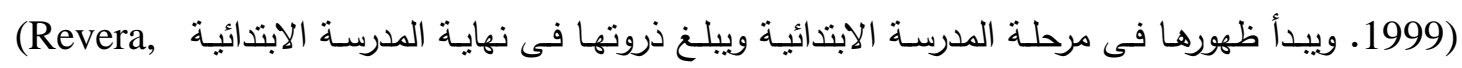

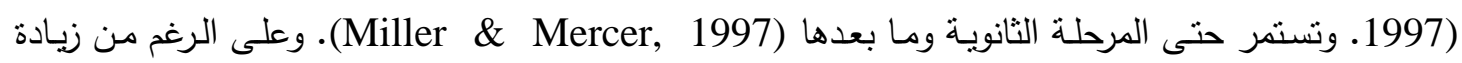

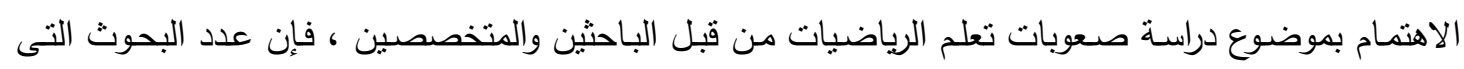

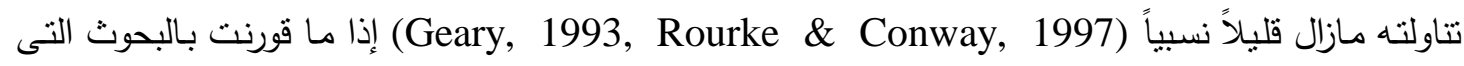

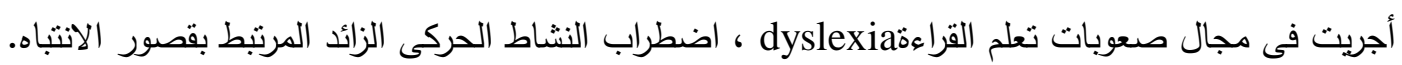

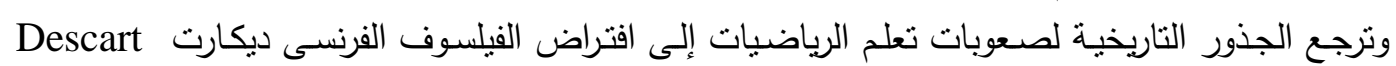

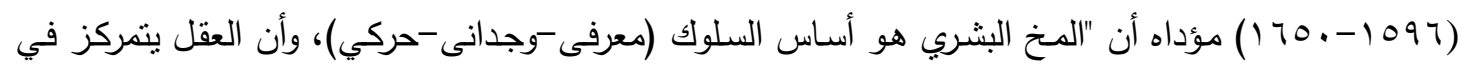

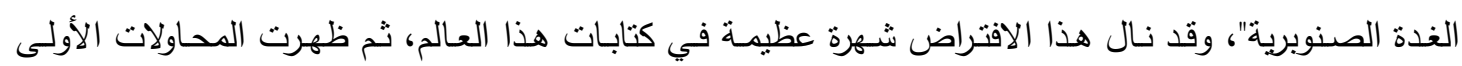

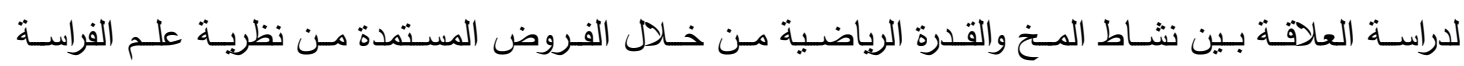
Phrenological Theory فيها أن مختلف القدرات تتموضع في المناطق المختلفة للهخ، وأن تلك الملكات تنعكس على حجم الجمجمة في

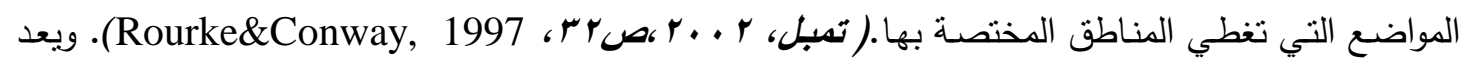
لوندوسكي وستادلمان Lewandowsky and Stadelman أول من نشر دراسة مفصلة عن الاختلال الوظيفي

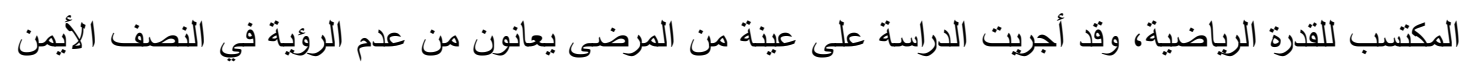

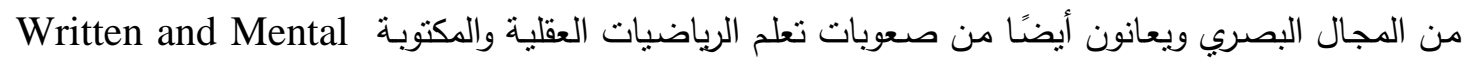
Calculation

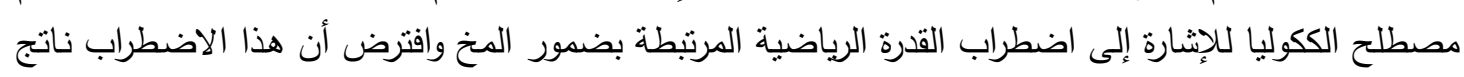

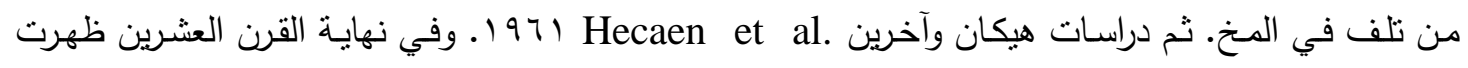


الدراسات التي اهتمت بدراسة النواحي الوراثية، والمعرفية، ودراسة صعوبة تعلم الرياضيات مـع الزملات المرضية الأخرى (Ried\&Hresko1981, Rourke and Conway, 1997).

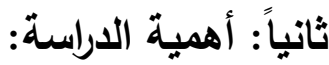

ترجع أهمية دراسة صعويات تعلم الرياضيات إلى عدة أسباب منها:-

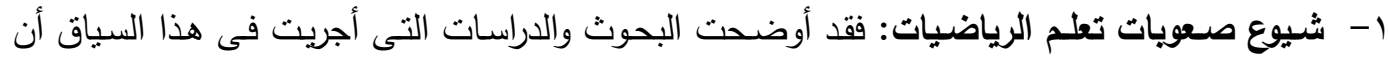

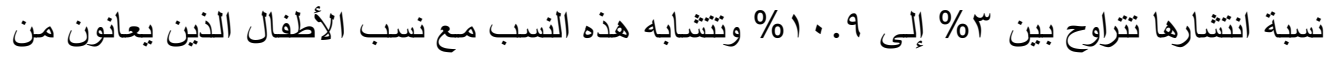

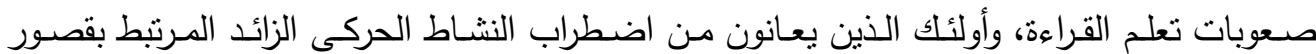
الانتباه) (Geary, 1993; Butterworth, 2005, Badian, 1999)

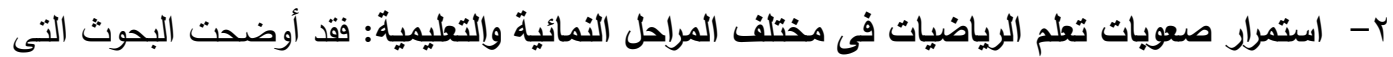

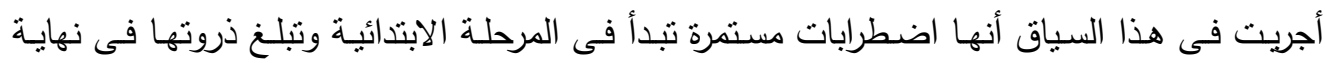

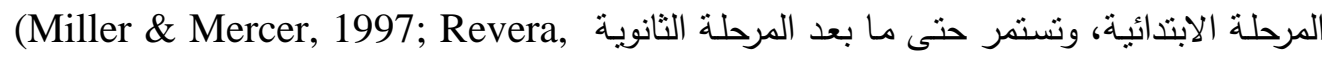
. 1997)

r- ارتباط صعويات تعلم الرياضيات بالعديد من الاضطرابات النمائية الأخرى : مثل زملة أسبرجر ، وزملة

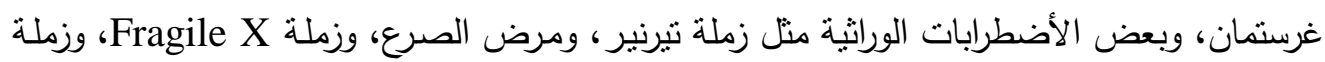
الفص الأيمن النمائى Gross- Tsur, Manor \& Amir, 1995; Shalev, Manor \& Gross) .Tsur, 1997)

ع - ارتباط صعويات تعلم الرياضيات بالعديل من صعويات التعلم الأكاديمية: مثل صعوبة تعلم القراءة،

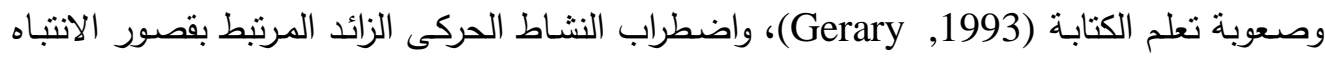
(Shalev, et al., 1997 Monuteax, Faraone, Herzig, Navsaria \& .(Biedermorn,2005

0- عدم الاهتمـام الكـافي بصعويات تعلم الرياضيات فعلى الرغم من تنـابه نسب انتشـارها مـع انتشـار صـوبات تعلم القراءة، واضطراب النشـاط الحركى الزائد المرتبط بقصسور الانتبـاه ، مـازال الاهتمـام ضئيلاً نسبياً مقارنه باضطراب النشاط الحركى الزائد المرتبط بقصور الانتباه

القراءة) (Geary, 1993; Badian, 1999)

ويتبنى الآباء، والباحثتن افتراض مهم مؤداه " أن مفهوم الذات والذكاء عوامل للنجاح الأكاديمي". فالأطفال ذوو نسب الذكاء المرتفعة ولديهم شعور جيد نحو ذاتهم وينقون في قدراتهم على إقامة علاقات جيدة مع أقرانهم يكونون أكثر نجاحا في النواحي الأكاديمية مقارنة بنظرائهم (Kershner, 1990). وعلى دئى

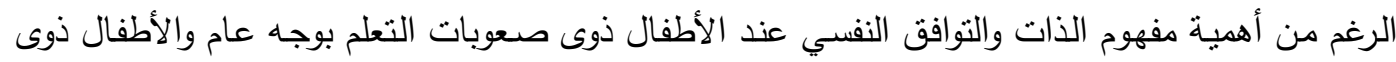

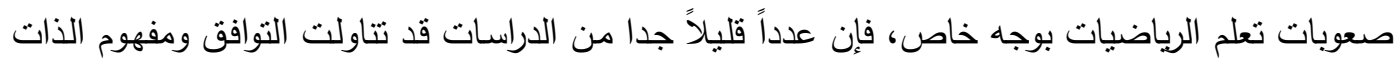

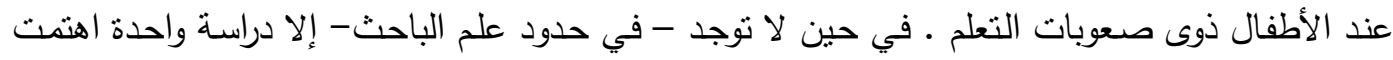

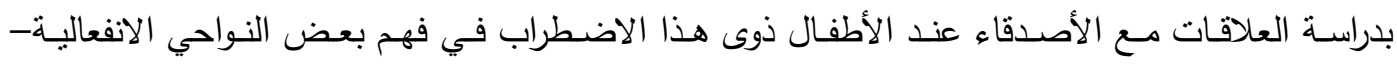

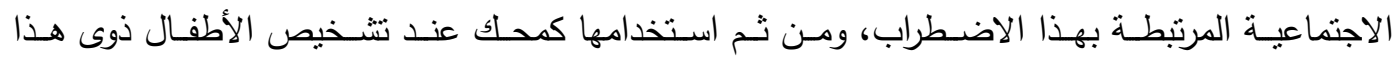

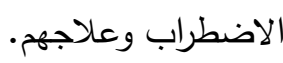


1- التعرف على الفروق بين الأطفال ذوى صعوبات تعلم والأطفال الأسوياء في الأداء على مقياس بيرز هاريس لقياس مفهوم الذات

r- التعرف على الفروق بين الأطفال ذوى صعوبات تعلم والأطفال الأسوياء في الأداء على قائمة كاسيل

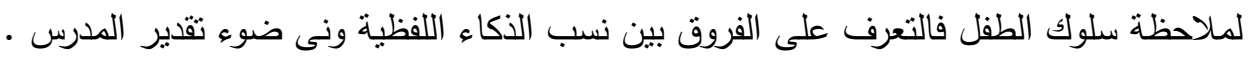

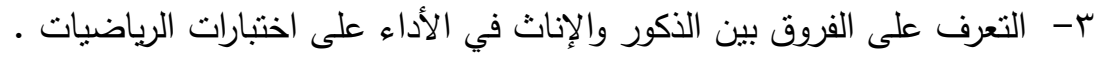

رابعاً: تعريف مصطلحات الدراسة

1 - 1 صعويات تعلم الرياضيات

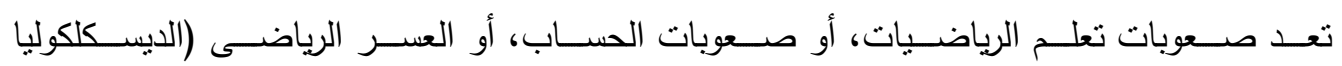

Dyscalculia Developmental Dyscalculia

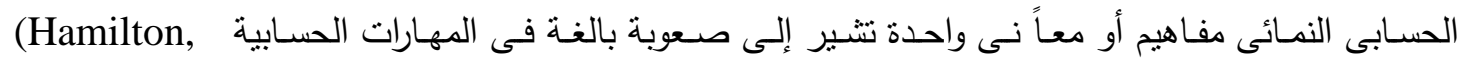
1996,97)

ويرى كوسك Cited in: Rourke \& Conway, 1997) 19 \ Kosc) أن صعوبات تعلم الرياضيات

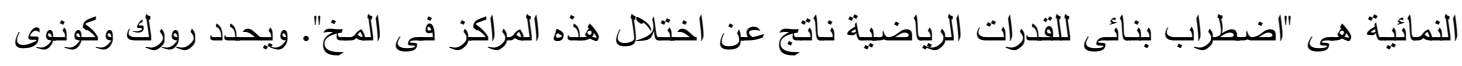
(Rourke \& Conway, 1997)

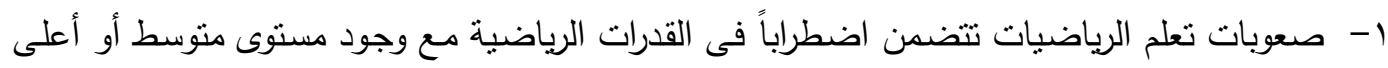
من المتوسط فى القدرة العقلية العامة.

r- تحدد صـعوبات تعلم الرياضيات مـن خـلال العلاقـة بين القدرة الرياضـية الحاليـة للطفل والقدرات

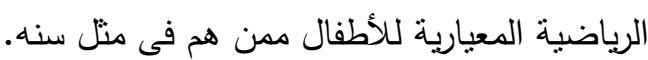

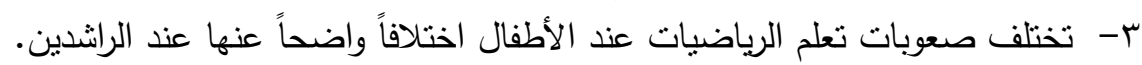

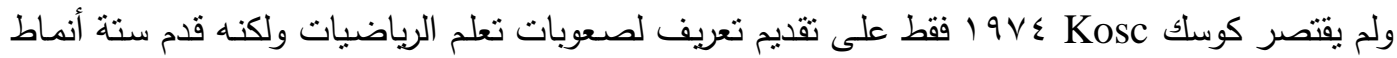
فرعية من صعوبات تعلم الرياضيات تتتشر عند الأطفال والراشدين وهى تفريف

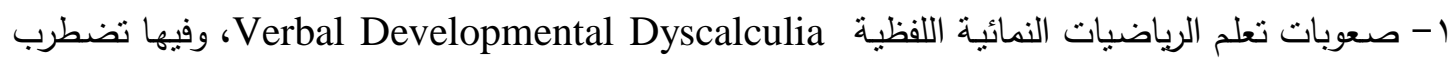
القدرة على تسمية المصطلحات Terms والعلاقات Relations والرموز Symbols الرياضية.

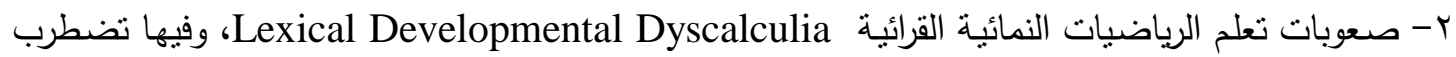
mathematical signs القدرة على قراءة الرموز والإشارات الرياضية

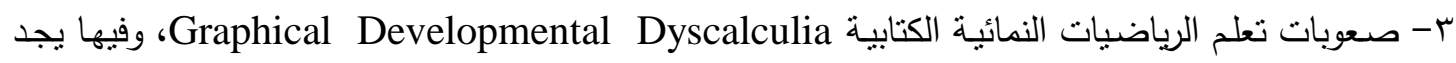
Operational Number and Symbols الطفل صعوبة فى كتابة الأعداد والرموز الحسابية الكابية ع - صعوبات تعلم الرياضيات النمائية الإجرائية Operational Developmental Dyscalculia، وفية ولابية وفيها يجد الطفل صعوبة فى إجراء العمليات الحسابية مثل الجمع والطرح والضرب الضرب والقسمة.

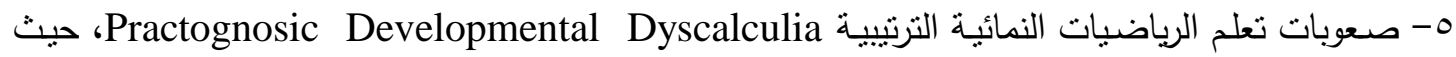

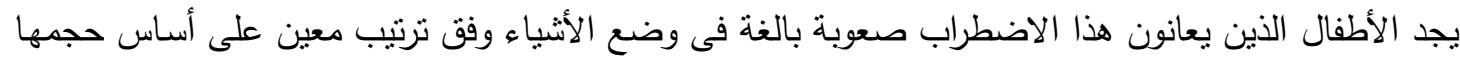

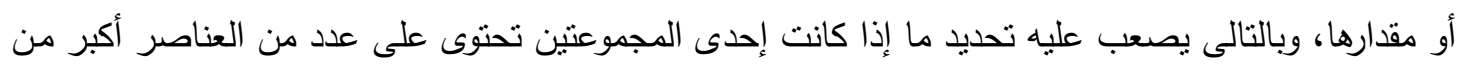

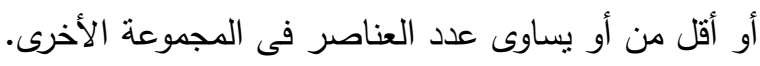

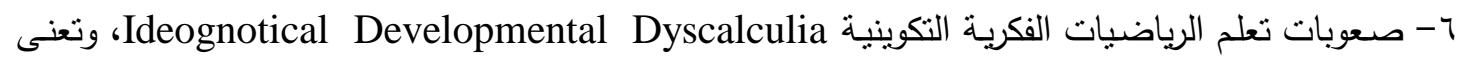
عدم القدرة على فهم الأفكار الرياضية Mathematical ideas، والعلاقات الخاصة بالحساب العقلى Mental 
ماكئم. Calculation ما يكتبونه أو ينطقونه.

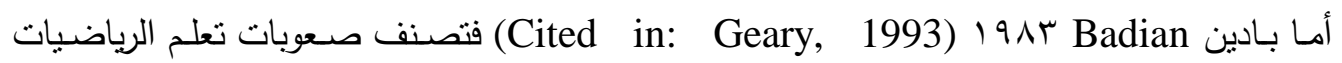
(الديسلكولبا) إلىى: (الى بادن)

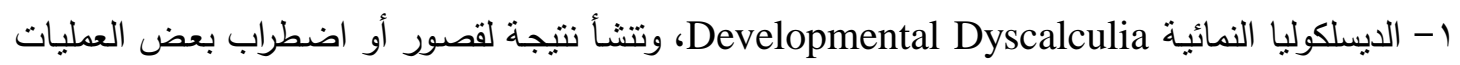
المعرفية منل الانتباه، والإدراك، والذاكرة، والتصور البصري المكاني، البكاني، معالجة المعلومات.

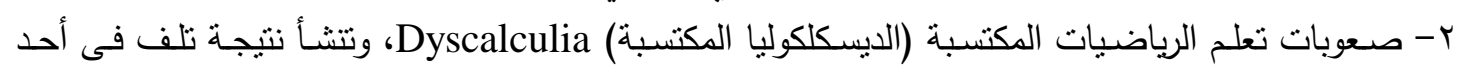
نصفى المخ أو كليهما. أما كورسين (Corsini, 1999) فيميز في قاموسـه بين ثناث مصطلحات مرتبطة بصعوبات تعلم الرياضيات هى:

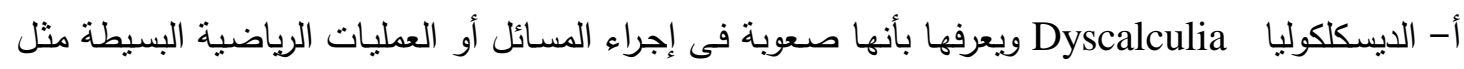

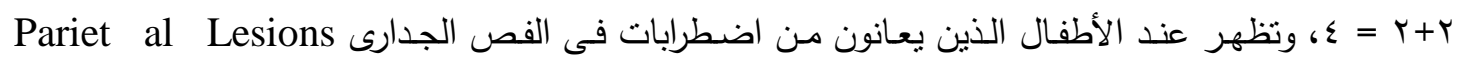

.(Corsini, 1999, 305)

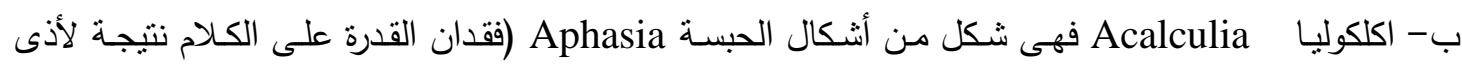

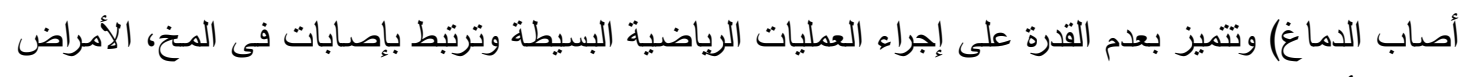

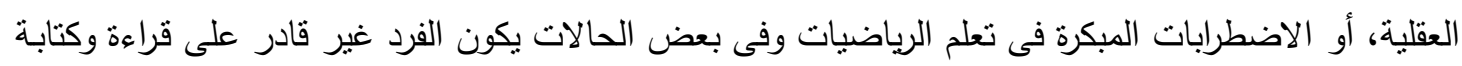

الأعداد (Corsini, 1999, 6) ج- اللاحسابية Anarithmia وتعنى أيضًا شكل من أثنكال الحبسة تتميز بعدم القدرة على العد، واستخدام العدد (Corsini, 1999, 47).

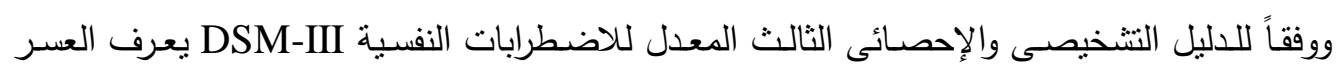

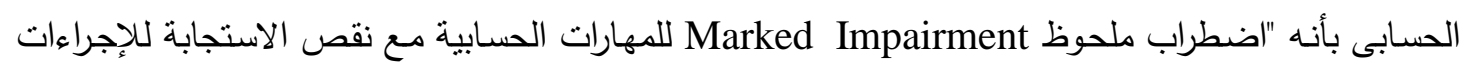
العلاجية Remedial والتربوية Educational (Shalev, Manor \& Kerem, 2001).

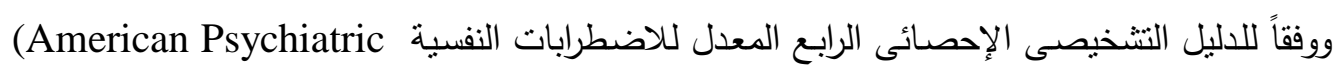
Association, 2004, 53) أ- انخفاض القدرة الحسابية، كما تقيسها الاختبارات المقننة المطبقة بشكل فردى بدرجة ملحوظة عمات هو منوقع

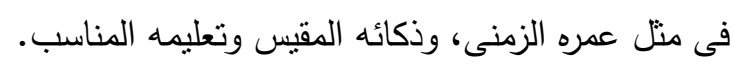
ب- الاضطراب الموجود فى (أ) يعيق بدرجة ملحوظة تحصيله الدراسى، أو أنشطة حياته اليومية التى تتطلب القدرة الحسابية. ج- صعوبات القدرة الحسابية فى حالة وجود قصور حسى تتجاوز ما هو مألوف فى هذه الحالة.((')

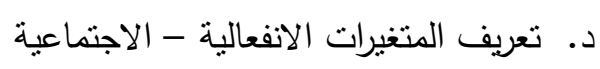

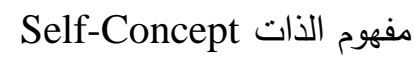
نظرا لأن الدراسـة الحالية تستخدم مقياس بيرز -هاريس Piers- Harris فإن التعريف الوارد في المقياس يعد

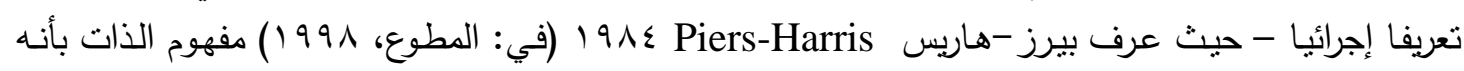

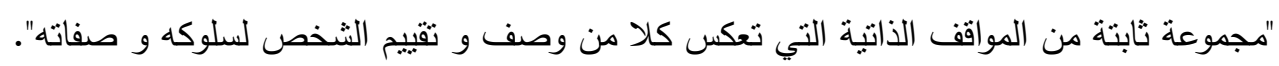

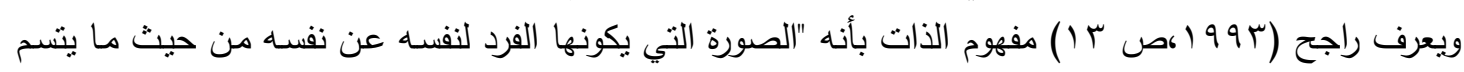
به من صفات وقدرات جسمية وعقلية وانفعالية". 
أما في ضوء مقياس مفهوم الذات متعدد الأبعاد(The Multidimensional Self-Concept (MSCST من Then

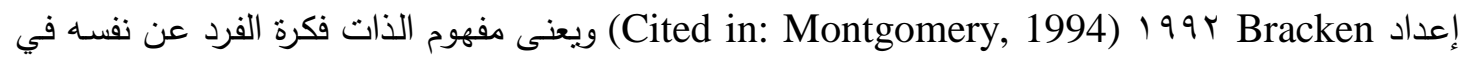

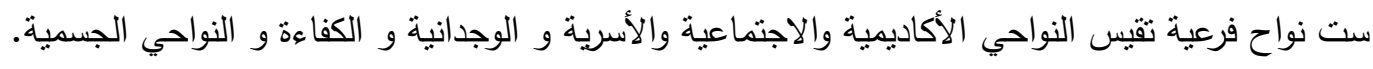

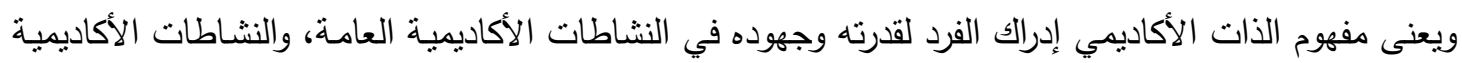
الخاصة (الرياضيات -القراءة -العلوم).

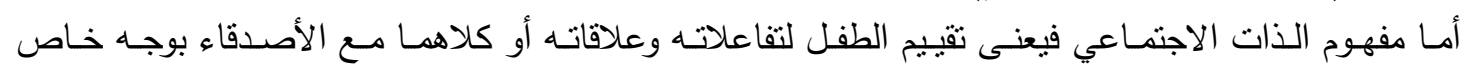
والآخرين بوجه عام.

ويحدد مفهوم الذات الأسرى إدراكات الطفل للتدعيم الانفعالي الذي يتلقاه من الأسرة.

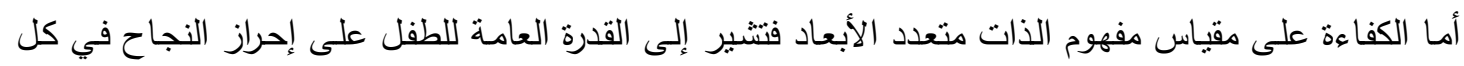

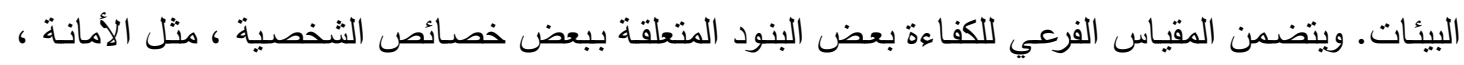
الصدق، التكاسل ، والجبن. أما مفهوم الذات الوجداني فيتعلق بالاستجابات والمشاعر الانفعالية نحو قدراته. ومن الأمتلة على البنود للمفهوم

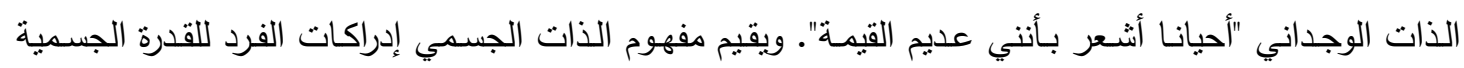

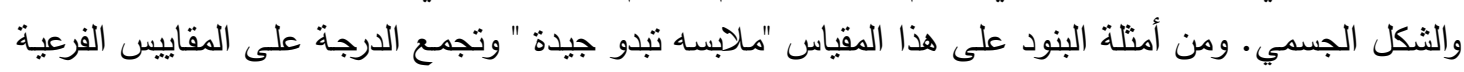

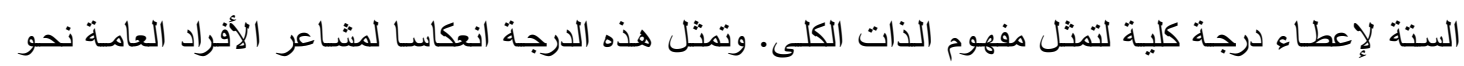

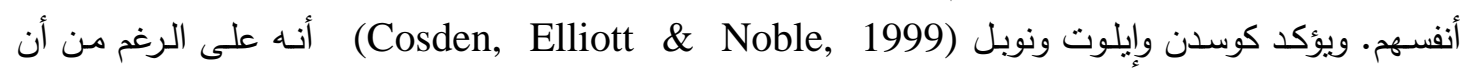

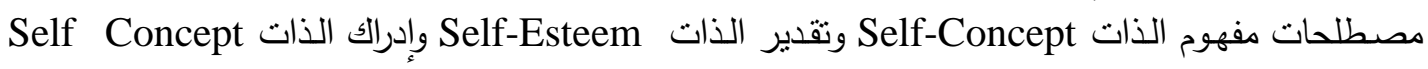

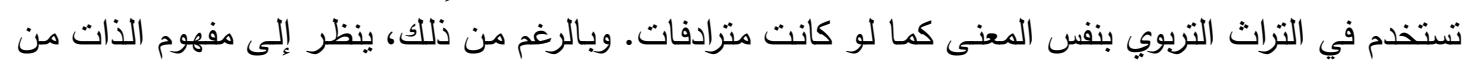

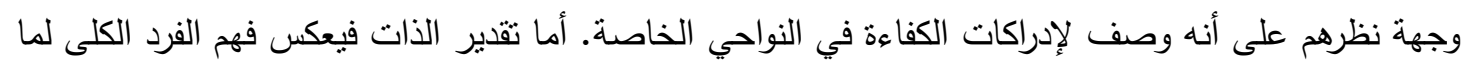
هو عليه. في حين إدراك الذات لصعوبة تعلم الفرد فتعكس فهم الفرد للخصائص النوعية المرتبطة من المعاناة

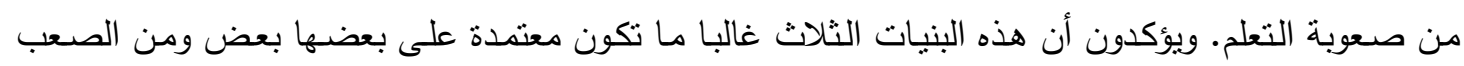

تحديدها كبنيات منفصلة.

ويعرف براين Bryan 199 (Cited in: Wong, 1996, 94) مفهوم الذات بأنه فهم الثخص لصفاته و الطرق التي بها يب أو يكره الآخرين. التوافق Adjustment

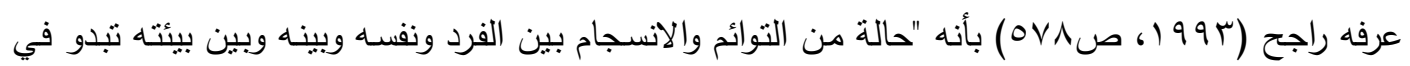

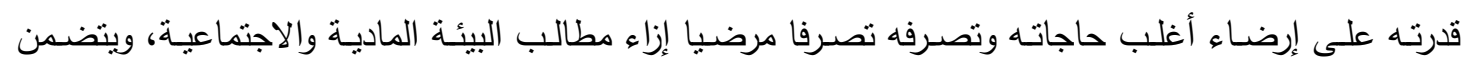

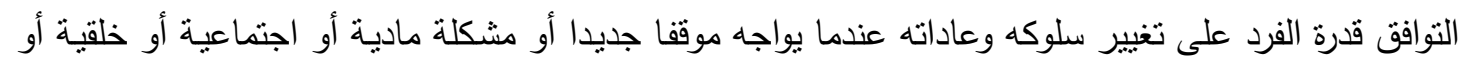
صراعا نفسيا تغيراً يناسب هذه الظروف الجديدة. فإن عجز الفرد عن إقامة هذا التواؤم والانسجام بينه وبين نفسها

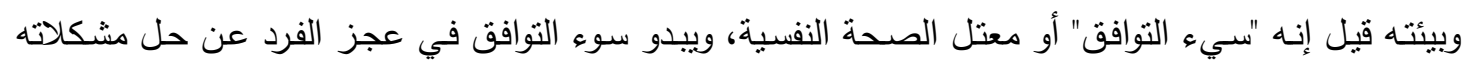

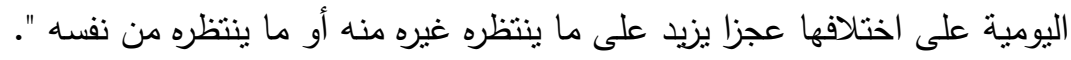

خامسا :- الارراسات السابقة علية

أجريث بعض الدراسات العربية التي اهتمت بدراسة بعض النواحي الوجدانية عند الأطفال ذوو

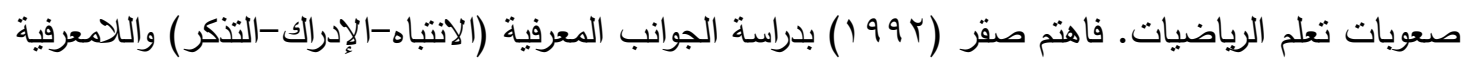

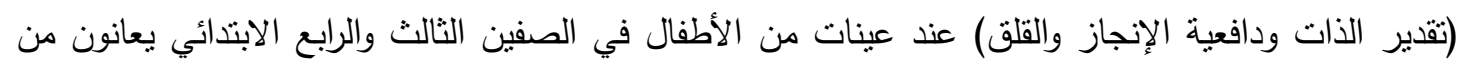

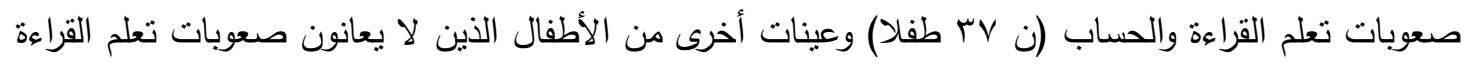

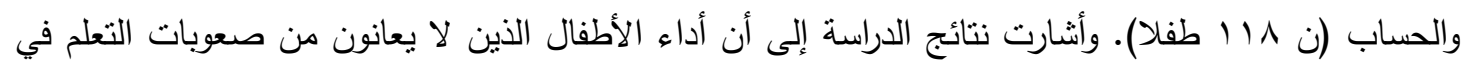


القراءة والحساب أفضل على نحو دال مقارنة بأداء الأطفال الذين لا يعانون من صعوبات التعلم في القراءة و

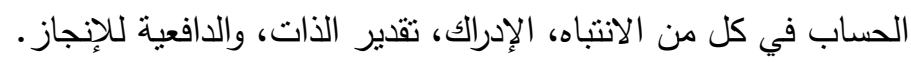

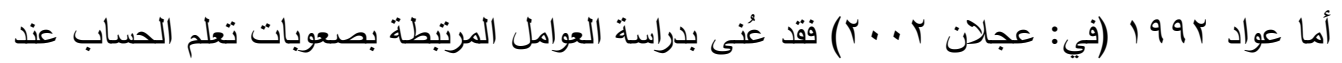
عينة من أطفال الصف الثالث الابتدائي تعاني من صعوبة تعلم الحساب (ن= •r) وعينة أخرى تماتلها لا تعاني

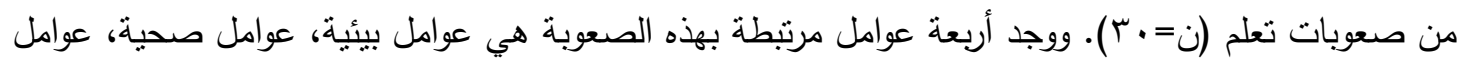

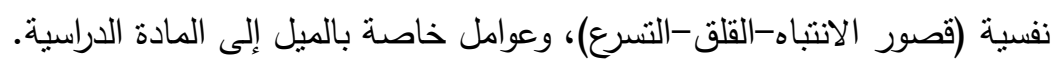

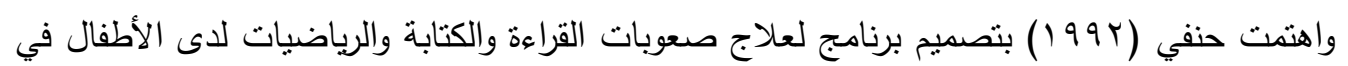

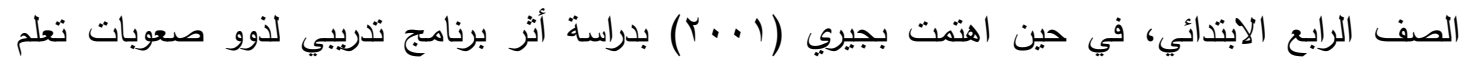
الرياضيات في ضوء نظرية معالجة المعلومات. وعلى نحو أكثر حداثة ، أجرت عجلان (r...r) دراسة للعلاقة بين صعوبات التعلم الأكاديمية

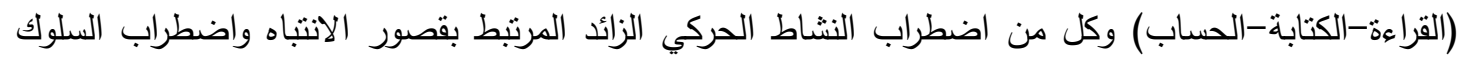
لاى تلاميذ المرحلة الابتدائية. بعض الجوانب غير المعرفية عند الأطفال ذوى صعوبات تعلم الرياضيات. لإنهات.

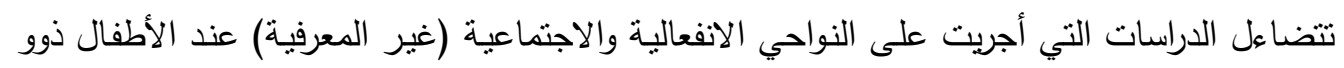

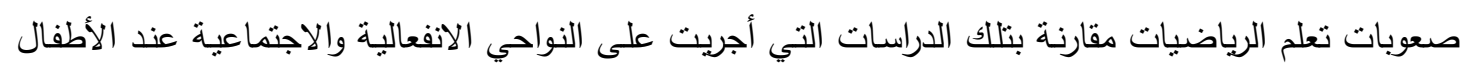

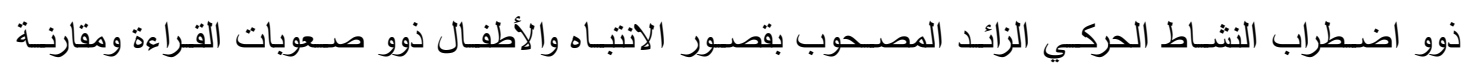

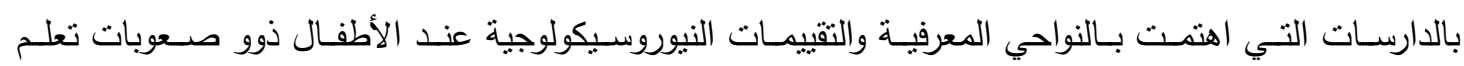
الرياضيات. ونظـراً لندرة الدراسـات التي تتاولت النواحي الانفعاليـة والاجتماعيـة سـوف نعرض بعض الدراسـات

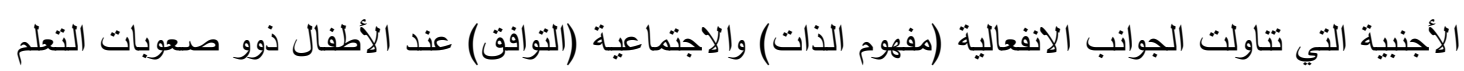
بوجه عام، ويتم عرض الدراسات تحت منحيين هما:المنحى الأول : الدراسات التي تناولت مفهوم الذات عند الأطفال ذورو صعويات التعلم. وتشعى الدراسات التي أجريت في هذا السياق إلى اختبار فرض يومان Cited in: 191. Youman فالاطئل Kershner, 1990)

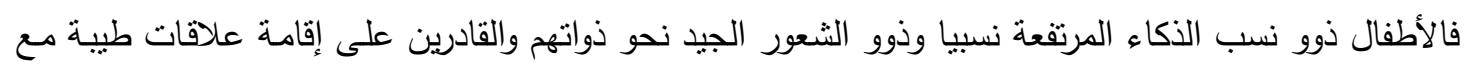

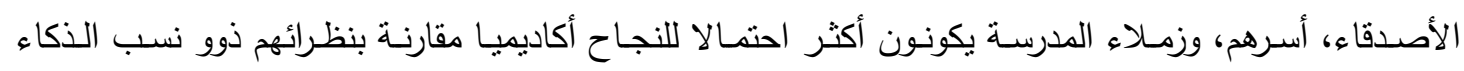
المنخفضة وذوو الثعور السيئ نحو ذواتهم وغير القادرين على إقامة علاقات طيبة مع أسرهم، الأصدقاء، زملاء المدرسة.

وقد أجريت دراسات عديدة لاختبار هذا الفرض فوجد براوت ومارسيه ومارسيه Prout, Marcal \& وقون ذات ذات منخفضة في حين يتميز الأطفال الموهوبون أكاديميا بمفهوم للذات مرتفع، علاوة على ذللك، يعاني الأطفال

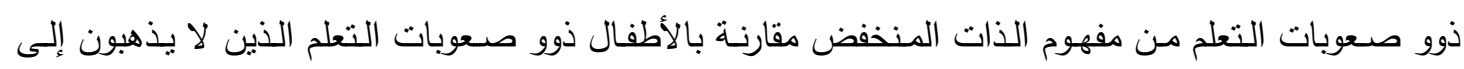
مراكز التربية الخاصة فيما يتعلق بالنواحي الأكاديمية. 


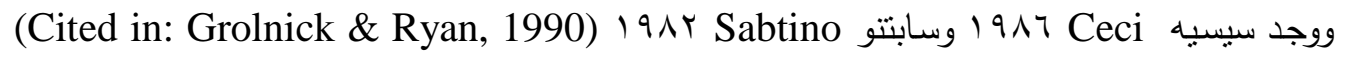
أن الأطفال ذوو صعوبات التعلم يختلفون على نحو دال مقارنة بالأطفال الذين لا يعانون من صعوبات التعلم

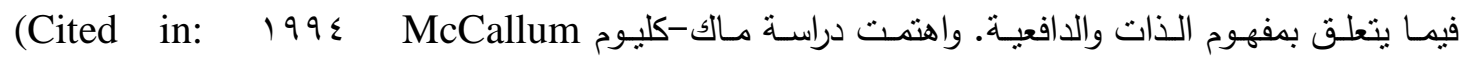
بontgomerg, 1994)

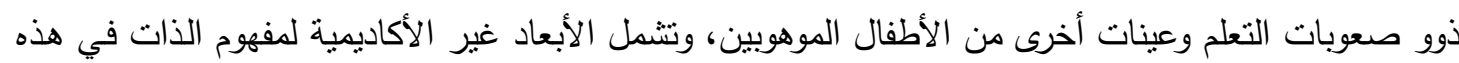

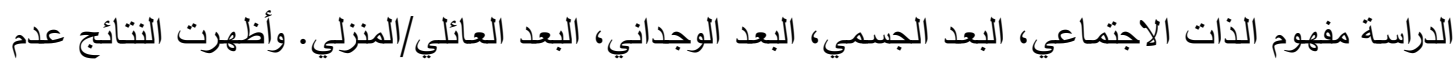

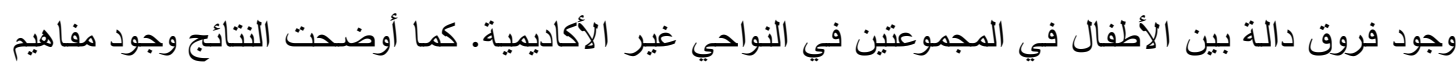
ذات أكاديمية منخفضة عند كل من الأطفال ذوى صعوبات التعلم والأطفال الموهوبين.

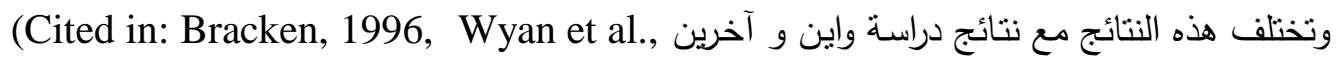
(267 التي أظهرت عدم وجود فروق دالة في مفهوم الذات العام عند التلاميذ في المرحلة الرابعة حتى المرحلة

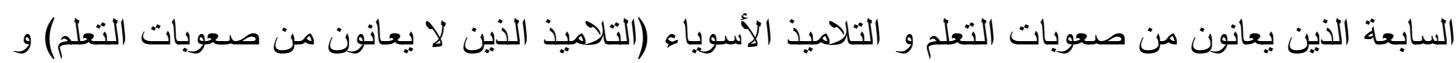
التلاميذ الموهوبين الذين لا يعانون من صعوبات تعلم. صعاته واهتمت دراسات أخري بمقارنة مفهوم الذات عند الأطفال ذوو صعوبات لعنون التعلم مع الأطفال المتخلفين (Cited in: Bracken, 1996, ع ع ع Carroll et al., عقليا والأطفال الأسوياء. فقارن كارول وآخرون (267 بين التلاميذ الذين يعانون من صعوبات التعلم و التلاميذ ذوو التخلف العقلي البسيط (الذين تقع نسب

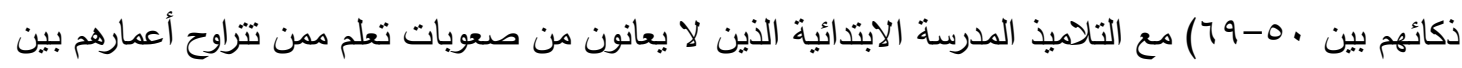

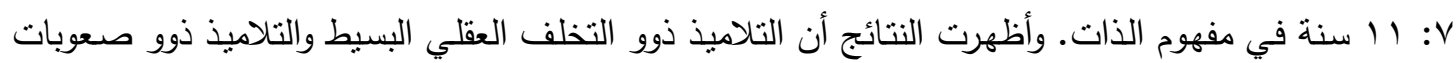

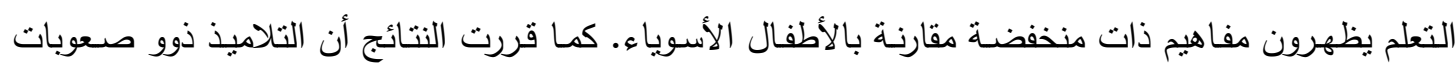
التعلم يظهرون مفاهيم ذات مرتفعة إلى حد ما مقارنة بالأطفال ذوو التخلف العقلي البسبط. وعلى نحو مشابه

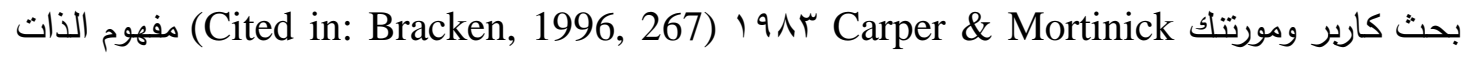
عند عينة مختلطة من التلاميذ في مرحلة رياض الأطفال وفي المرحلة الثالثة الابتدائية الذين التحقوا بفصول

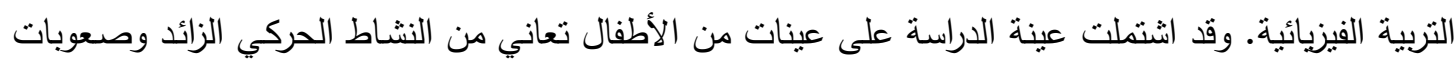

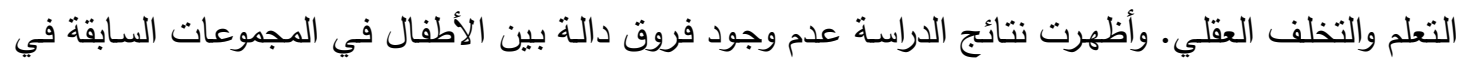
مفهوم الذات. بالإضافة إلى ذلك، أظهرت نتائج الدراسة عدم وجود علاقة دالة بين مفهوم الذات العام ومقاييس الأداء الحركي

ووجد هل وريتشموند أن 1910 Hall \& Richmond)

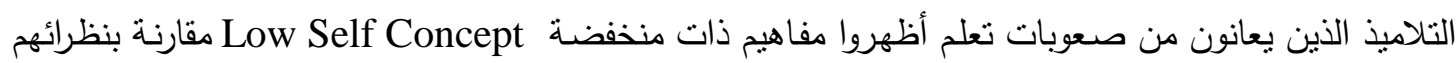
الذين لا يعانون من صعوبات تعلم. وبحث مورتروف Cited in: Bracken, 1996, 267) 1919 Mortorff قضية مفهوم الذات عند الأطفال عند الموهوبين من المرحلة الثالثة حتى المرحلة الخامسة الذين شخصوا بذوى صعوبات التعلم. أظهرت نتائج الدراسـة أن التلاميذ الموهوبين ذوو صعوبات التوبن التعلم يظهرون مفاهيم ذات منذفضـة على نحو دال مقارنة بالتلاميذ الموهوبين الذين لا يعانون من صعوبات تعلم.

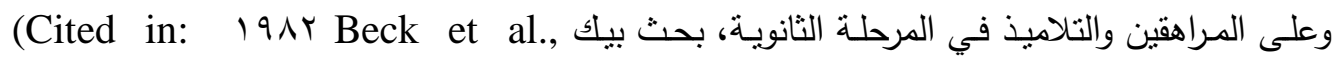
Bracken, 1996, 267)

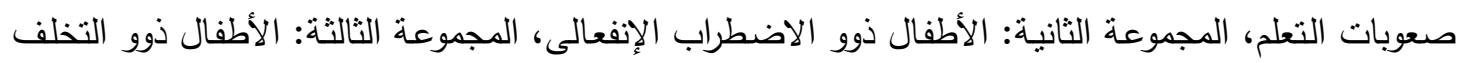


العقلي القابلون للتعلم في المرحلة الرابعة (• (سنوات) حتى المرحلة الثانية عشر (V سنة). وأظهرت نتائج الدراسة عدم وجود فروق دالة بين الأطفال في الثناث مجموعات. وعلى نحو مشابه وجد سيلفرمان وزيجموند r ralverman \& Zigmond المراهقين في المرحلة السادسـة حتى المرحلة الثانية عثرة ذوو صعوبات التعلم ونظرائهم الأسوياء في مفهوم الذات.

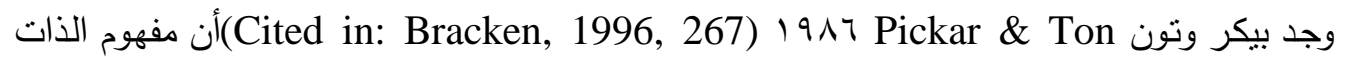
العام للمراهقين في المرحلة العاشرة حتى المرحلة الحادية عشر الذين لا يعانون من صعوبات تعلم هو نفسه عند عينة المقارنة من المراهقين الذين لا يعانون من صعوبات التعلم. وانتقد جرولنك وريان (Grolnick \& Ryan, 1990) الدراسات التي قارنت الأطفال ذوو صعوبات النعلم والأطفال الأسوياء في أنها أهلت نسبيا كلا من الأطفال ذوو التحصيل المنخفض والأطفال ذوو نسب

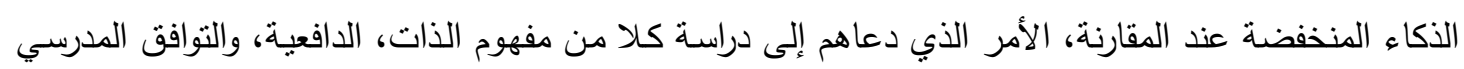

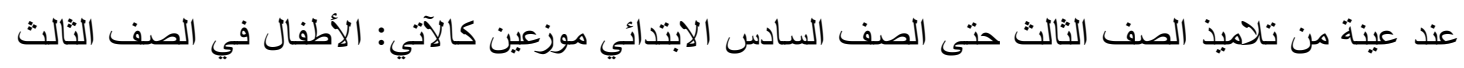

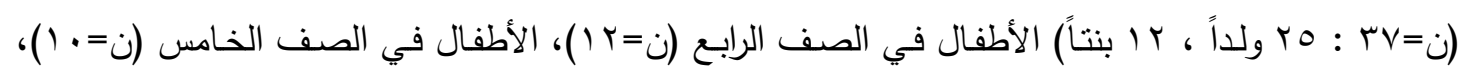
والأطفال في الصف السادس (ن= YVY) ووزع الأطفال على أربع مجموعات فرعية.

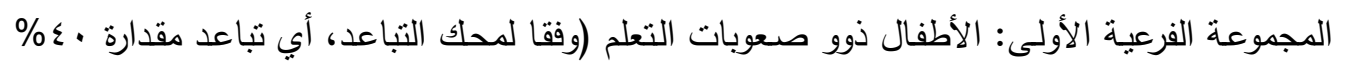

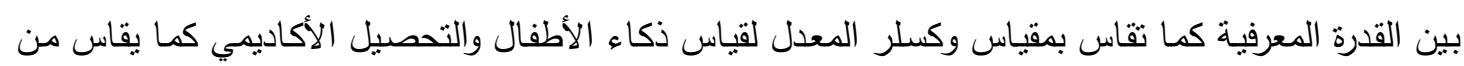

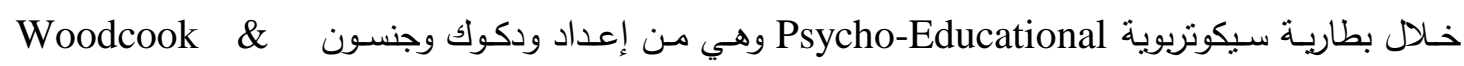
19VV Johnson صعوبات الحساب، و 19 طفلاً يعانون من صعوبات كل من القراءة والحساب معا، أما المجموعة الفرعية الثانية

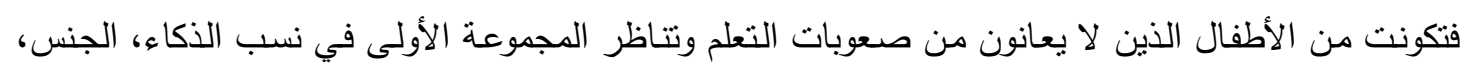
المرحلة الدراسية بصرف النظر عن درجاتهم على بطاريـة التحصيل المستخدمة. واختيرت المجموعة الفرعية الثالثة من الأطفال الذين لا يعانون من صعوبات التعلم (لم يركز الباحث في اختيارها على التحصيل أو نسب

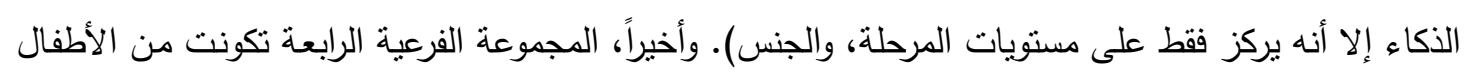

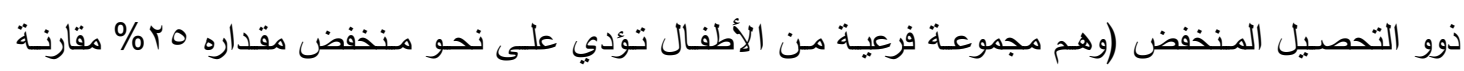
بنظرائهم في نفس المرحلـة على اختبار التحصيل) وبتطبيق مقاييس لتقرير الذات-للطفل، ومقيـاس للكفاءة

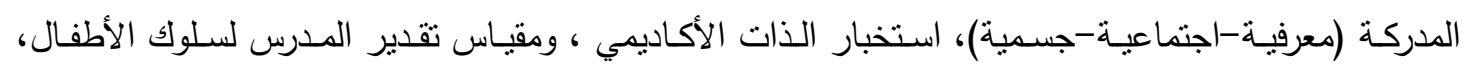

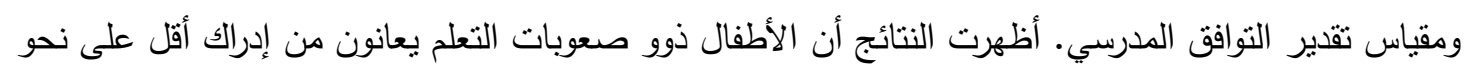

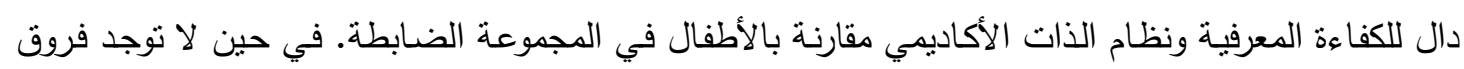
دالة بين الأطفال ذوو صعوبات التعلم والأطفال في المجموعتين الأخيرتين على نفس المتغيرات.

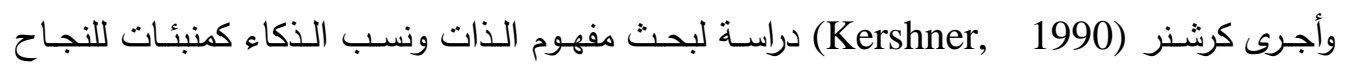

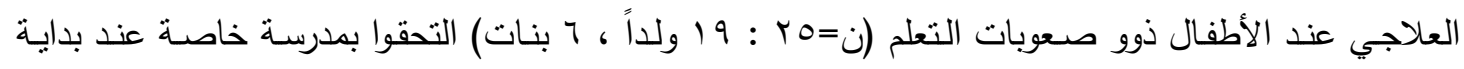

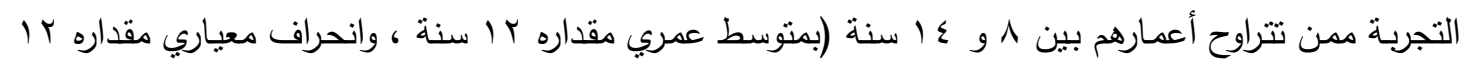
شـهر ). ووصف الأطفال في هذه الدراسـة بأنهم يعانون من صعوبات التعلم من خلال التقييمات السيكوتربوية

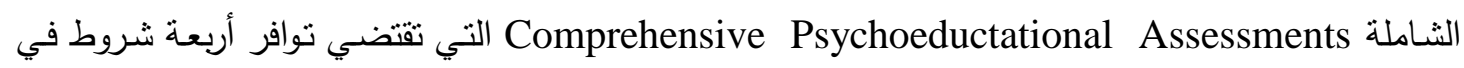
الأطفال الذين يعانون من صعوبات التعلم هي: أن تزيد نسبة الذكاء على مقياس وكسلر المعدل لقياس ذكاء 


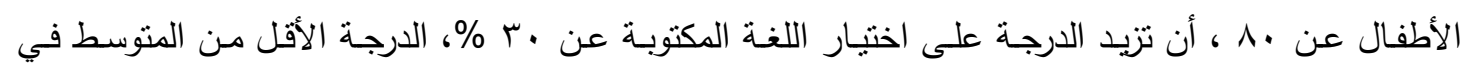

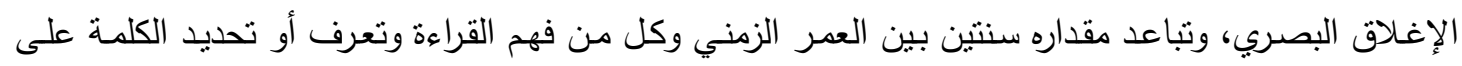
اختبارات مونروشبرمان Monroesherman النتخيصية لاختبارات القراءة. وقيست المتغيرات المنبئة في هذه

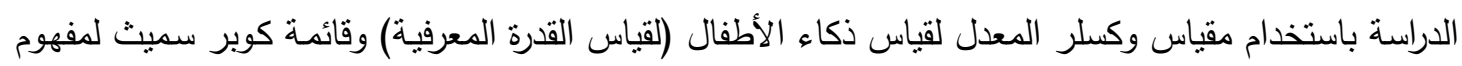

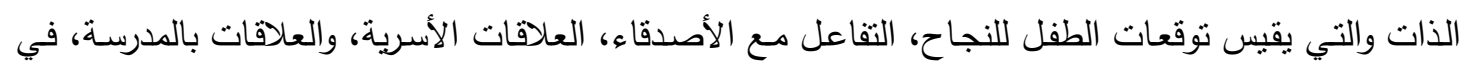
التطبيق الأول. وبعد سنتين من التطبيق الأول، أعبد التطبيق مرة ثانية على نفس العينة من الأطفال، وأظهرت النتائج ثبات نسب الذكاء اللفظية والعملية للأطفال ذوو صعوبات التعلم على مقياس وكسلر لقياس ذكاء التهاء الأطفال

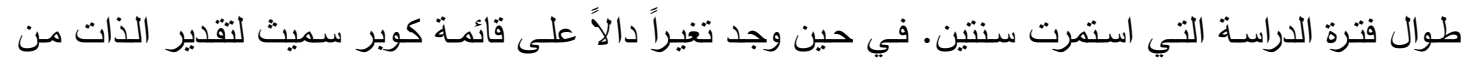

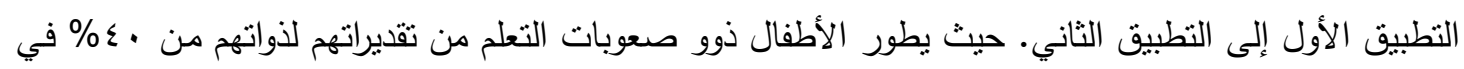

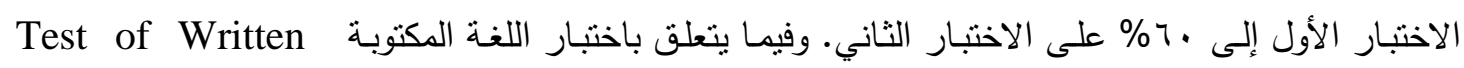
Language بين متوسطات أداء الأطفال ذوى صسعوبات التعلم في التطبيقين على اختبـار القراءة والتهجي مـن اختبـار التحصيل واسـع المدى، في حين وجدت فروق دالة بين التطبيقين على كل من اختبار الحساب من اختبار

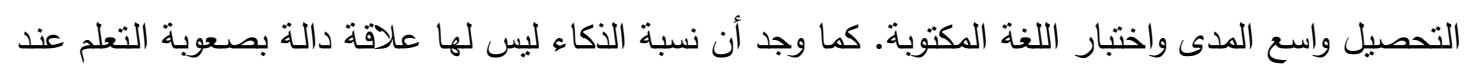
الأطفال، في حين يعد مفهوم الذات منبأ دالاً للتحصيل الأكاديمي الناجح في الحساب والتهجي واللغة المكتوبة.

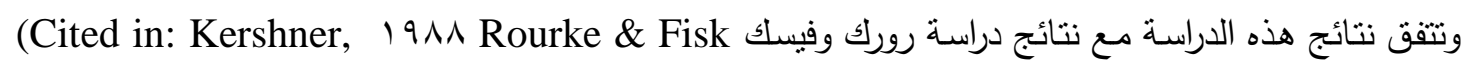
(1990 التي قارن فيها التأثنير الدال لمفهوم الذات مقارنـة بنسب الذهاء دراء على التحصيل الأكاديمي النـاجح. وأظهرت نتائج الدراسة أن لمفهوم الذات تأثيراً سببياً على صعوبة التعلم مقارنة بتأثير نسب الذكاء.

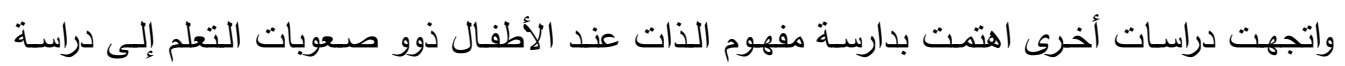

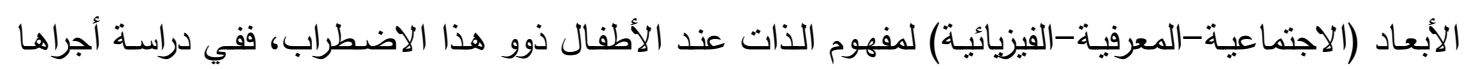

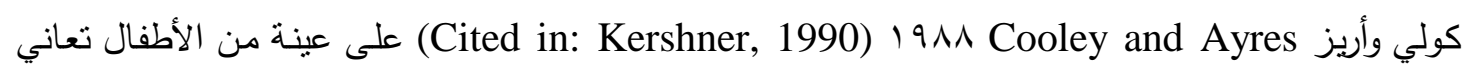
من صعوبات التعلم وعينة أخرى من الأطفال الأسوياء. ووجد أن أداء التلاميذ ذوو صعوبات التعلم أضعف على الألى

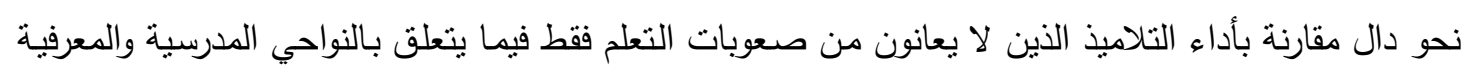

على مقاييس بير -هاريس Piers-Harris.

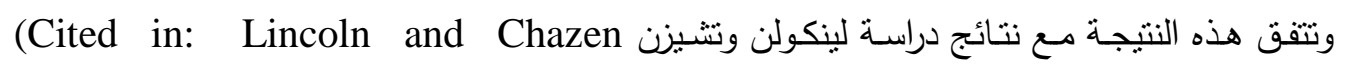
الذين وجدوا أن الإدراكات السالبة للذات عند الأطفال ذوو صعوبات التعلم

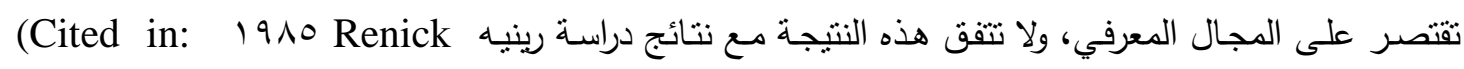
Grolinick \& Ryan, 1990) الذات عبر الأبعاد المختلفة مقارنة بالأطفال الذين لا يعانون من صعوبات النعلم.

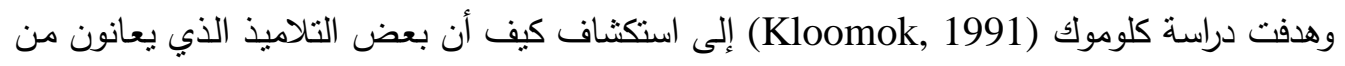

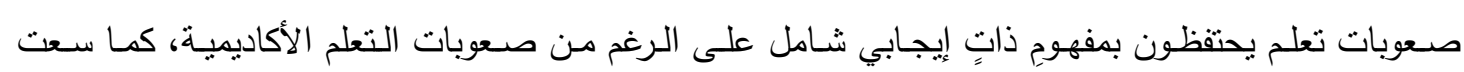

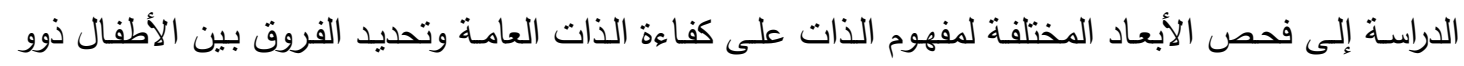
مفهوم الذات العام الإيجابي وأولئك ذوو مفهوم الذات العام السلبي. واستخدمت الدراسـة لتحقيق هذه الأهداف التهات

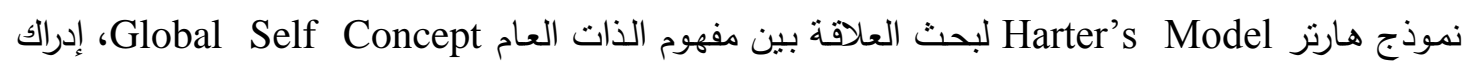

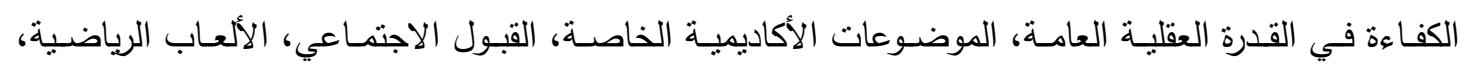


السلوك، المظهر الجسمي Physical appearance. كما يفحص النموذج تأثثر مقارنة المجموعة الاجتماعية وإدرالك التعمبم الاجتماعي على مفهوم الذات.

واستخدم لتحقيق أهداف الدراسة عينة من الأطفال ذوو صعوبات التعلم في مرحلة المدرسـة الابتدائية

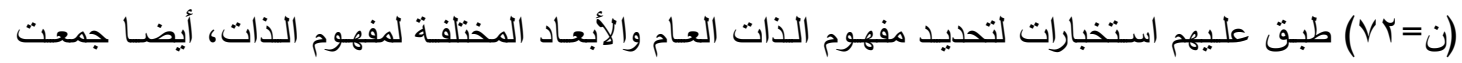
الدرجات على الاختبارات المقننة للتحصيل لبحث العلاقة بين مفهوم الذات الأكاديمي والأداء الأكاديمي الفعلي.

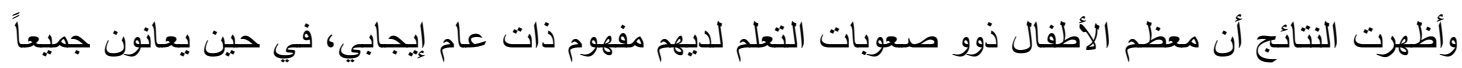

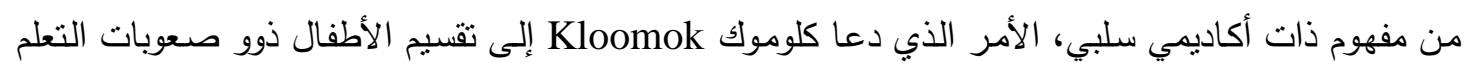

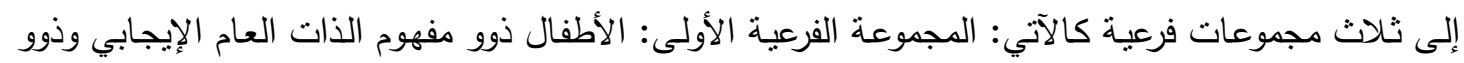
مفهوم الذات الأكاديمي السلبي High Global/Low Academic Self Concept، أما المجموعة الفرعية

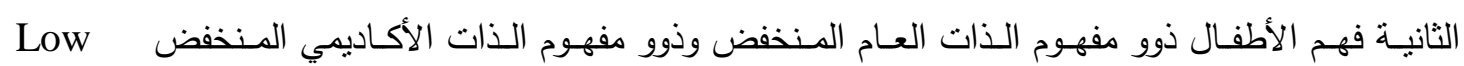

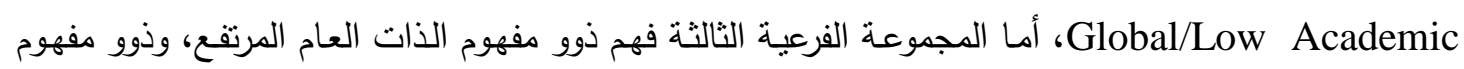

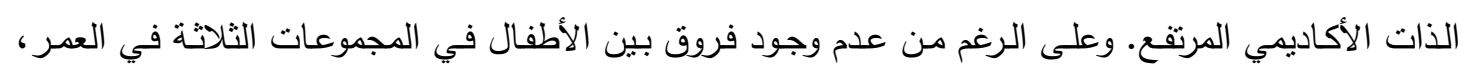

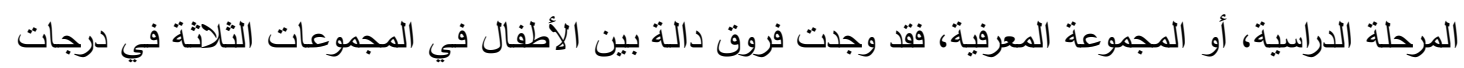

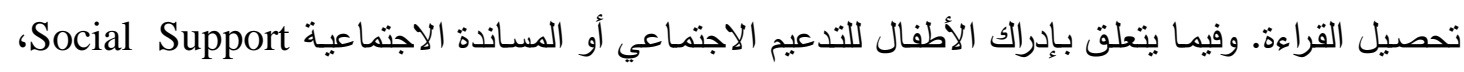

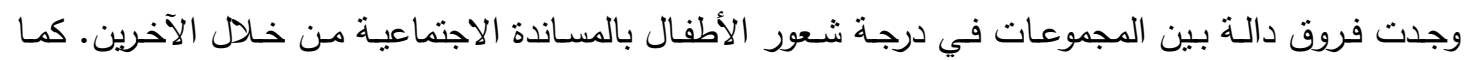
أوضحت تحليلات الحركة أن الوضع الجسمي، القبول الاجتماعي، والتدعيم الوالدي منبأت دالة لتقديرات مفهوم الذات العام عند الأطفال ذور صعوبات التعلم.

أما كوفين وهجر وهجن وكوزكه ناني

فينتقدون الدراسات الني أجريت على مفهوم الذات عند الأطفال ذوو صعوبات التعلم ويرون أن تلك الدراسات

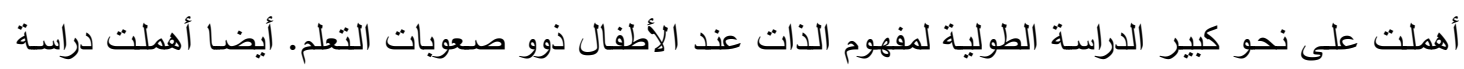

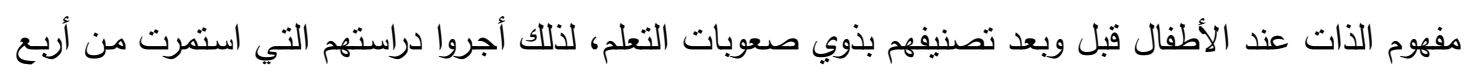

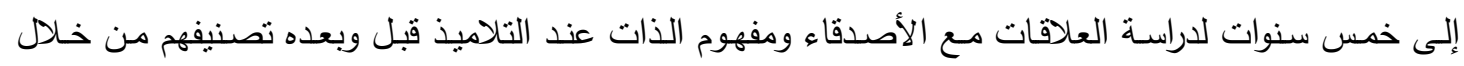
مقاطعة المدرسة بأنهم يعانون من صعوبات تعلم. وقد تم تقدير مفهوم الذات (من رياض الأطفال حتى المرحلة

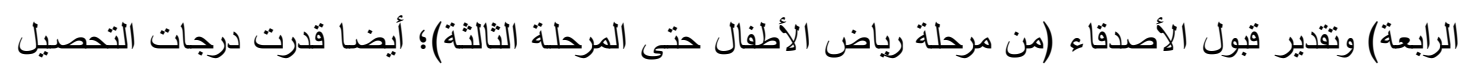

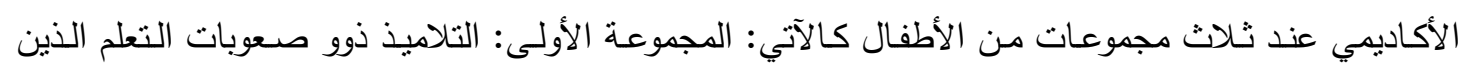

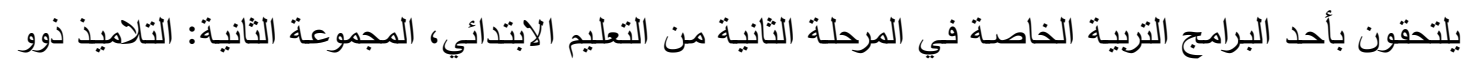
التحصيل الأكاديمي المنخفض، والمجموعة الثالثة التلاميذ ذوو التحصيل الأكاديمي المتوسط/المرتفع. وأظهرت النتائج أن درجات التلاميذ ذوو التحصيل الأكاديمي المرتفع وذوو التحصيل الأكاديمي المنوسط أعلى على نحو

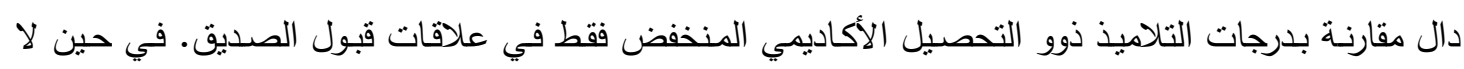
توجد فروق دالة بين المجموعات الثلاثة خلال أية سنة دراسية على مقياس تقدير الذات. وتقترح هذه النتيجة أن

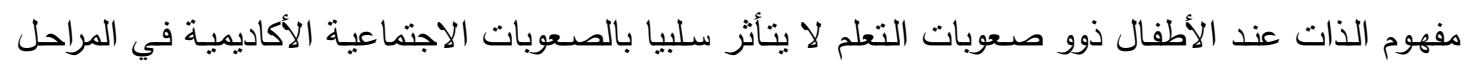
المبكرة، ومع ذلك فمن الصعب تعميم هذه النتيجة نظراً لصغر حجم العينة. وهدفت دراسة مونتجموري (Montgomery, 1994) إلى تحديد مفهوم الذات للتلاميذ ذوو صعوبات التعلم، مقارنة بتقديرات الملاحظ وتقارير الذات داخل مجموعات ذوو صعوبات التعلم، الأطفال الذين لا يعانون

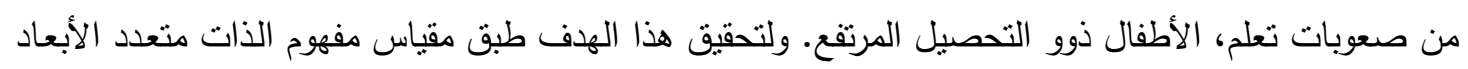


على عينـة من الأطفال (ن=هـ (1) في المراحل السادسة والسابعة والثامنـة. أمـا الوالدان والمدرسون فقد قدروا

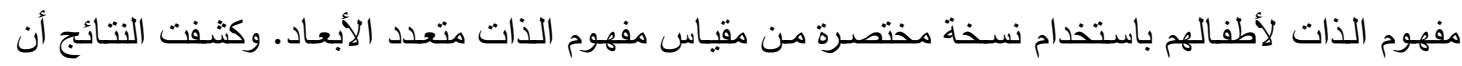
المدرسين يخسون مفهوم الذات لكل من التلاميذ ذوو صعوبات التعلم والتلاميذ الذين لا يعانون من صعوبات

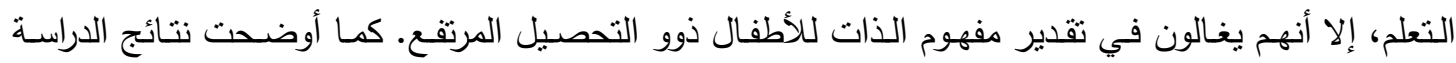
الانسجام بين تقديرات للأطفال ذوو صعوبات التعلم وآبائهم تختلف اعتمادا على مجال مفهوم الذات. وقارن (Gans,Kenny,Ghany,2003) مفهوم الذات عند عينة من الأطفال يعانون صعوبات تعلم

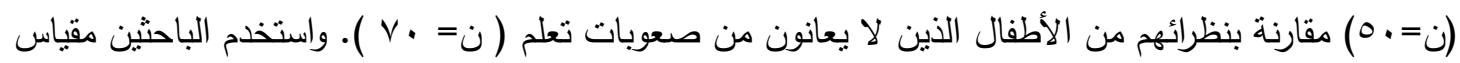

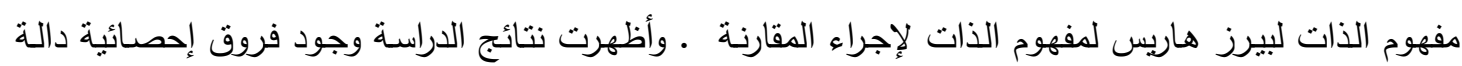

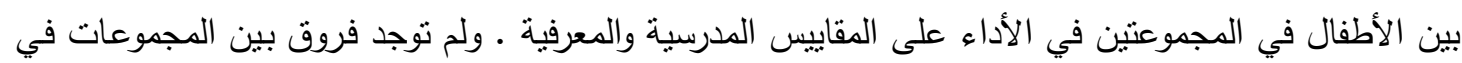

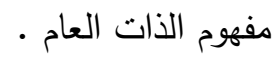
وعلى نحو أكثر حداثة هدفت دراسة (Barton,North,2007) إلى بحث مفهوم الذات عند الأطفال

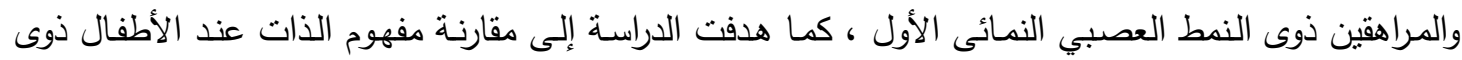

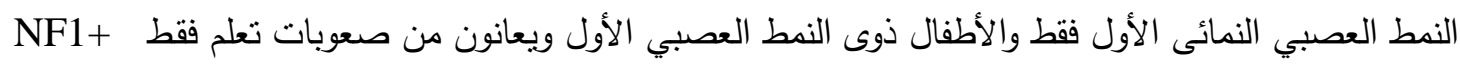
Learning Disabilities الحركي الزائد المرتبط بقصور الانتباه NF1+ADHD وفقا للمحكات الموضوعية وتقديرات المدرسين • وقد طبقت مقاييس مفهوم الذات والتحصيل الأكاديمي والذكاء على عينة الأطفال ( ن = 9 ؟) وعينة من المراهقين

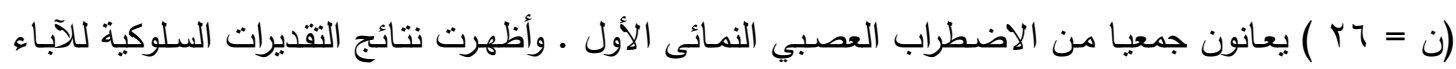

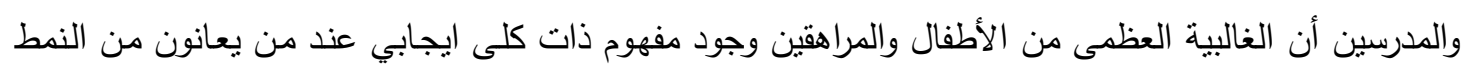

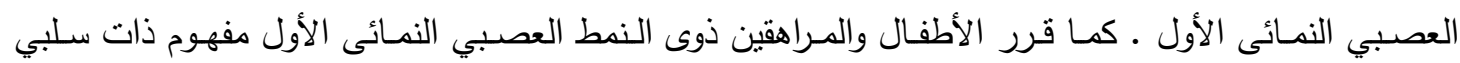

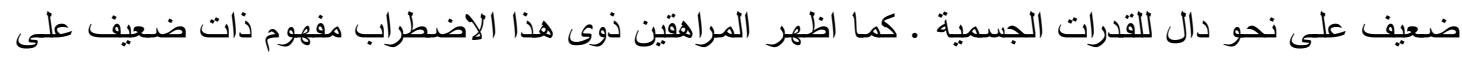

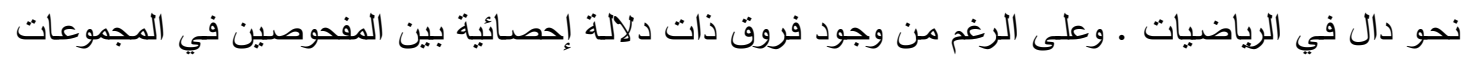

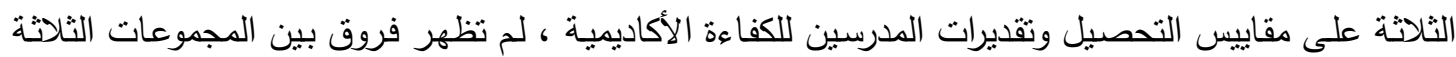

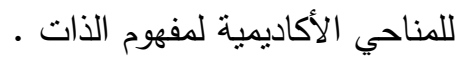

أما فيما يتعلق بدراسة النواحي الانفعالية عند الأطفال ذوو صعوبات تعلم الرياضيات أو ذوو صعوبات تعلم الرياضيات فلا يوجد -في حدود علم الباحث- سوى دراستين أجريتا في هذا السياق هما:أما الدراسة الأولى فتلك التي أجراها روزمان وكوسدن Rothman \& Cosden) الرياضيات مع درجات إدراك الذات عند الأطفال ذور صعوبات تعلم الرياضيات.

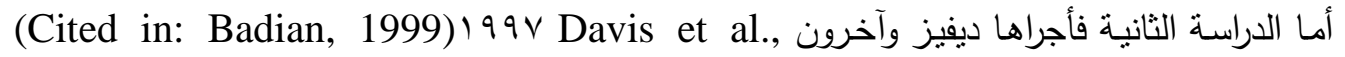
لمقارنة الأداء على المهام اللفظية والمهام غير اللفظية والمشكلات الانفعالية عند مجموعتين من الأطفال. تعاني المجموعة الأولى من صعوبة تعلم الحساب فقط، وتعاني الأخرى من صعوبة تعلم كل من القراءة والتهجي معا.

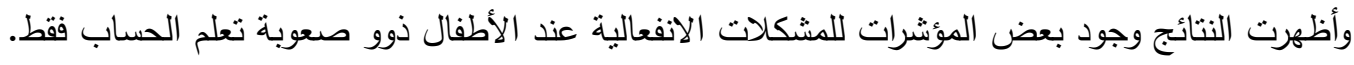
المنحى الثاني: الاراسات التي تناولت التوافق عند الأطفال ذوو صعويات تعلم الرياضيات.

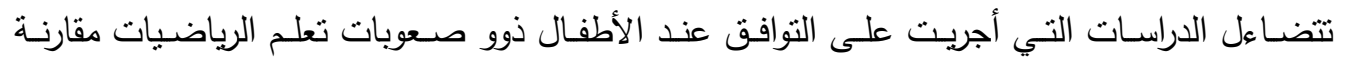
بالدراسات التي أجريت على التوافق عند الأطفال ذوو صعوبات التعلم بوجه عام، ومقارنة بالدراسات التي أجريت 
على التوافق عند الأطفال ذوو اضطراب النشـاط الحركي الزائـد المصـوب بقصـور الاتنبـاه، والأطفـال ذوى

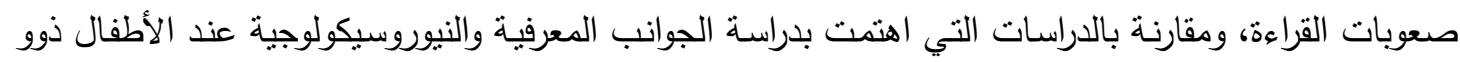
صعوبات تعلم الرياضيات.

ففي دراسة روسنبرج (Rosenberg, 1989) التي تتاولت العلاقات مع الأصدقاء (التوافق الاجتماعي) عند عينة من الأطفال تعاني من صعوبات تعلم الرياضيات وعينة أخرى من الأطفال الأسوياء. لم تظهر النتائج

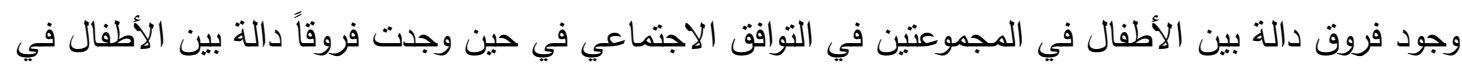

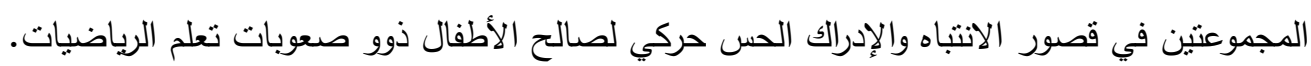

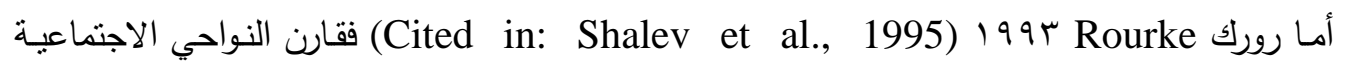
ومشكلات التعلم عند مجموعنين من الأطفال، تعـاني المجموعة الأولى من صسوبات في القراءة والتهجي،

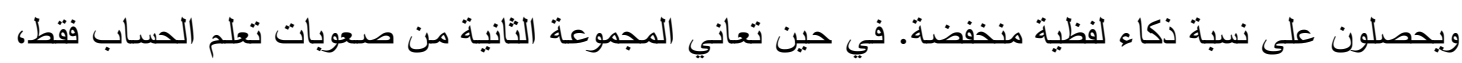

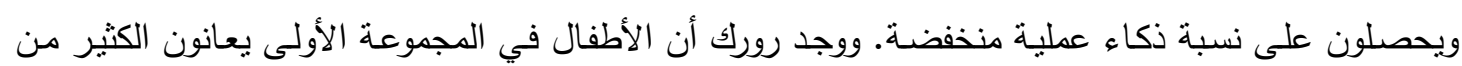

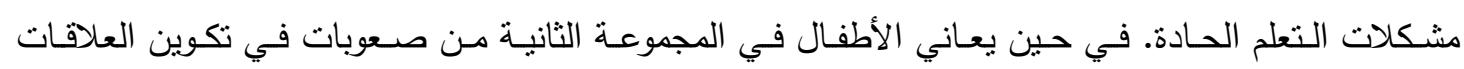

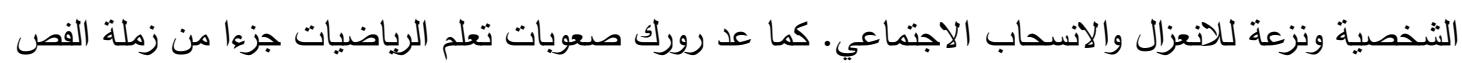

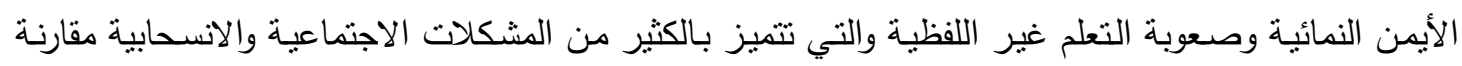
بالأطفال ذوو صعوبات القراءة فقط أو الأطفال ذوو اضطراب النشاط الحركي الزائد المصحوب بقصور الانتباه.

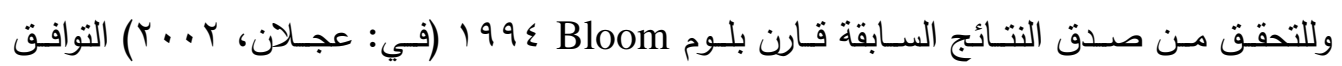

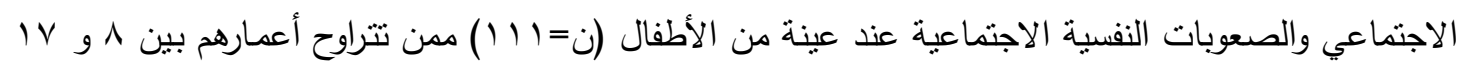

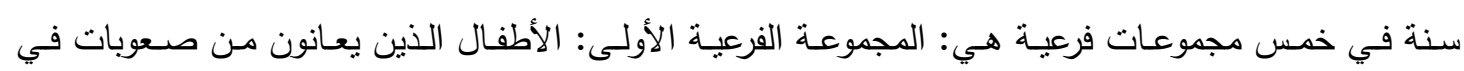

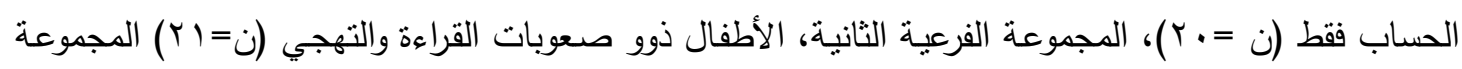
الفرعية الثالثة: الأطفال ذوو صعوبات القراءة والتهجي والحساب (ن = r r)، والمجموعة الفرعية الرابعة: الأطفال

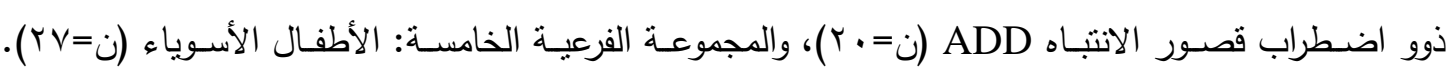
وأظهرت نتائج الدراسة الأثر النسبي الأسوأ لصعوبات الحساب على الأداء النفسي الاجتماعي للتاميذ مقارنة

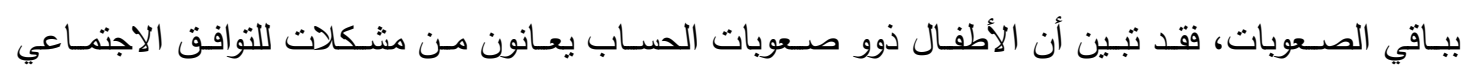

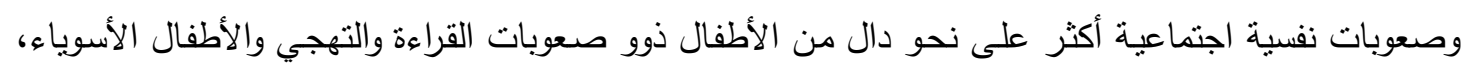

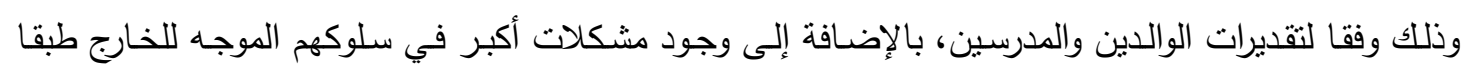
لمقاييس الوالدين. كذلك أظهرت النتائج عدم إمكانية التمبيز بين الأداء النفسي الاجتماعي للإفراد الذين يعانون

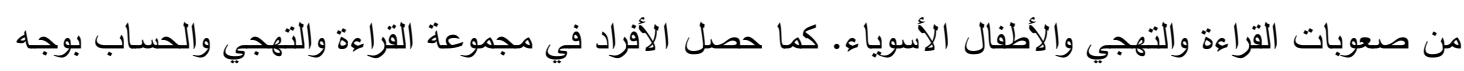

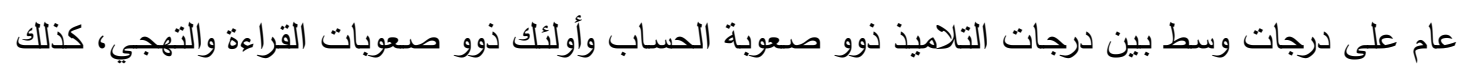

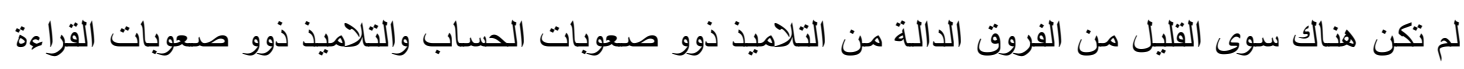
والتهجي والحساب على مقاييس الأداء النفسي الاجنماعي. وقارن ديفيز وآخرون P9v Davis et al, 99 (Cited in: Badian, 1999) الأداء على المهام اللفظية والمهام غير اللفظية والمشكلات الانفعالية الاجتماعية عند عينـة من الأطفال تعاني من صعوبة تعلم

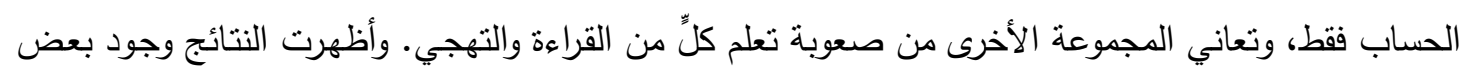

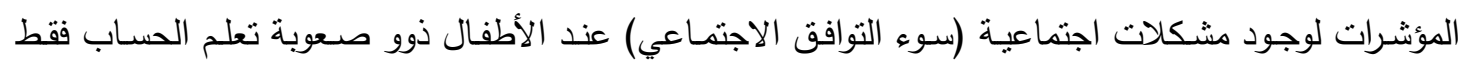
مقارنة بالأطفال ذوو صعوبات كل من القراءة والتهجي معا. 
وفيما يتعلق بدراسة التوافق عند الأطفال ذوو صعوبات التعلم بوجه عام، فحص فرست وفيسك ورورك (Fuerst, Fisk \& Rourke, 1990)

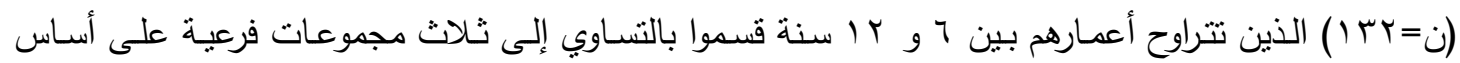
الفرق بين نسبة الذكاء اللفظية ونسبة الذكاء العملية من مقياس وكسلر لقياس ذكاء الأطفال على النحو التالي: المجموعة الأولى: فيها تزيد نسبة الذكاء اللفظية عن نسبة الذكاء العملية، المجموعة الثانية: فيها تزيد نسبة فئة

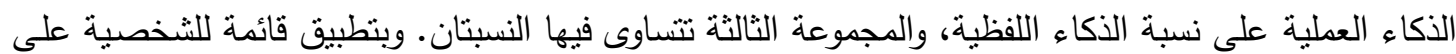

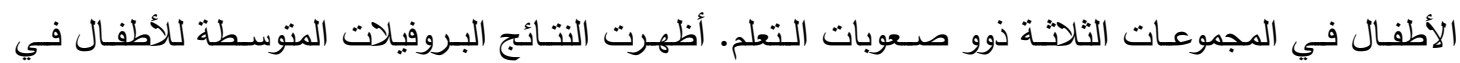
المجموعـة الأولـى والثالثـة. وبـالرغم مـن ذلــ، أظهـر الأطفـال فـي المجموعـة الثانيـة التقييمـات الباثثلوجيـة Pathological Assessments وفي محاولـة أخرى في هذا السياق درس جيوفون وبير (Juvonen \& Bear 1992) التوافق

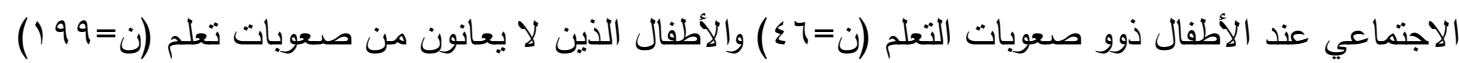
في الصف الثالث الابتدائي، ووجد أن ثلثي الأطفال ذور صعوبات التعلم لديهم على الأقل صديق واحد منبادل، وأكثر من نصف الأطفال لديهم علاقة مع صديق بدون صعوبة تعلم، الأمر الذي جعل الباحثين إلى إجراء

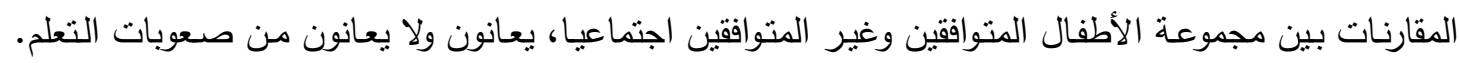

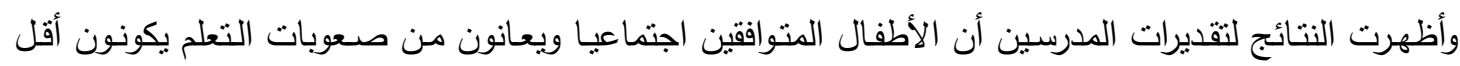

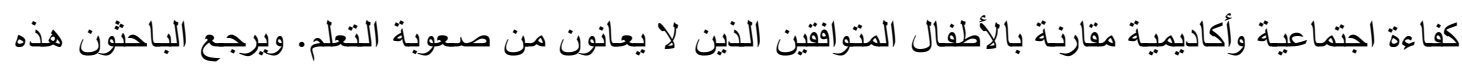

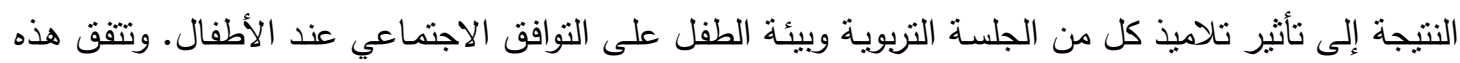

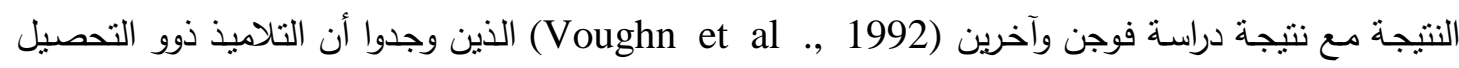
الأكاديمي المرتفع/المتوسط أعلى مقارنـة بدرجات التلاميذ ذوو التحصيل المنخفض في التوافق الاجتماعي أو

وعلى نحو أكثر حداثة، قارن فينز وسبرستان (Wenz \& Siperstein, 1998) الضغوط، المساندة

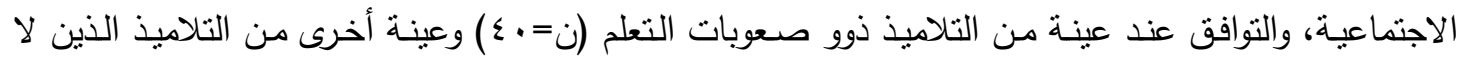

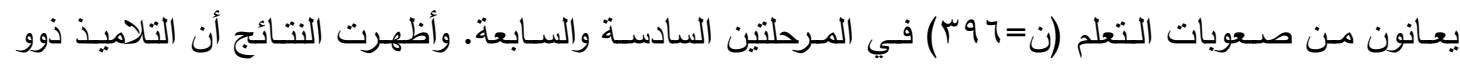

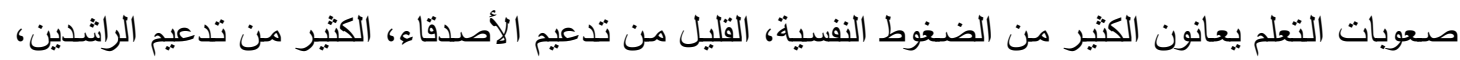

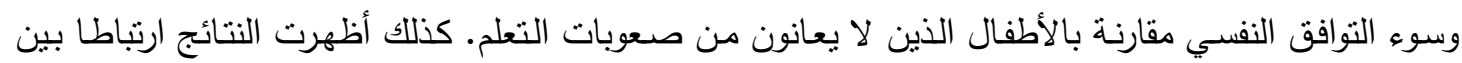
التوافق النفسي والضغوط عن الأطفال في المرحلة الابندائية. ثانيا : الاراسات التي تناولت الفروق بين النوعين في صعويات تعلم الرياضيات:-

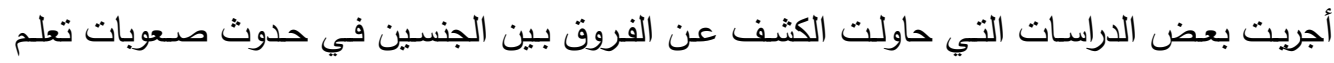

الرياضيات، وقد أظهرت نتائج تلك الدراسات تتاقضاً كبيرا فيما بينها. فقد أوضحت نتائج دراسة لويس وآخرين (Lewis et al., 1992) التي كان أحد أهدافها الفرعية دراسة

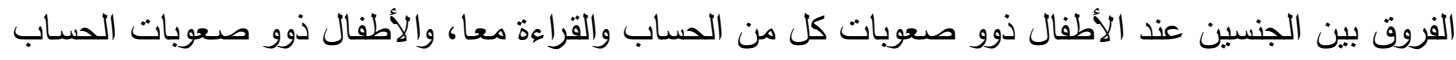

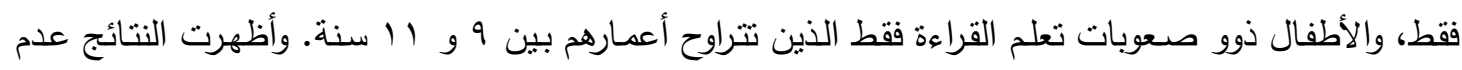

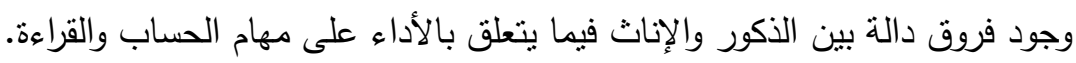

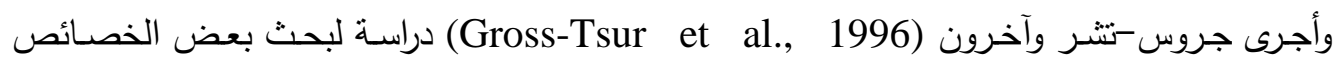

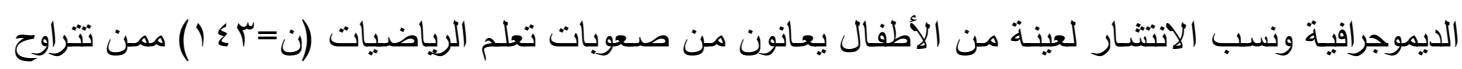


أعمارهم من 11 إلى T/ سنة، وبعد استبعاد r من الأطفال في عينة ذوو هذا الاضطراب نظراً لانخفاض نسب

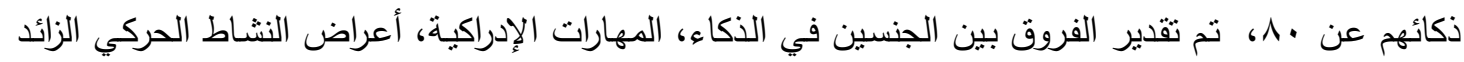

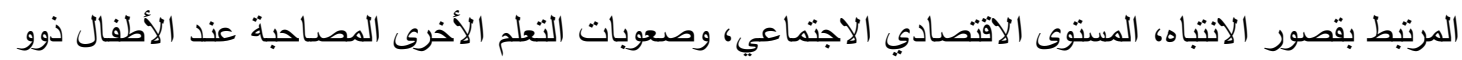

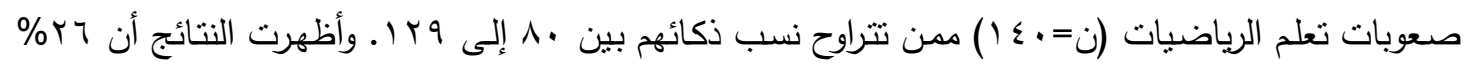

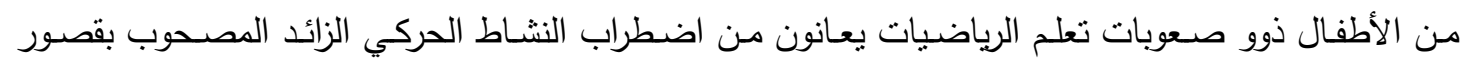

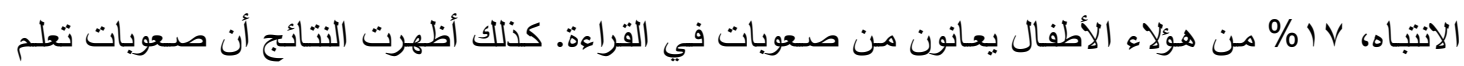

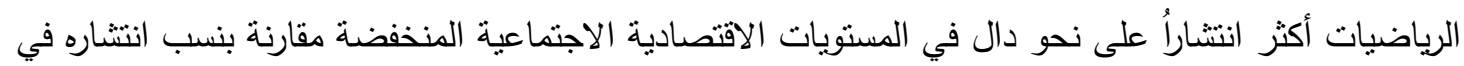
المستويات الاقتصادية الاجتماعية المرتفعة. وتبلغ نسب انتشار هذا الاضطراب عند الأطفال في العينة الأصلية

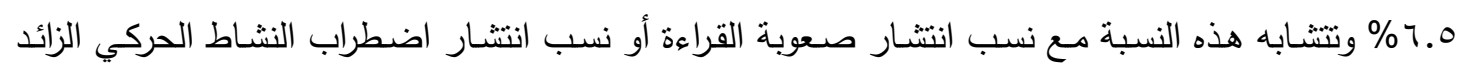

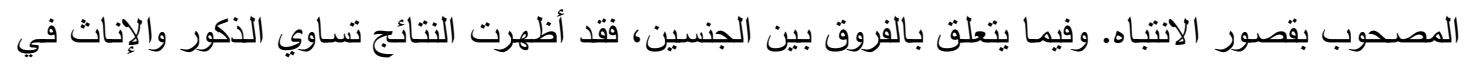
حدوث صعوبات تعلم الرياضيات على العكس من صعوبات التعلم الأخرى أو الاضطرابات النشاط الحركي الزائد المصحوب بقصور الانتباه الذي يظهر فيه تفوق الذكور على الإناث في حدوثذه.

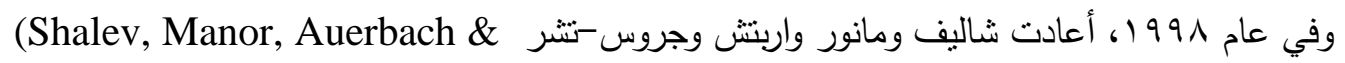
Gross-Tsur, 1998) تقييم بعض العوامل المرتبطة بصعوبات تعلم الرياضيات. وذلك على عينة من الأطفال

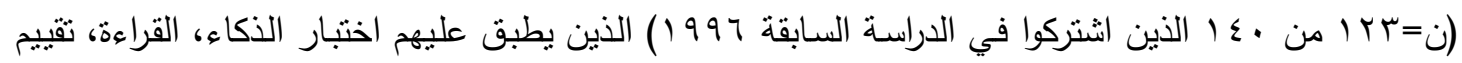

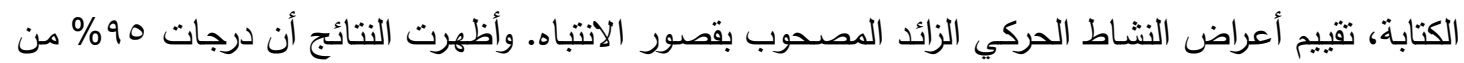

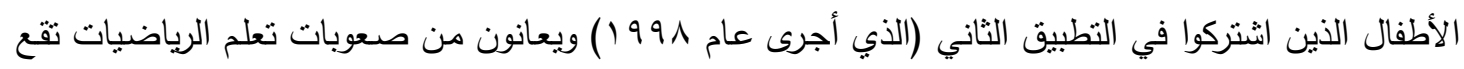
درجاتهم في الحساب في الربيع المنخفض مقارنة بدرجات زملائهم في نفس الصف على نفس الاختبار . كما

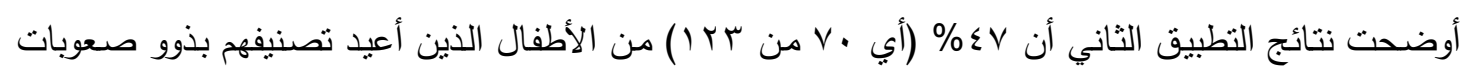

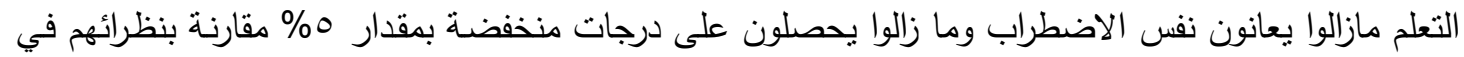

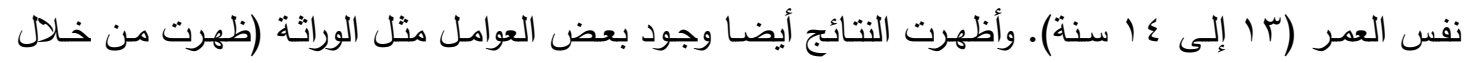

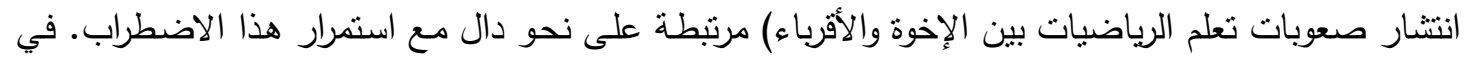

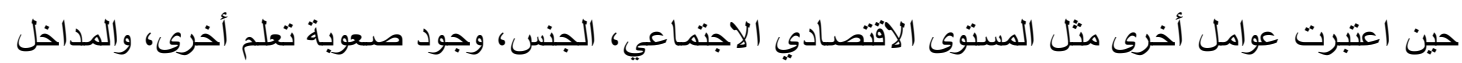
التربوية من العوامل غير المرتبطة باستمرار هذا الاضطراب. وعلى نحو أكثر حداثة، وجد ليند ساي وآخرون (Lindsay et al., 2001) باستخدام اختبار الأداء

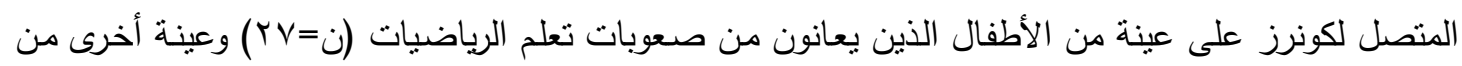

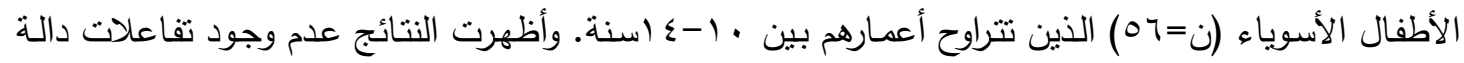

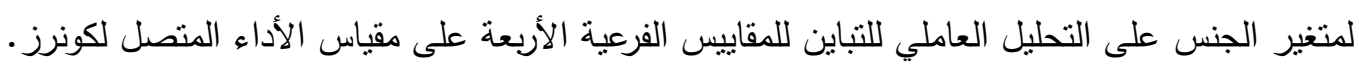

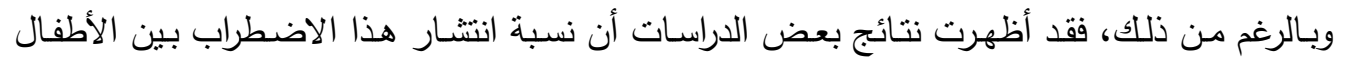
الإناث أعلى على نحو دال مقارنة بنسب انتشاره عند الذكور . ففي دراسة شارا وآخرين (Share et al., 1988) التي أجريت على عينة من الأطفال تعاني من صعوبات القراءة والحساب معا وعينة أخرى من الأطفال تعاني

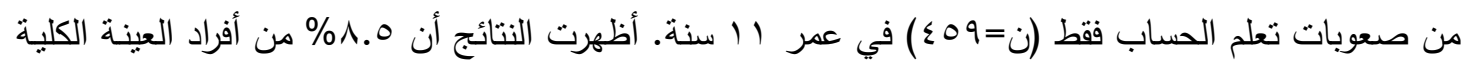

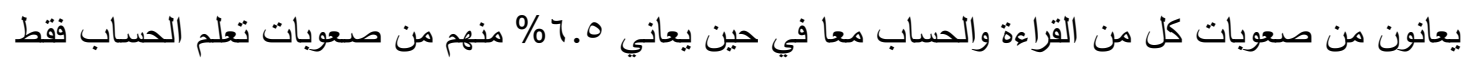

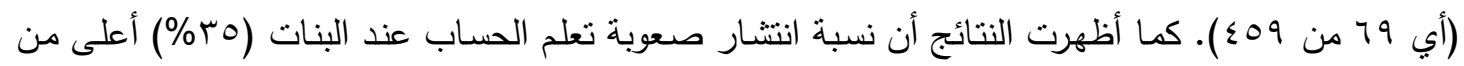


نسبة انتشارها عند الذكور (•r\%) أو أن نسب انتشار صعوبة تعلم الرياضيات عند الأطفال الذكور والإناث (1) $\cdot(1 . \vee:$

وعلى نحو أكثر حداثة، أظهرت نتائج العديد من الدراسات التي أجريت في الولايات المتحدة الأمريكية

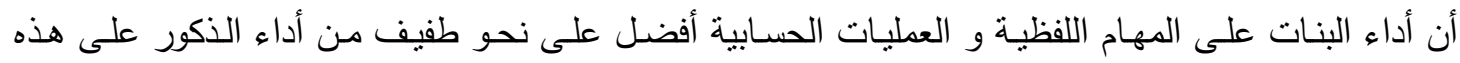
المهام و تلك العمليات. في حين أداء الأولاد على الاستتناج العددي أفضل على نحو طفيف مقارنة بأداء البنات عليه (Bee, 1998, 239).

وعلى العكس من الدراسات السابقة ، أظهرت دراسة ناس (Nass, 1993) أن نسبة إصابة الأطفال

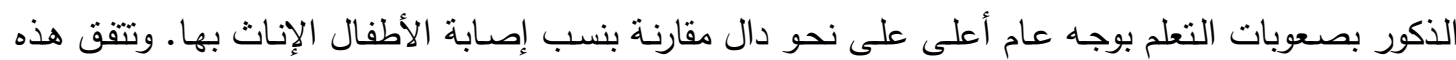
النتيجة مع رأي بادين (Badian, 1999) القائل بوجود فروق عديدة بين الذكور والإناث فيما يتعلق بالعينات

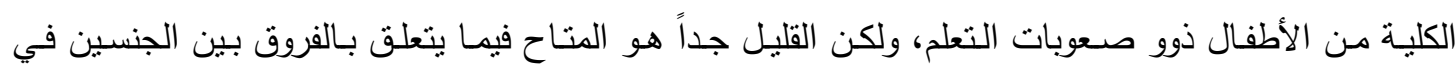
المجموعات الفرعية لذوى صعوبات التعلم الرياضيات-القراءة-الكتابة.

مشكلة الدراسة

\section{تكمن مشكلة الرداسة الحالية فى النقاط الآتية:}

1- تضاؤل وتتاقض نتائج الدراسـات التي تتاولت النواحي الانفعالية الاجتماعية عند الأطفال ذوى صعوبات تعلم

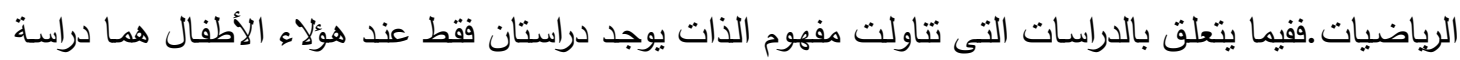
روزمان وكوسدن Cited in: Cosden et al., 1999) 1990 Rathman\& Cosden) ودراسة ديفيزو آخرين (Cited in: Badian, 1999) 199 V Davis et al ودرجات التحصيل في الرياضيات مع درجات تقدير الذات عند الأطفال ذوى صعوبات التعلم، ووجود بعض وجل

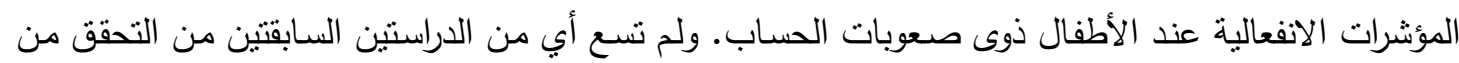

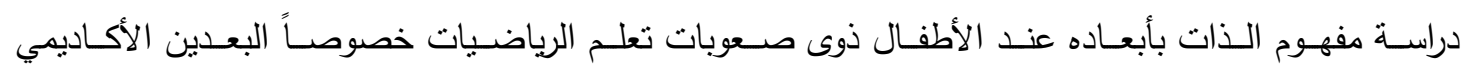

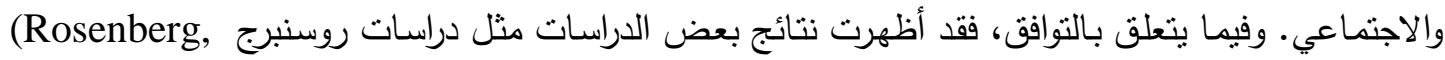

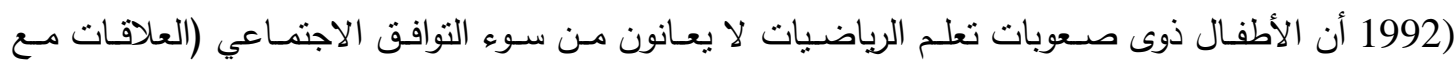

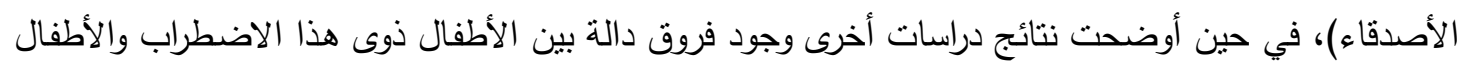
الأسوياء في التوافق منل دراسة بلوم r- تتاقض نتائج الدراسات التي حاولت الكثف عن الفروق بين الجنسين عند الأطفال ذور صعوبات بات تعلم الرياضيات فقد أظهرت نتائج دراسـة جروش نتـر وآخرين (Gross-Tsur et al., 1996) دراسـة

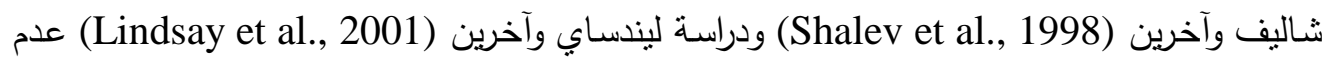

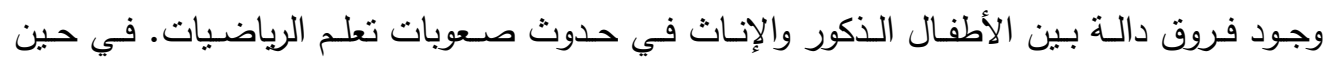
أوضحت نتائج دراسـة شـارا وآخرين (Share et al., 1988) أن نسبة انتشار صعوبة فئة تعلم الحساب

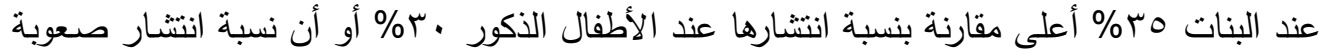

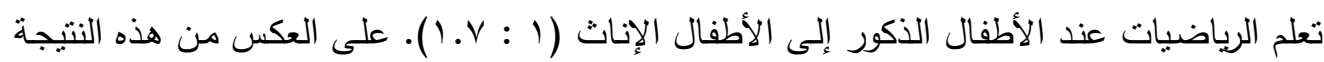

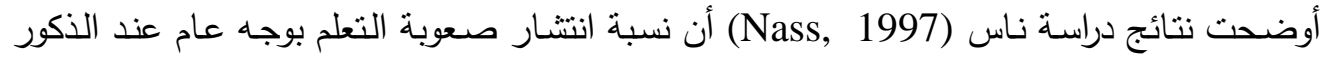
أعلى على نحو دال مقارنة بنسب انتشارها عند الإناث. 
1- توجد فروق ذات دلالة إحصائية بين الأطفال ذوى صعوبات تعلم الرياضيات والأطفال الأسوياء في

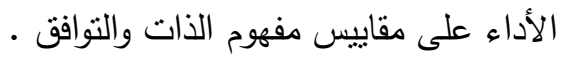
r- توجد فروق دالة بين الأطفال الذكور ذوي صعوبات تعلم الرياضيات ونظرائهم الإناث اللائي يعانون

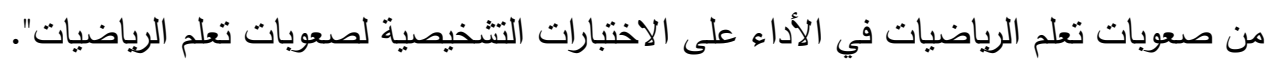

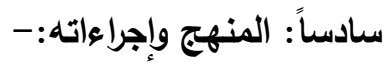

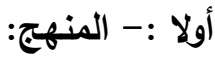

اعتمدت الدراسـة الراهنة على المنهج الوصفى، حيث تم تحديد العلاقة بين متغيرات صعوبة التعلم

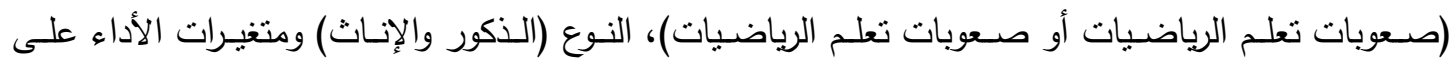

الجوانب الانفعالية - الاجتماعية [ مفهوم الذات الاكاديمى والاجتماعى) والتوافق جـ

كما تم استخدام التصميم الخاص بالقطاعات المستعرضـة المتجانسـة، وفيه يتم إحداث التجانس بين

القطاعات المستعرضة في المجموعتين محل الدراسة (الأطفال الذين يعانون صعوبات تعلم الرياضيات والأطفال

الذين لا يعانون صعوبات تعلم الرياضيات) على أساس المطابقة بينهما في عدد من المتغيرات الدخيلة بهدف

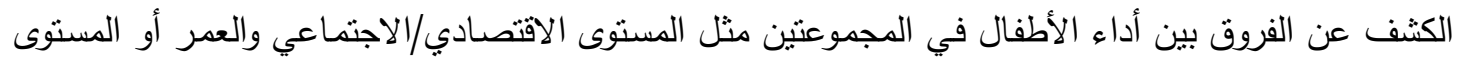

المرحلي، والذكاء (نسبة الذكاء اللفظية ونسبة الذكاء العطلية ونسبة الذكاء الكلية)، والإعاقات الحسبة (السمعية-

البصرية)، وصعوبة القراءة، والنوع •

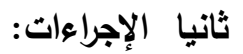

1- العينة وطرق التعرف على أفرادها

(أ) إجراءات التعرف على الأطفال ذوى صعوبات تعلم الرياضيات.

استخدمت الدراسة الراهنة مجموعة من الإجراءات للتعرف على الأطفال ذوى صعوبات تعلم الرياضيات

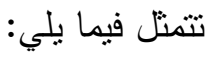

ا. تم اختيار ثناثثة مدارس ابتدائية حكوميـة بطريقة عشوائية بمدينـة شبين الكوم هي مدرسـة السيدة خديجة

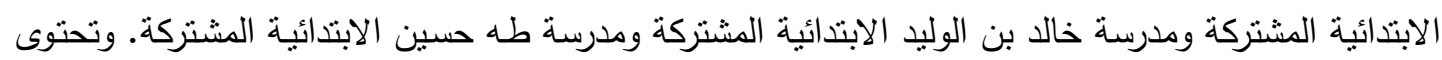

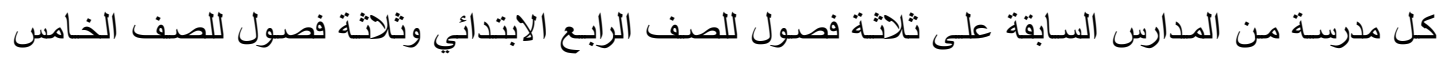
الابتدائي.

r. تم تحديد درجات كل طفل من الأطفال في الفصول الثلاثة داخل كل مدرسة في مادة الحساب في شهور أكتوبر ونوفمبر وديسمبر ونصف العام. ثم تحديد الأطفال الذين تقع درجاتهم أقل من المتوسط والأطفال الذين

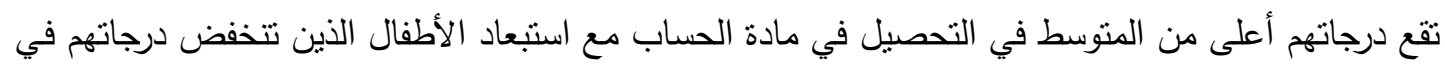
التحصيل في مادة القراءة عن المتوسط في شهور أكتوبر ونوفمبر وديسمبر ونصف الته العام.

ويوضح جدول رقم (ع- (1) توزيع الأطفال الذكور والإناث في الصفين الرابع والخامس الابتدائي الذين

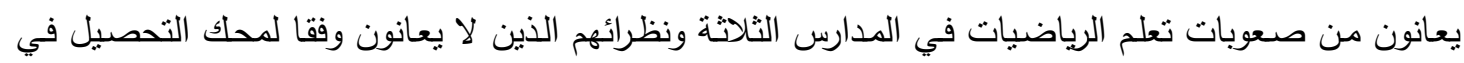

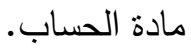




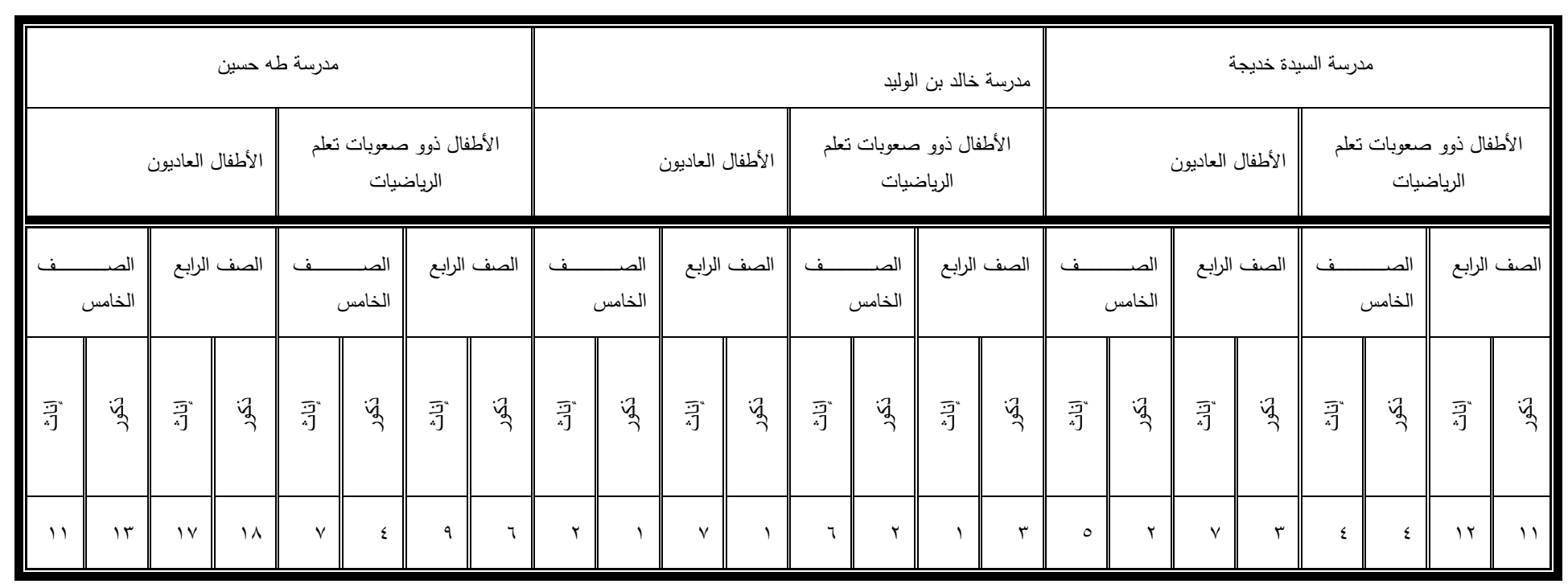

r. بطلب من المدرسين بعد تدريبهر على تطبيق مقياس تقدير الأطفال ذوى صعوبات تعلم الرياضيات تطبيق

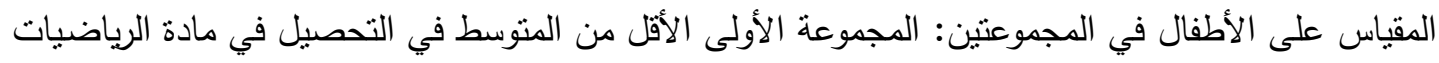
خلال شهور أكتوبر ونوفمبر وديسمبر ونصف العام. والمجموعة الثانية: الأعلى من المتوسط فى التحصيل في في التئي مادة الحساب خلال شهور أكتوبر ونوفمبر وديسمبر ونصف العام. واستبعاد الأطفال في المجموعة الأولى التى ونى تقع درجاتهم أقل من المتوسط على مقياس تقدير الأطفال ذوى صعوبات تعلم الرياضيات. كذللك استبعاد

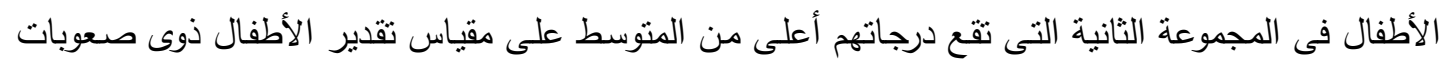

تعلم الرياضيات.

ويوضح جدول (ع-r) توزيع الأطفال الذكور والإناث فى الصفين الرابع والخامس الابتدائى الذين تقع

درجاتهم أقل من المتوسط فى التحصيل من مادة الحساب خلال شهور أكتوبر ونوفمبر وديسمبر ونصف العام. وتقع درجاتهم أعلى من المتوسط على مقياس تقدير الأطفال ذوى صعوبات تعلم الرياضيات والأطفال الذكور

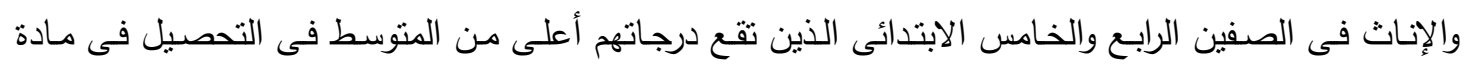
الحساب خلال شهور اكتوبر ونوفمبر وديسمبر ونصف العام وتقع درجاتهم أقل من المتوسط على مقياس تقدير الأطفال ذوى صعوبات تعلم الرياضيات.

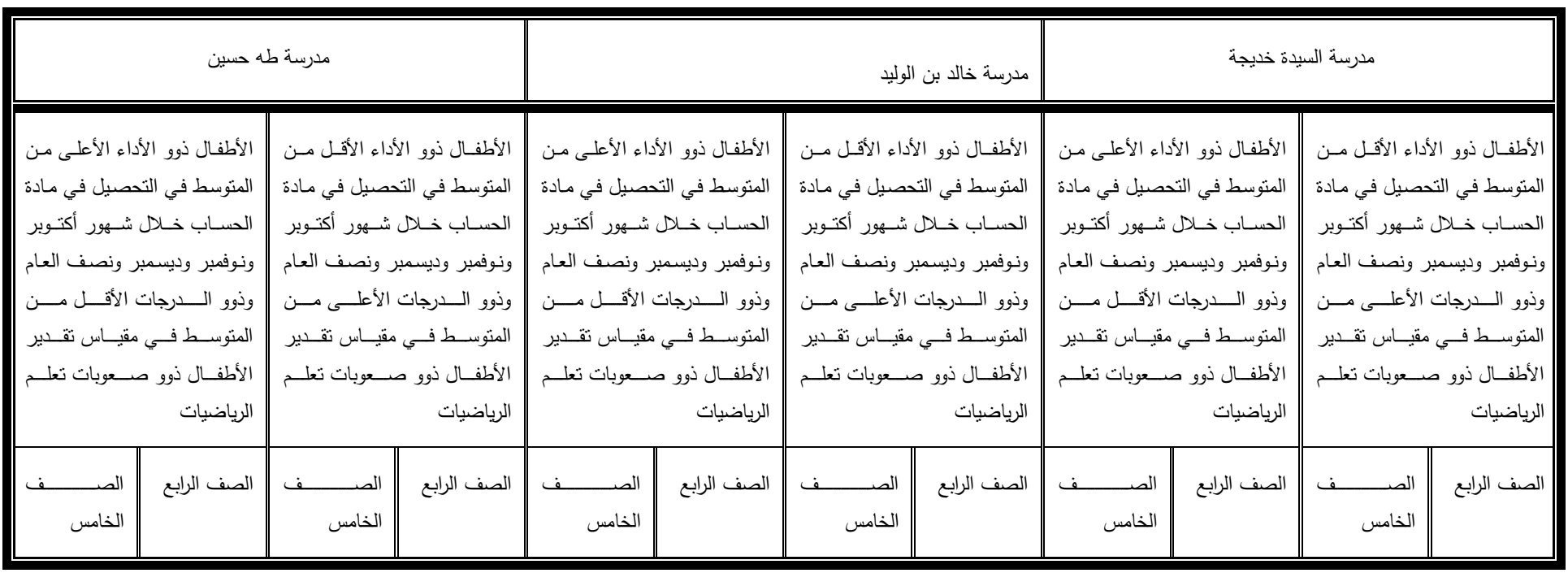




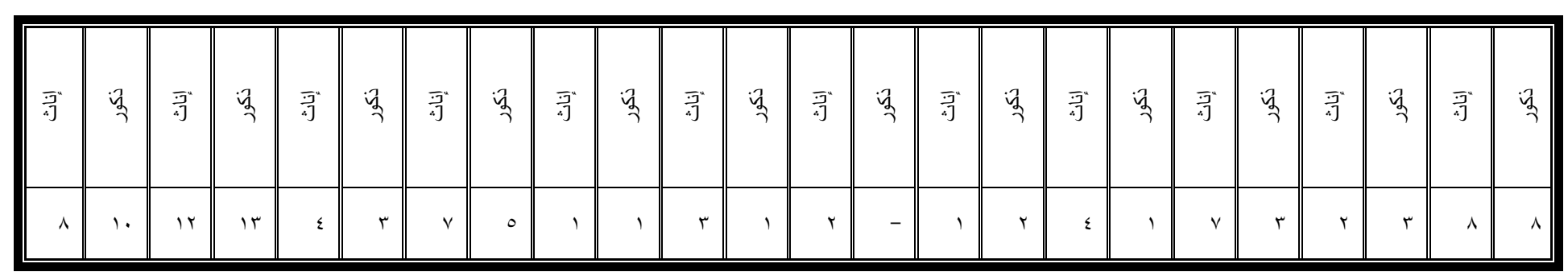

ء. تطبيق المقياس الفرعى للاستدلال الحسابى من مقياس وكسلر لقياس ذكاء الأطفال على الأطفال فى

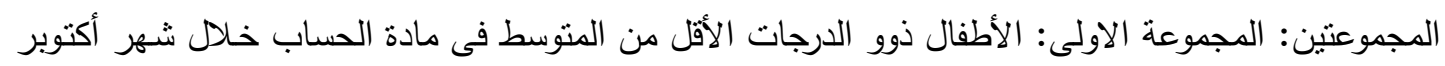

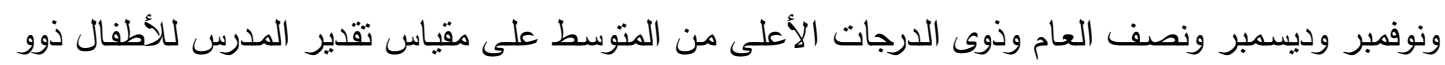

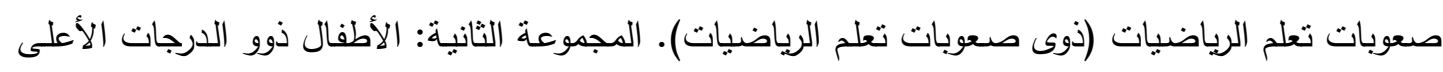

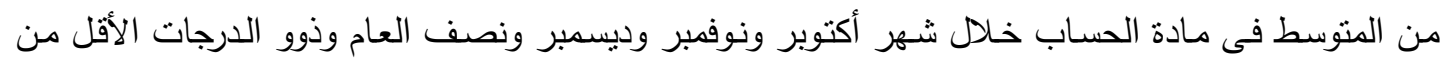

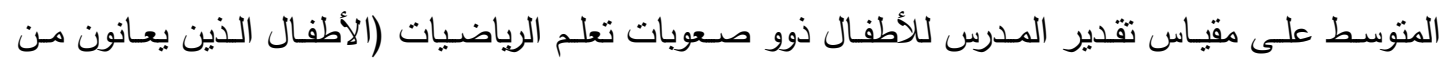
صعوبات تعلم الرياضيات).

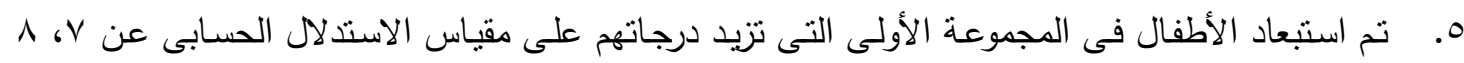

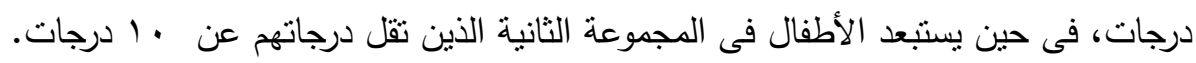

ويوضح جدول (ع-r) توزيع الأطفال الذكور والإناث ذوى الدرجات الأقل من المتوسط فى تحصيل مادة الحساب في شهور أكتوبر ونوفمبر وديسمبر ونصف العام وذوى الدرجات الأعلى من المنوسط على مقياس

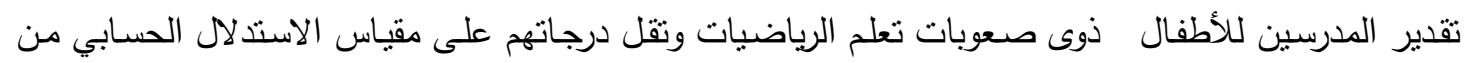

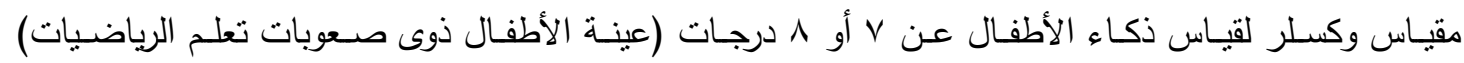
والأطفال الذكور والإنـاث ذوى الدرجات الأعلى مـن المتوسط فى تحصيل مـادة الحسـاب فى شـهور أكتوبر

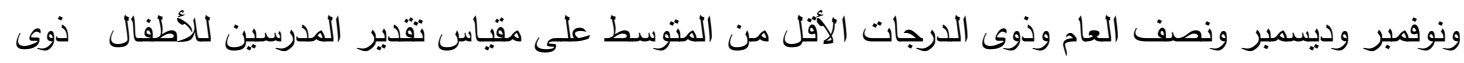

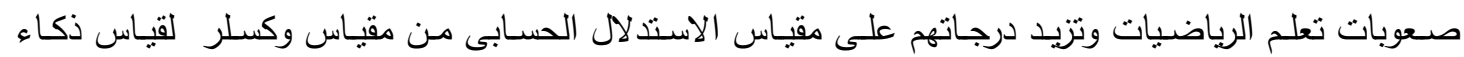
الأطفال عن · م إنعات.

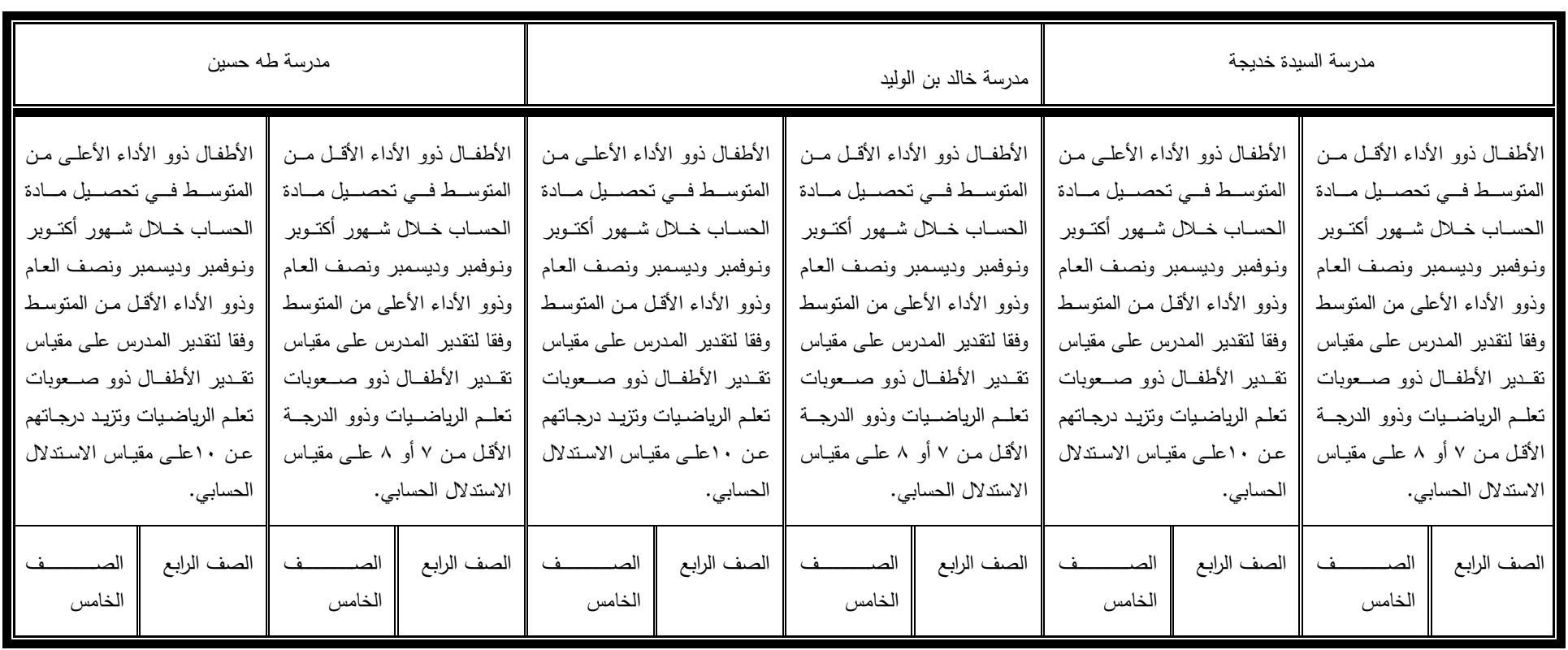




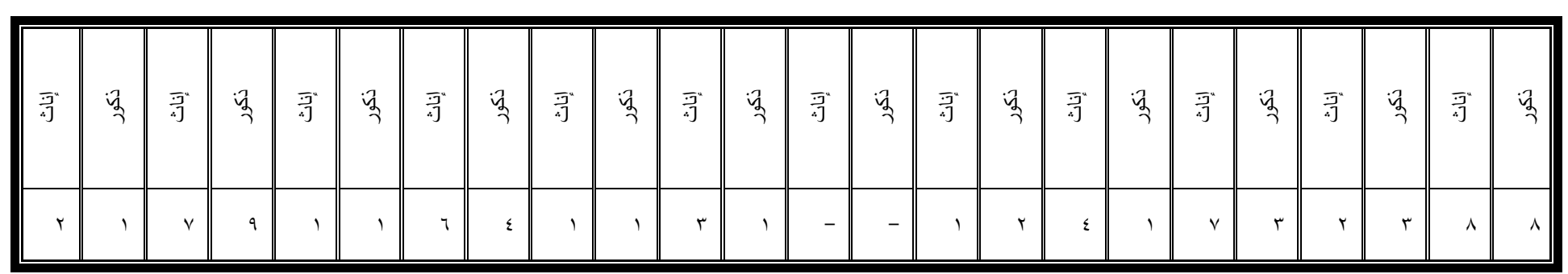

وبذلك أصبحت نتكون عينة الدراسة الحالية من V7 من الأطفال الذكور والإناث بالمدارس الابندائية الحكومية موزعين على مجموعتين كالآتي:

المجموعة الأولى: مجموعة الأطفال ذوبي صعوبات تعلم الرياضيات (ن= דس: 1 ا ذكور و 1 1 إناث). المجموعة الثانية: مجموعة الأطفال الذين لا يعانون من صعوبات تعلم الرياضيات (ن= . ع: 1 أذكور و ؟ب إناث). ويوضح الجدول (ع - §) خصائص الأطفال في المجموعنين:

\begin{tabular}{|c|c|c|c|c|c|}
\hline \multirow[t]{2}{*}{ 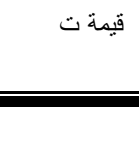 } & \multicolumn{2}{|c|}{ 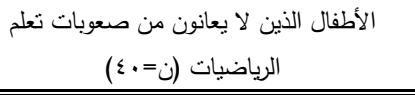 } & \multicolumn{3}{|c|}{ الأطفال ذوو صعوبات تعلم الرياضيات (ن=؟r) } \\
\hline & 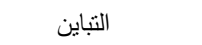 & المتوسط الم & التباين & المتوسط & الهتغير \\
\hline$* * V \cdot r \cdot r$ & $1.99 .1 \mathrm{rVI}$ & rar & 1909.21 & rTt & 1- التحصيل في مادة الحساب. \\
\hline 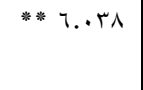 & $r \cdot r .0 \leq V \leq$ & 19.7 Y & TrE.901 & $\varepsilon \leqslant .79$ & r- مقياس تقدير المدرس للأطفال ذوي صعوبات تعلم \\
\hline$* * 1, . \wedge \leq 7$ & r.or & $1 . .17$ & $1 . r 94$ & 7.917 & وكسلر لقياس ذكاء الأطفال. الفرعي للاسـتـلال الحسـابي مـن مقيـاس \\
\hline & & & & & ع- الذكاء \\
\hline .041 & $7 . .04$ & A. . & $\varepsilon . \wedge \wedge$ & $\Lambda . \leqslant \vee$ & أ. الذكاء العملي. \\
\hline i.v. & $1 . . \mathrm{ror}$ & 11.00 & $1 . .291$ & $1 ., \mathrm{rV}$ & ب. الذكاء اللفظي. \\
\hline 1.200 & 19.4 .9 & r..lvo & 17..rIT & 11..vo & ت. الذكاء الكلي. \\
\hline $1.77 r$ & r.9Tr & $r \cdot . T r$ & 7.010 & r.. ro & 0- المستوى الاقتصادي-الاجنماعي. \\
\hline
\end{tabular}

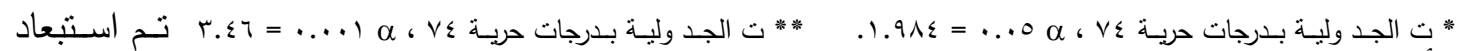

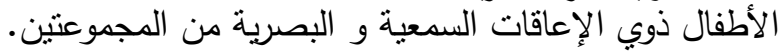

تم إحداث التكافؤ بين الأطفال في المجموعتين في العمر من خلال السجالات المدرسية و كذلك استمارة المستوى الاقتصادي/الاجتماعي من إعداد منسي (ب191).

\section{r - الأدوات وخصائصها السيكومترية}

استخدم بالإضافة إلى درجات التلامبذ في مادة الحساب في شهور أكتوبر ونوفمبر وديسمبر والفصل الفدول الدراسي الأول اختبارين آخرين لنشخيص الأطفال ذوى صعوبات تعلم الرياضيات هي: D. Wechsler أ- الاختبار الفرعي للحساب من مقياس وكسلر لقياس ذكاء الأطفال من إعداد ديفيد وكسلر واقتبسه وأعده للبيئة المصرية اسماعيل ومليكة (س99 ( ). ويعد هذا الاختبار أحد الاختبارات الفرعية من مقياس وكسلر لقياس ذكاء الأطفال ممن تتراوح أعمارهم بين هو 7 اسنة، وهو يقيس قدرة الطفل على تكوين المفهوم الرياضي. ب) مقياس تقدير خصائص الأطفال ذوى صعوبات تعلم الرياضيات من إعداد ميلر وميرسر \& Mercer, 1997) وترجمه الباحث. ويتكون المقياس من اس بنداً تمثنل الصعوبات الحركية، صعوبات المعاًلجة السمعية، مشكلات الذاكرة، مشكلات التصور البصري المكاني، مشكلات الانتباه، مشكلات المعرفة وما وراء 
المعرفة، وبعض الخصائص الانفعالية للأطفال الذين يعانون صعوبات تعلم الرياضيات. ينم تقدير الطفل في كل فقرة من فقرات المقياس على مقياس مكون من ست نقاط وفقاً لارجة أو تمثيل الصفة لمظهر معين من مظاهر

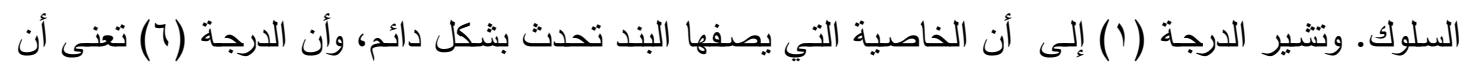
الخاصية لا تحدث مطلقاً. ج- اختبار الفهم القرائي للأطفال إعداد خيري عجاج (991 (1)): ويقيس قدرة الطفل على فهم معنى الكلمة من خلال (تعيين الكلمات المضادة وتعيين الكلمات الغريبة وتصنيف الكلمات) وفهم معنى الكلمة من خلال (التوفيق

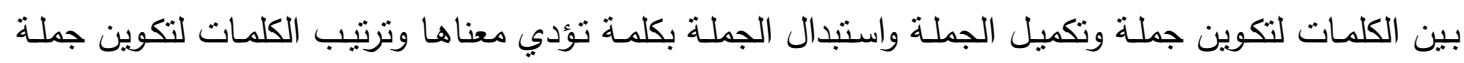
مفيدة) وإدراك العلاقات اللغوية وإدراك المتعلقات اللغوية. الخصائص السيكومترية للأدوات التشخيصية:

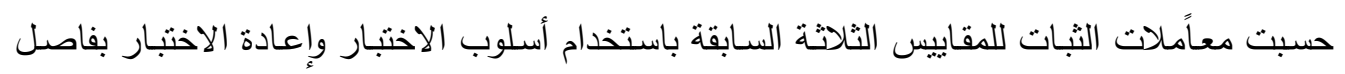
زمني مقداره إب يوم بين التطبيقين فجاءت معاًملات الارتباط كالآتي:

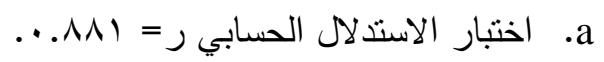

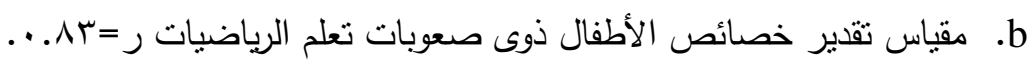

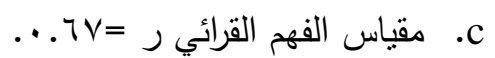

وفيمـا يتعلق بالصـدق، فقد استخدم الباحث الحسالي صـدق المحك لحسـاب صدق مقيـاس الفرعي للاستـلال

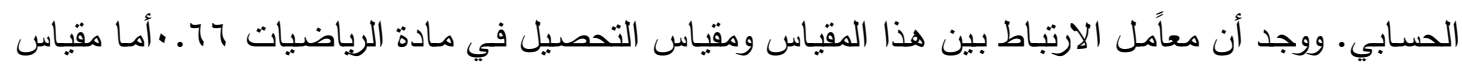
تقدير الأطفال ومقياس الفهم القرائي فقد اهتم الباحث بصدق الاربن المحكمين.

r- أدوات قياس الجوانب الانفعالية الاجتماعية: (أ) مقياس بيرز هاريس لمفهوم الذات:

من إعداد بيرز هاريس Peries-Harries وترجمه الباحث. يتكون المقياس من •م بنداً تقيس ستة أنماط فرعية من مفهوم الذات هي: هين إعدرن

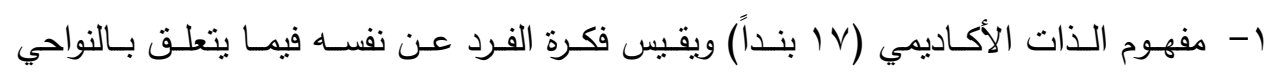

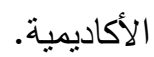

ץ- مفهـوم الـذات الاجتمـاعي (ب (بنـداً) ويقيس فكـرة الفـرد عـن نفسـهـ فيمـا يتعلـق بـالنواحي الاجتماعية كتكوين الصداقات والمشاركة في الألعاب.

ب- مفهوم الذات الانفعالي (ع (بنداً) يقيس فكرة الفرد عن نفسه فيما يتعلق بالنواحي العاطفية. ع - السعادة (• (بنود) تقبس فكرة الفرد عن نفسه فيما يتعلق بالثعور العام بالسعادة.

ه- - مفهوم الذات الجسمي (ب ابنداً) يقيس فكرة الفرد عن نفسه فيما يتعلق بالجوانب الجسمية كالقوة البدنية.

7- بعض أنمـاط السلوك (7 (بنداً) يقيس آراء الطفل في المشـاكل التي يتعرض لها وتحديد المكان الذي تحدث فيه تلك المشكلات. 
وقد استبعدت بنود مفهوم الذات الجسمية، بعض أنماط السلوك، مفهوم الذات الانفعالي والسعادة.

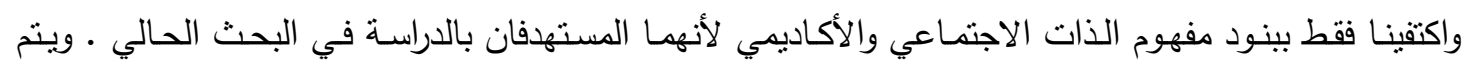
الإجابة على كل بند من بنود الاختبار باختيار إحدى إجابتين نعم أولا. حيث تشير الإجابة بنعم إلى انطباق البند

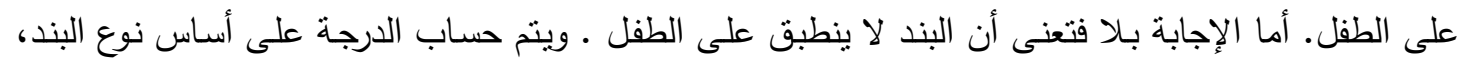

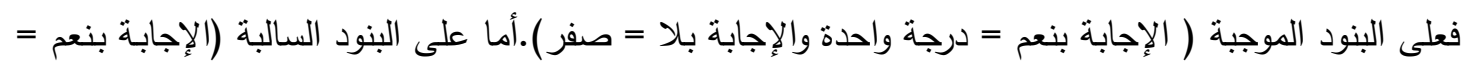

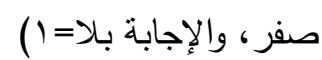

وقد فضل الباحث استخدام هذا المقياس على الرغم من وفرة مقاييس مفهوم الذات المقننة في البيئة العربية لسببين:-

1- على الرغم من أن الغالبيـة العظمى مـن الدراسـات الأجنبيـة التي أجريت لدراسـة الجوانب

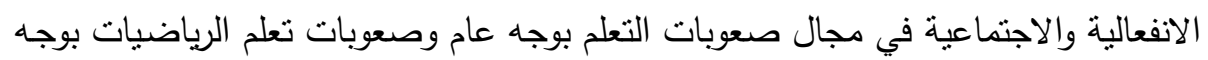
خاص استخدمت مقياس بيرز هاريس لمفهوم الذات. لا يوجد - في حدود علم الباحثدراسة عربية واحدة أجريت في مجال صعوبات التعلم بوجه عام أو في مجال صعوبات تعلم

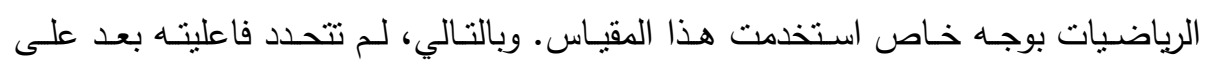
الأطفال ذوى صعوبات التعلم في البيئة العربية. ץ- لا يوجد- في علم الباحث - إلا دراسـة عربيـة واحدة أجرتها المطوع (1991 (1) في البيئة

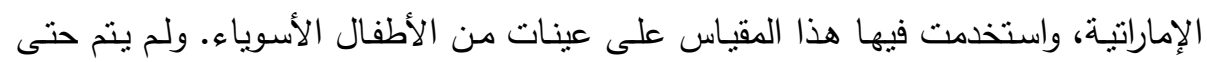

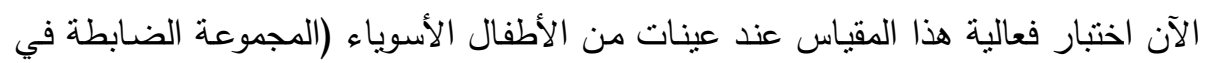
الدراسة الحالية) في البيئة المصرية.

وقد نشرت بنود المقياس ( • بند- نسخة ـ99 (1) ومفتاح التصحيح باللغة الإنجليزية في رسالة قدمتها

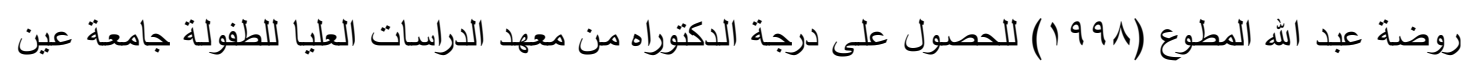

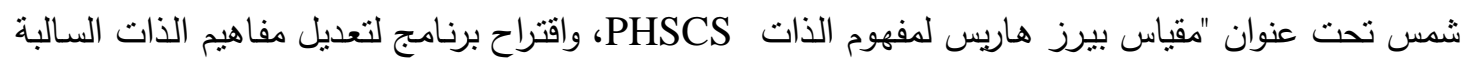
لدى أطفال دولة الإمارات: دراسة تحليلية". وبعد أن أعدت صورة لفئ عربية للمقياس لاستخدامها في دولة الإمارات

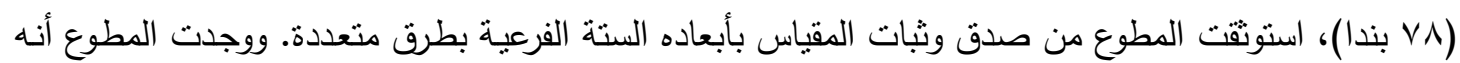
يتمتع بمعاملات ثبات وصدق مرضية. ملحق رقم ( • (). وقام الباحث الحالي بحساب صدق وثناته المقياس.

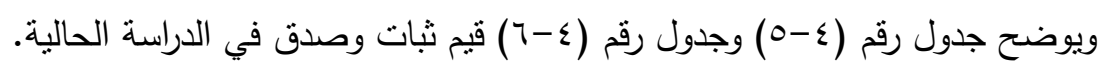

Child Behavior Rating Scale (CBRS) قائمة ملاحظة سلوك الطفل

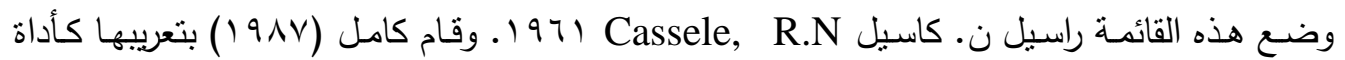

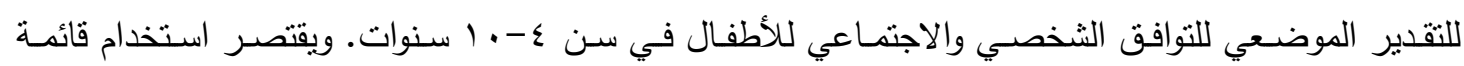
ملاحظة سلوك الطفل (CBRS) على الملاحظين الذين قاموا بملاحظة سلوك الطفل موضع التقدير ، أو الذين

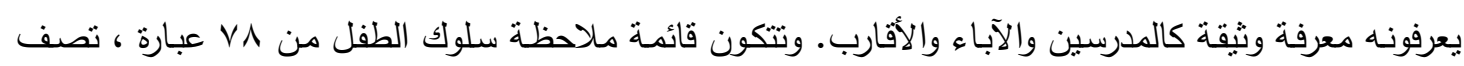

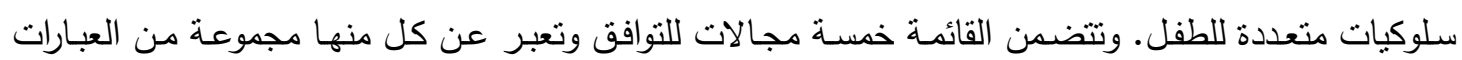

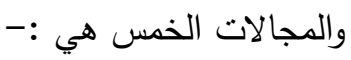


ا-التوافق الثخصي Self-Adjustment تمثنله عشرون فقرة هي الفقرات من احتى رقم •r. r- التوافق الأسرى Home Adjustment تمثله عشرون فقرة هي الفقرات من ابحتى رقم •ـ. r- التوافق الاجتماعي Social Adjustment تمتله عشرون فقرة هي الفقرات من اء حتى رقم .7.

ع - التوافق المدرسي School Adjustment تمثله اثثتا عشرة فقرة هي الفقرات من الحتى .V

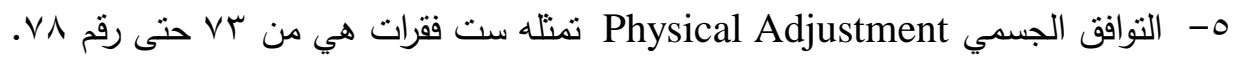
ويتم تقدير الطفل في كل فقرة من فقرات القائمة على مقياس مكون من ست نقاط وفقا لدرجة أو مدى

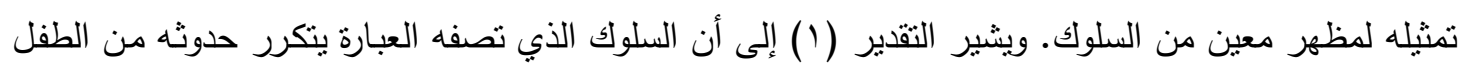

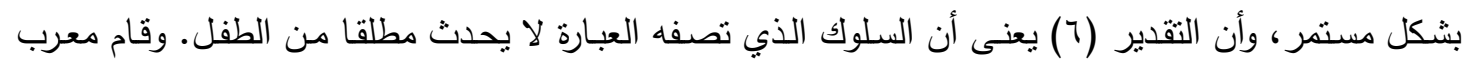

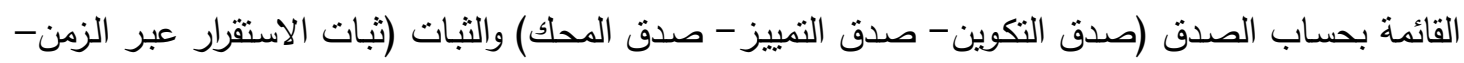

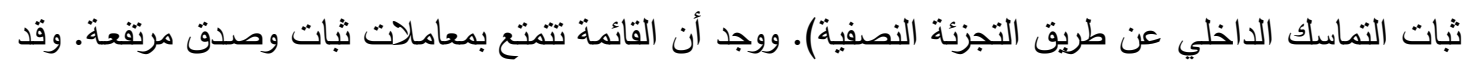

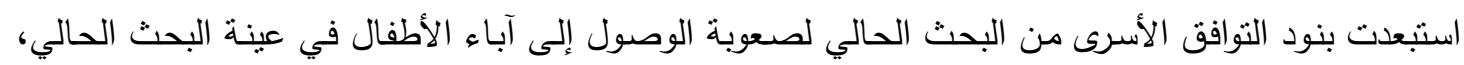

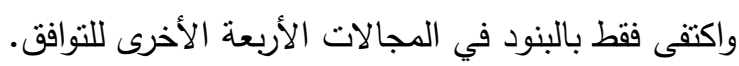
وبمراجعة بنود القائعة لاحظ الباحث وجود بعض الأخطاء، ولذا قام الباحث بإجراء بعض التعديلات

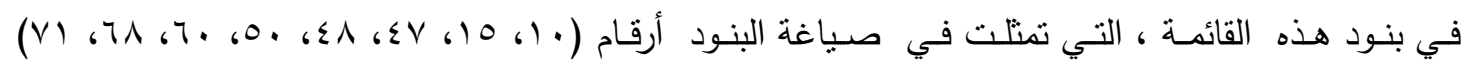

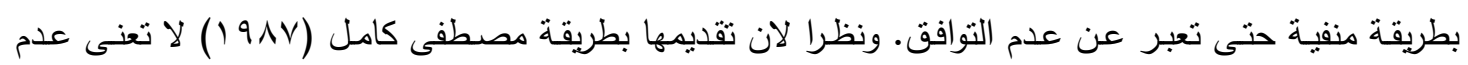
التوافق. ففي صياغته يعد الطفل الذي يعتذر أو يتأسف عن الأخطاء التي يرتكبها (البند رقم • (1) ونشاطه كبير

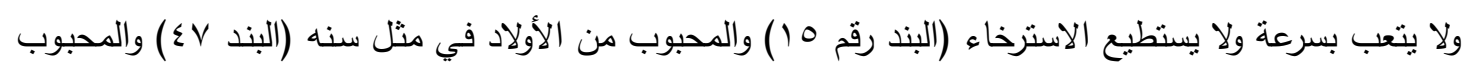

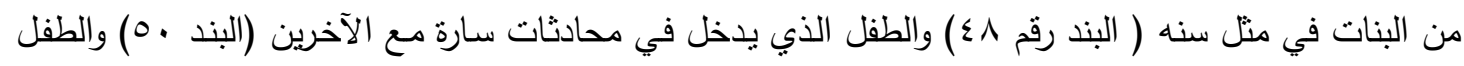

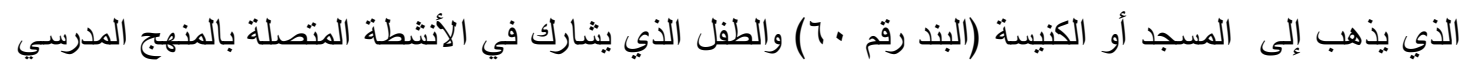

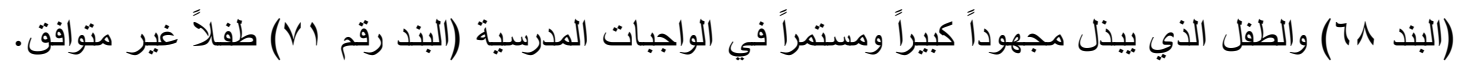
لاللك قام الباحث الحالي بصياغتها بطريقة منفية كالآتي:- لا يعتذر أو يتأسف عن الأخطاء التي يرتكبها (البند رقم • (). - مكروه من الأولاد في مثل سنه (البند رقم \؟). - مكروه من البنات في مثل سنه (البند رقم ^^). - لا يدخل في محادثات سارة مع الآخرين (البند رقم •). - ل الذهب للمسجد أو الكنيسة ( البند رقم . آ). - لا يشارك في الأنشطة المتصلة بالمنهج المدرسي (البند رقم لج).

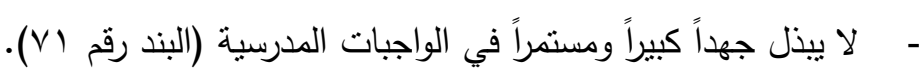


وبعد إجراء هذه التعديلات لتلك البنود عرض الباحث الحالي القائمـة على مجموعة من أساتذة علم

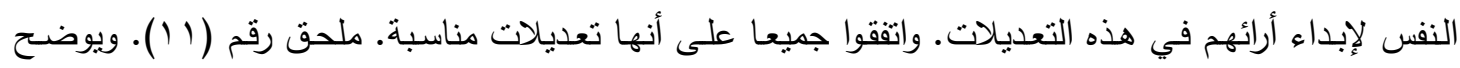

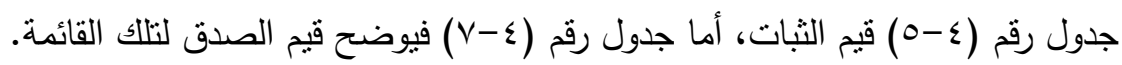
r-حساب الخصائص السيكومترية للأدوات أولاً: الثبات:

تكونت عينة الثبات من ه أطفال (ذكور و إناث) من مجموعة الأطفال ذوب صعوبات التعلم، والأطفال

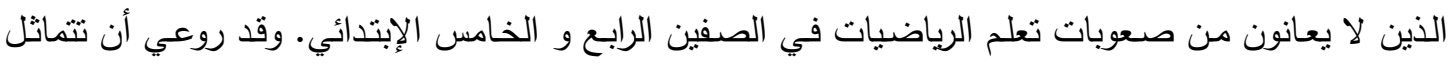

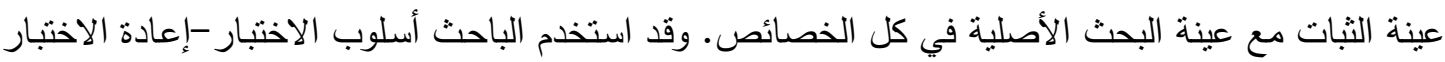
Test-Retest ويوضح جدول (ع-0) معاملات ثبات اختبارات الدراسة الحالية لدى عينة الثبات.

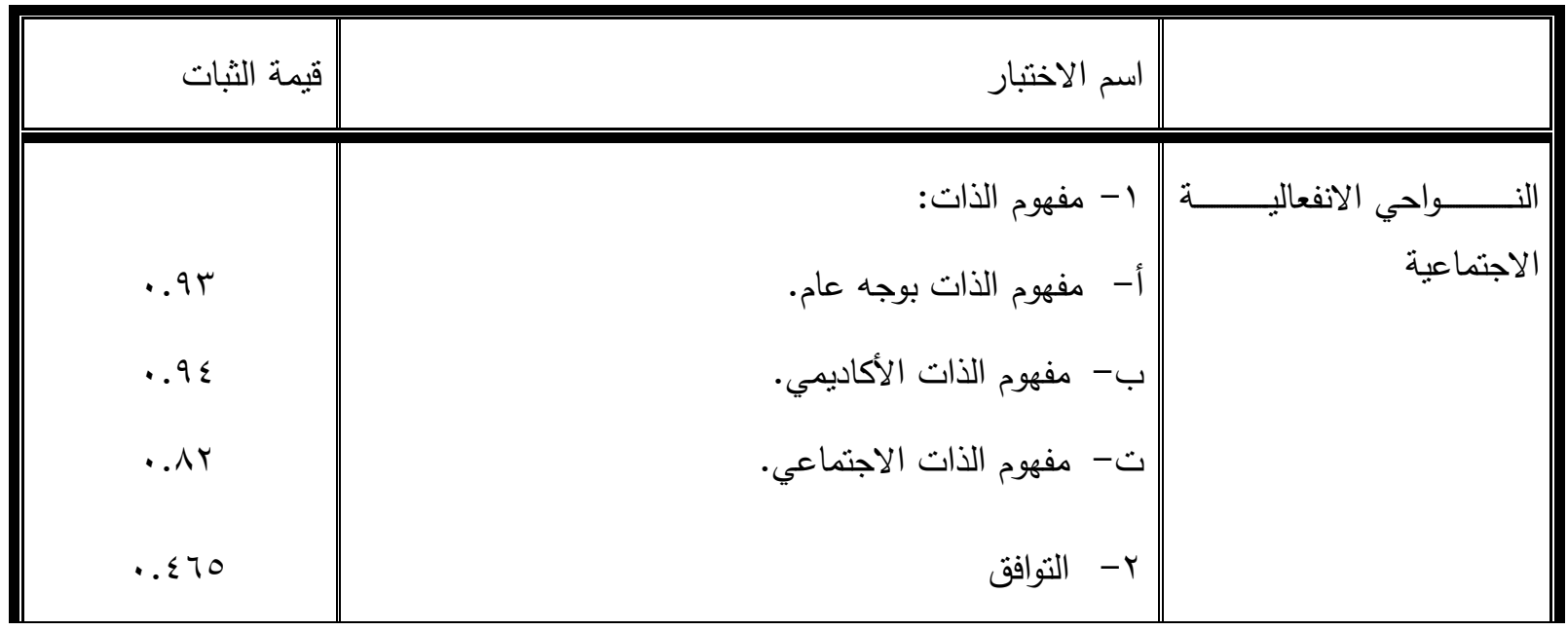

ثانيا : الصدق

يوضح جدول (ع-7) قيمة الصدق للاختبارات المستخدمة.

\begin{tabular}{|c|c|}
\hline قيمة الصدق & معامل الارتباط بين \\
\hline. .74 & 1- مقياس تقدير الأطفال ذوي صعوبات تعلم الرياضيات و التحصيل في مادة الحساب (صدق \\
\hline .74 & 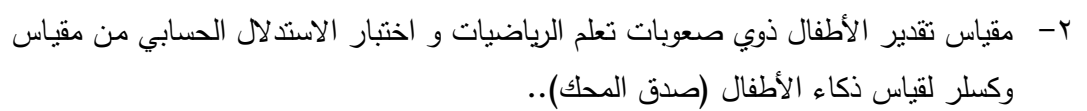 \\
\hline 74. & r- اختبار مفهوم الذات من مقياس بيرز هاريس واختبار مفهوم الذات عند الأشول (عادل عز \\
\hline r & ع- اختبار مفهوم الذات الأكاديمي ومفهوم الذات الاجتماعي من مقياس بيرز هاريس (صدق \\
\hline
\end{tabular}




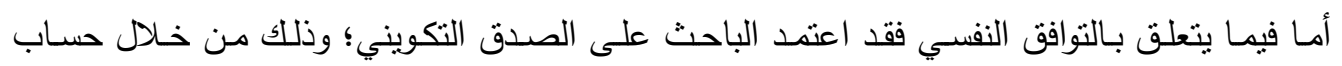
معاملات الارتباط البينية بين التوافق الثخصي و التوافق الاجنماعي والتوافق الجسمي و الدرجة الكلية. ويوضح جدول (ع-V) معاملات الارتباط البينية بين المقاييس الأربعة.

\begin{tabular}{|c|c|c|c|c|c|}
\hline الدرجة الكلية & التوافق الجسمي & التوافق الددرسي & التوافق الاجتماعي & التوافق الثخصي & قائمة ملاحظة سلوك الطفل \\
\hline ...991 & $.01 \varepsilon$ &. $.7 V \cdot 9$ &. TV & & التوافق الثخصي \\
\hline . .AVIV & $.901 r$ & 1 & & & التوافق الاجتماعي \\
\hline. $.9 T V$ &. $.90 \lambda r V$ & & & & التوافق المدرسي \\
\hline..$\wedge r v$ & & & & & التوافق الجسمي \\
\hline
\end{tabular}

ع - إجراءات التطبيق

تم التطبيق فرديـا داخل المدارس التي تطبق فيها الاختبارات موضـع الدراسـة على كل من الأطفال

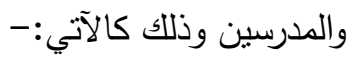

1- اختبارات تطبق على الأطفال وتتمتل في مقياس الاستدلال الحسابي ومقياس الفهم القرائي مقياسي مفهومي

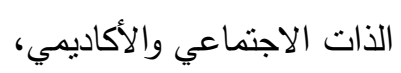

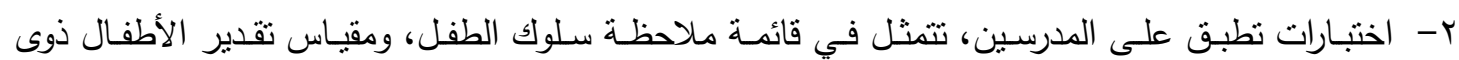
صعوبات نعلم الرياضيات

$$
\text { ه - الأساليب الإحصائية }
$$

لاختيـار عينـة البحثث واختبـار فروضـه والتحقق من صدق أدوات الدراسـة الحاليـة وثباتهـا استخدمت لاحت

$$
\text { الأساليب الإحصائية الآتية:- }
$$

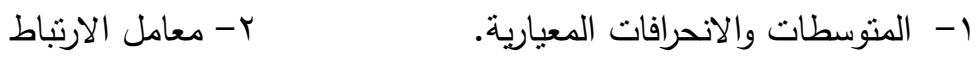

$$
\begin{aligned}
& \text { r- اختبار "ت" لبيان دلالة الفروق بين متوسطات الهجموعات }
\end{aligned}
$$

سابعا : عرض نتائج الاراسة وتفسيرها أولا: عرض نتائج الفرض الأول ومناقشتها: وينص هذا الفرض على "توجد فروق دالة بين الأطفال ذوب صعوبات تعلم الرياضيات ونظرائهم الأسوياء فيما ينعلق بالأداء على اختبارات مفهوم الذات (الأكاديمي و الاجتماعي) واختبار التوافق". وللتحقق من صحة هذا الفرض نم استخدام اختبار "ت" لبيان دلالة الفروق بين متوسطي المجموعتين. جدول (0-r) يوضح الفروق بين منوسطي عينة الأطفال ذوي صعوبات تعلم الرياضيات (ن=؟r) وعينة الأطفال الذين لا يعانون من صعوبات تعلم الرياضيات (ن=.؛ ) فيما يتعلق بالأداء على اختبارات مفهوم الذات (الأكاديمي و الاجتماعي) واختبار التوافق. 


\begin{tabular}{|c|c|c|c|c|c|}
\hline \multirow{2}{*}{ 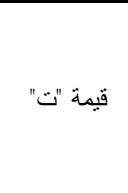 } & \multicolumn{2}{|c|}{ 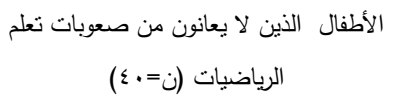 } & \multicolumn{2}{|c|}{ الأطفال ذوبي صعوبات تعلم الرياضيات } & \\
\hline & 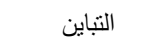 & المنوسط المط & التباين & المتوسط & \\
\hline & & & & & 1- مقياس مفهوم الذات: \\
\hline $1.0 \leqslant$ & $0.1 \mathrm{VT}$ & 10.110 & $7.0 \mathrm{rV}$ & $1 \leqslant .0 \wedge r$ & أ. مفوم الذات الأكاديمي. \\
\hline . TAK & $r . \cdot v \cdot$ & A. $\leqslant r_{0}$ & $1.7 r V$ & A.OYV & ب. مفهوم الذات الاجتماعي. \\
\hline $1.1 \vee \wedge$ & $1 . .174$ & $r \leq . .0$ & $11 . r v q$ & rt.ith & ت. مفهوم الذات الأكاديمي والاجتماعي معا. \\
\hline$* * Y . \vee \leq ฯ$ & rark..101 & r94.9Y० & rNo..VTV & TOV.NTr & r- اختبار التوافق. \\
\hline
\end{tabular}

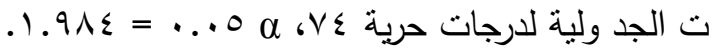

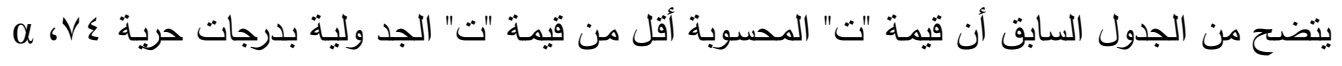
ه .. • لكل من مفهوم الذات الأكاديمي ومفهوم الذات الاجتماعي ومفهومي الذات الأكاديمي والاجتماعي معا. وهذا يعني غيـاب فروق دالـة بين الأطفـال ذوي صـوبات تعلم الرياضـيات والأطفال الذين لا يعانون مـن صـوبات تعلم الرياضـيات في كل مـن مفهوم الـات الأكـاديمي ومفهوم الذات الاجتمـــي ومفهومي الذات الأكاديمي والاجتماعي معا. في حين توجد فروق دالة بين المجموعتين في التوافق النفسي.

\section{تفسير نتائج الفرض الأول:}

أظهرت نتائج المعالجة الإحصـائية التي أجربت للتحقق من فرض التوافق النفسي بوجود فروق دالـة إحصـائية بـين الأطفال ذوى صـوبات تعلـم الرياضـيات والأطفـال الأسـوياء في التوافق في ضـوء تقديرات المدرسين. وتتفق هذه النتيجة مـع نتائج دراسـات عديدة منل دراسـة روسنبرج (Rosenberg, 1989) ودراسـة

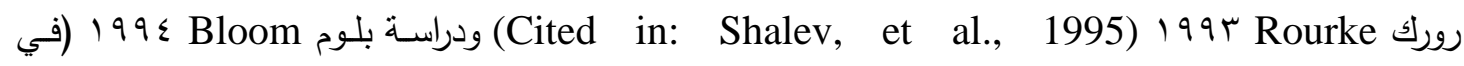

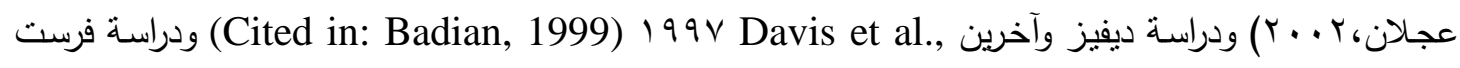
وآخرين (Fuerst et al.,1990) ودراسـة جيوفون وبير (Juvonen \& Bear, 1992) ودراسة فينز وسبرستان (Wenz \& Siperstein, 1998) (Cited in: Shalev, Auerbach \& Gross-1 99 r Rourke وصعوبات نعلم الرياضيات. وقد فسر رورك) (هذه النتيجة على المستوى النيوروسيكولوجى باعتبار أن المشكلات الاجتماعيـة، والانسحابية، وصعوبات تعلم الرياضيات تكون جزءاً من زملة أعراض الفص الأيمن النمائية (DRHS) وصعوبات التعلم غير اللفظية (NVD). فقد وجد رورك أن الأطفال ذوى صعوبات تعلم الرياضيات يحصلون على نسب مرتفعة من المشكلات الاجتماعية والانسحابية مقارنة بما توقعه لهؤلاء الأطفال على وجه الخصوص. فلدى هؤلاء الأفراد صعوبات في العلاقات الثخصية ونزعة للانعزال والانسـاب الاجتماعي. وعلى المستوى النفسي يفسر وجود

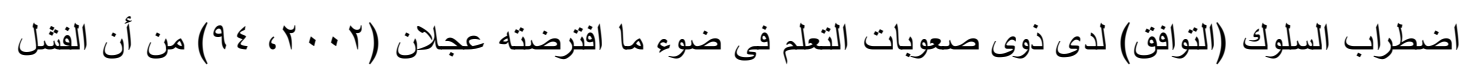
التحصـيلى وتقدير الـذات المـنخفض لـدى الطفل ذوو صـعوبة التعلم يعـد مـن عوامـل الخطـر التي تعرضــه لاضطراب السلوك. وقد يؤدى ذلك إلى افتقار الأطفال ذوى صعوبات التعلم لمهارات المشـاركة الاجتماعيـة 
واتخاذ الأدوار دون إزعاج للآخرين وانخفاض المرونة لليهم، وإلى نبذ أقرانهم، ويسهم ذللك كله في نشأة أعراض

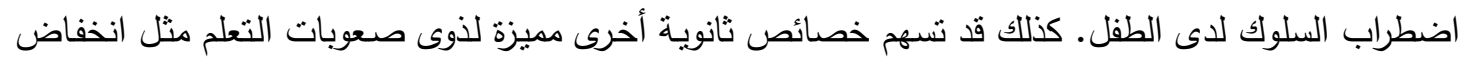

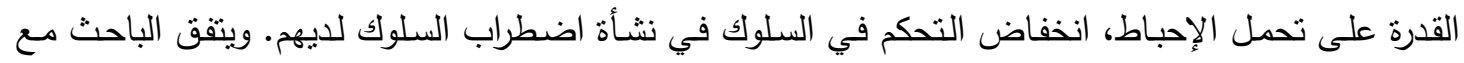

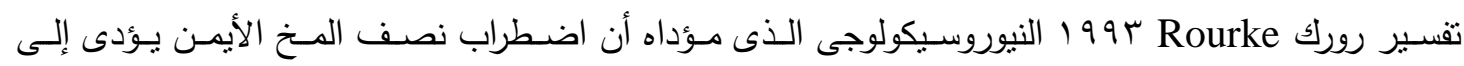

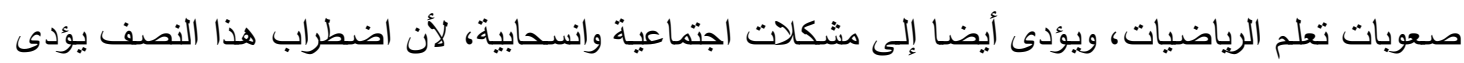

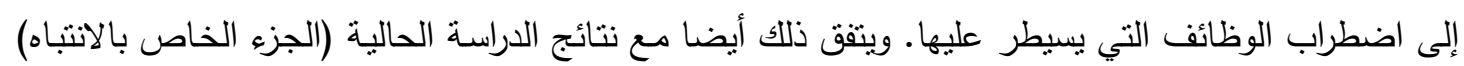

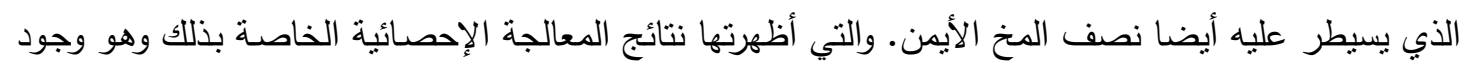
فروق دالة بين ذوى صعوبات تعلم الرياضيات ونظرائهم فيما يتعلق بأدائهم على مهمة الانتباه السمعي. وقد يفسر أيضا وجود فروق دالة بين الأطفال ذوى صعوبات تعلم الرياضيات ونظرائهم الأسوياء في

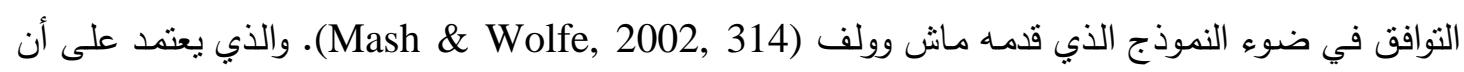
هناك ثلاث نظريات مفسرة لكيفية أن صعوبات التعلم ترتبط على نحو دال بمشكلات السلوكية وهى: 1- المشكلات النمائيـة المبكرة (التلف العضـوي - العوامل الوراثيـة والبنيويـة- انخفاض نسبة الذكاءمعالجـة المعلومات- التأخر أو عدم النضـج النمائى) تؤدى إلى مشكلات سلوكية (النشاط الحركي

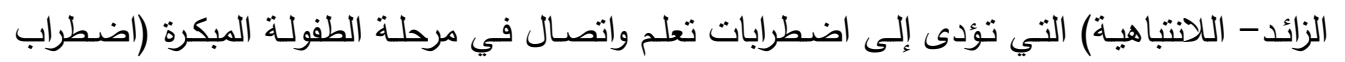
المعالجة الفينولوجية- اضطراب اللغة التعبيريـة) وصعوبات التعلم (في الرياضيات- القراءة-الكتابـة) في مرحلة الطفولة المتأخرة. r- الصعوبات النمائية المبكرة قد تؤدى إلى مشكلات في التعلم تؤدى بالضرورة إلى مشكلات في السلوك. r- الصعوبات النمائية المبكرة تؤدى إلى مشكلات في التعلم والسلوك تتفاعل معا لزيادة تأثير كل منهما على الآخر طوال الوقت. وهذا يعنى أن صعوبات التعلم بوجه عام نؤدى إلى سوء التوافق وقد يؤدى سوء التوافق إلى صعوبة التعلم. وفيما يتعلق بمفهوم الذات أظهرت نتائج المعالجة الإحصائية التي أجريت للتحقق من هذه الفرضية

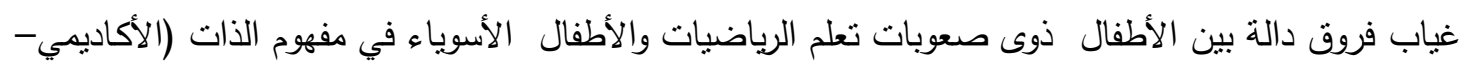

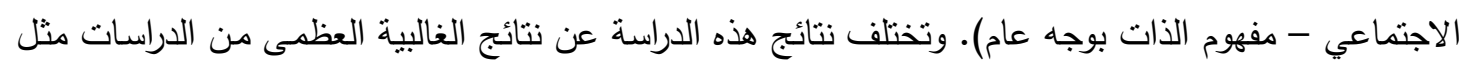
بروت ومارسيه ومارسيه Cited in: Montgomery, 1994) 99 r Prout, Marcel \& Marcal) ودراسة جرولنك وريان (Grolnick \& Ryan, 1990) ودراسة كرشنر (Kershner, 1990) ودراسة كلوموك (Kloomok, 1991) ودراسة مونتجمورى (Montgomery, 1994). وقد فسرت الدراسات التي وجدت فروقاً دالـة بين الأطفال ذوى صـعوبات التعلم والأطفال الأسـوياء في مفهوم الذات الأكاديمي بـأن مفهوم الذات الأكاديمي يعكس على نحو دقيق القدرات الأكاديمية الضعيفة. كما وجدت نتائج بعض من هذه الدراسات أن الأن

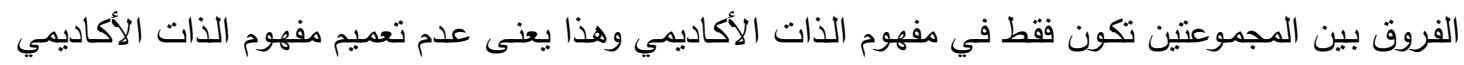

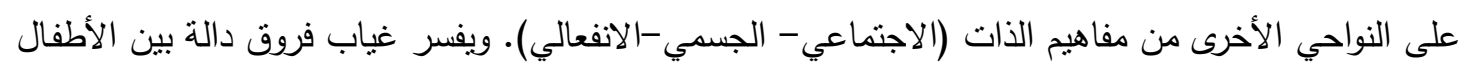

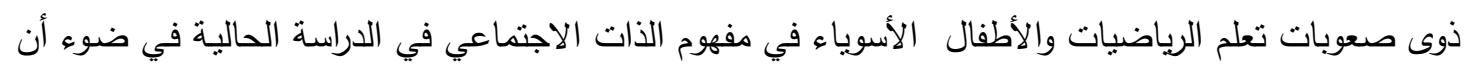

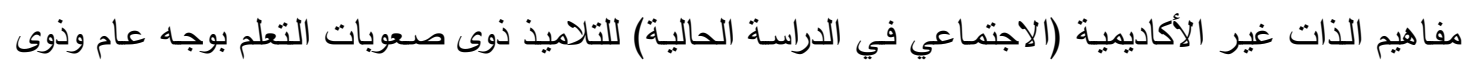
صعوبات تعلم الرياضيات بوجه خاص لا تتأثز بقدراتهم الأكاديمية الضعيفة. أما غياب فروق لاتية دالة بئة بين الأطفال 
في المجموعتين في مفهوم الذات الأكاديمي، فترجع إلى أن بنود مفهوم الذات الأكاديمي من مقاييس بيرز

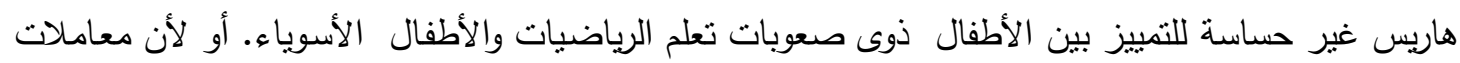

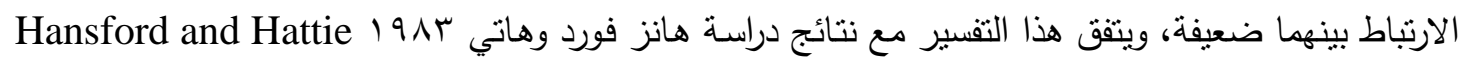
(Cited in: Bracken, 1996, 299)

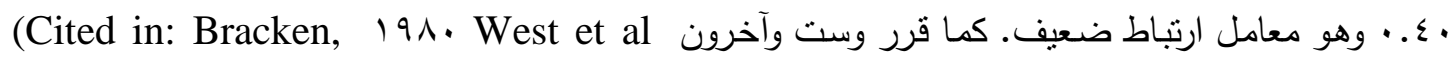

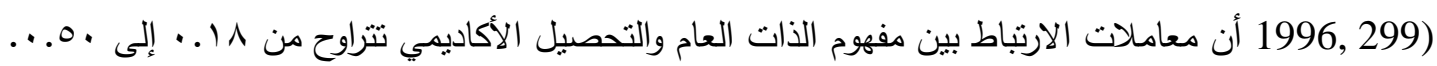
ثانيا : عرض نتائج الفرض الثاني ومناقشتها: وينص هذا الفرض على " توجد فروق دالة بين الأطفال الذكور ذوي صعوبات تعلم الرياضيات ونظرائهم الإناث اللائي يعانون من صعوبات تعلم الرياضيات في الأداء على الاختبارات التتخيصية لصعوبات تعلم الرياضيات". وللتحقق من صحة هذا الفرض تم استخدام اختبار "ت" لبيان دلالة الفروق بين متوسطي المجموعنين. جدول (0- §) الفروق بين متوسطي الذكور ذوي صعوبات تعلم الرياضيات والإناث اللائي يعانين من صعوبات تعلم الرياضيات في الأداء على اختبار التحصيل المدرسي والاستدلال الحسابي واختبار تقدير الأطفال ذوي صعوبات نعلم الرياضيات.

\begin{tabular}{|c|c|c|c|c|c|}
\hline \multirow{2}{*}{ 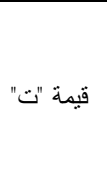 } & \multicolumn{2}{|c|}{ 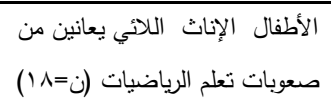 } & \multicolumn{2}{|c|}{ 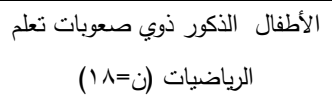 } & \\
\hline & التباين & 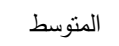 & 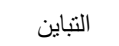 & المتوسط & \\
\hline $1.90 \mathrm{r}$ & $|\wedge \leq 1 . Y T|$ & rTr..00 & 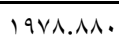 & r $10.9 \leq \leqslant$ & 1- اختبار التحصيل المدرسي في مادة الرياضيات. \\
\hline$. r q \leq$ & TIV.rtr & \&r.Arr & $r V^{\prime} . V T / 0$ & $\{0.000$ & الرياضيات. \\
\hline $.00 r$ & I.AY. & $V . .00$ & $1 \ldots 7$ & 7. $\vee V \vee$ & مقياس وكسلر لقياس ذكاء الأطفال الفرعي للاستلال الحسابي من \\
\hline
\end{tabular}

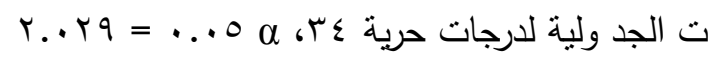

يتضح من الجدول السابق أن قيمة "ت" المحسوبة أقل من قيمة "ت" الجد ولية بدرجات حرية ؟ب، $\alpha$

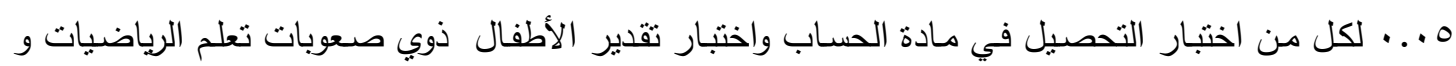
الاختبار الفرعي للاستدلال الحسابي من مقياس وكسلر لقياس ذكاء الأطفال. وهذا يعني عدم وجود فروق دالة دألة

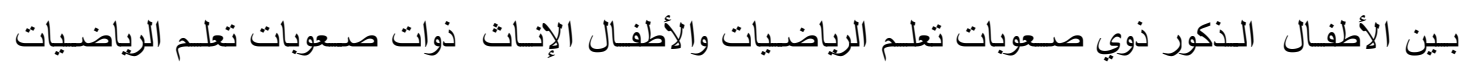
الاختبارات التشخيصية لصعوبات تعلم الرياضيات. تفسير نتائج الفرض الثاني :

أوضحت نتائج المعالجة الإحصائية التي أجريت للتحقق من صحة هذا الفرض غياب فروق إحصائية دالة بين الذكور ذوى صعوبات تعلم الرياضيات والإناث ذوات صعوبات تعلم الرياضيات في الأداء على اختبار 
التحصيل في مـادة الرياضيات واختبار الاستدلال الحسابي من مقياس وكسلر لقياس ذكاء الأطفال واختبار

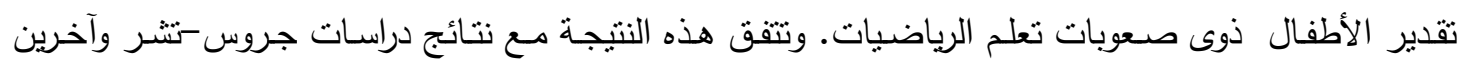
(Shalev, Manor, ودراسـة شـاليف ومانور واربتش وجروس-تشر (Gross-Tsur et al., 1996) Auerbach \& Gross-Tsur, 1998)

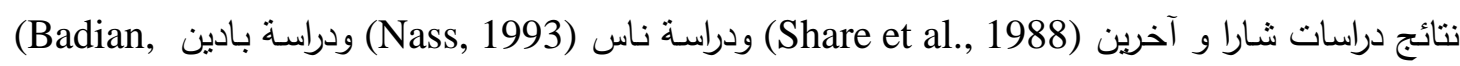

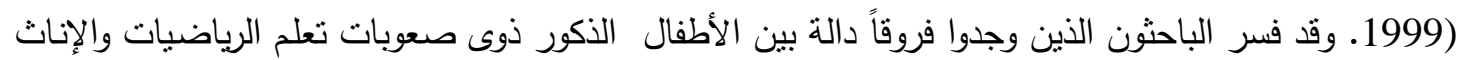
ذوات صعوبات تعلم الرياضيات هذه الفروق على مستويين: المستوى الأول هو المستوى النيوروسيكولوجى الذي دوني

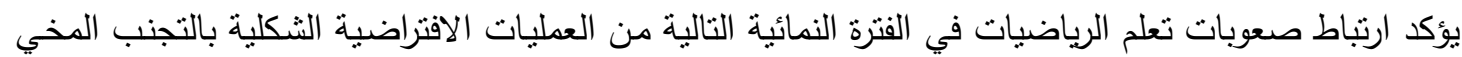
Brain Lateralization عن الأولاد؛ نظرا لأن النمو الاجتماعي للبنات بعيداً إلى حد ما عن المهام المكانية التي تؤدى دورا مهماً في

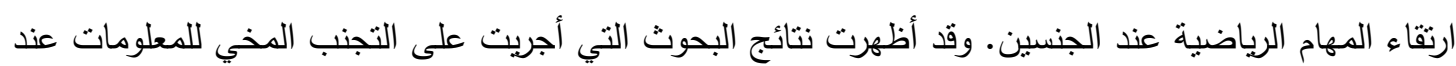

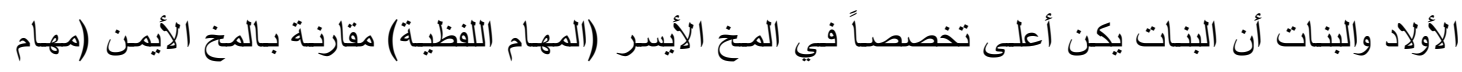
التصور البصري المكاني). وبالتالي يفضلن القراءة والمهام اللفظية عن الرياضيات (Newman, 1998, 92) Bee, 1998, 239 مثل أن الأولاد يأخذون الكثير من الدروس في الرياضيات مقارنة بالإناث، الاختلاف الملحوظ للاتجاهات الو الو

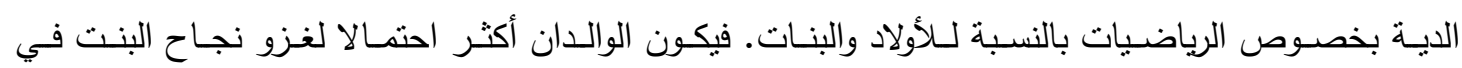
الرياضيات للمجهود الذي تبذله أو إلى التدريس الجيد. في حين يعزو الأداء الضعيف للبنت في هذه المادة لنقص القدرة الرياضية لديها. على العكس من ذلك، يعزو الوالدان نجاح الولد في الرياضيات إلى قدرته العقلية

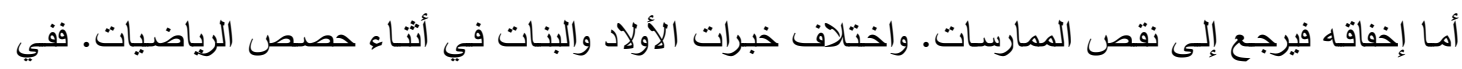

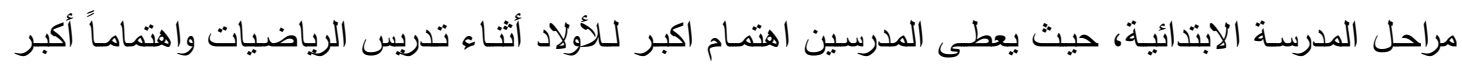

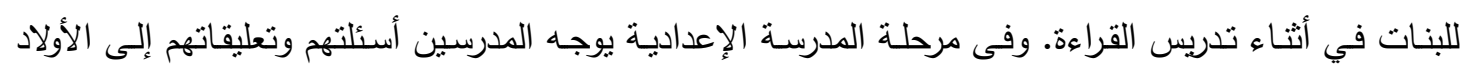
مقارنة بالبنات (Bee, 1998, 240). ويفسر الباحث غياب فروق دالة بين الأطفال الذكور ذوى صعوبات

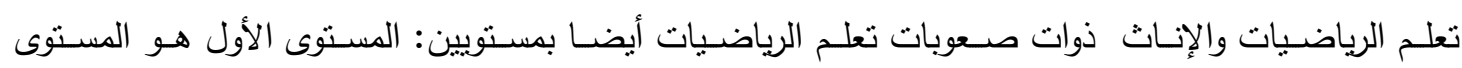

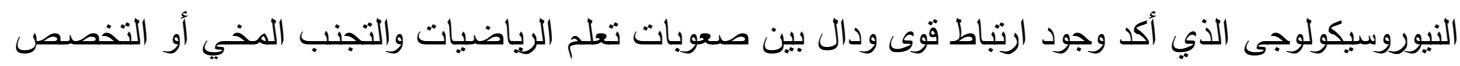

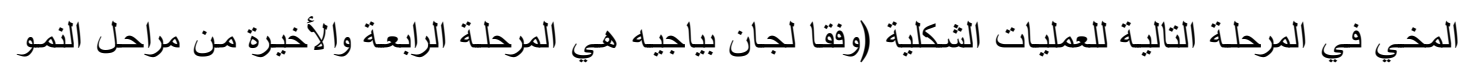

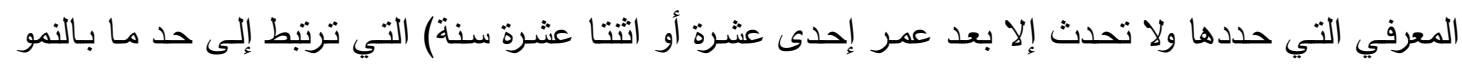
الاجتماعي الذي يركز على النواحي المكانية. أما في الدراسة الحالية، فقد أجريت على أطفال في أعمار تنتراوح

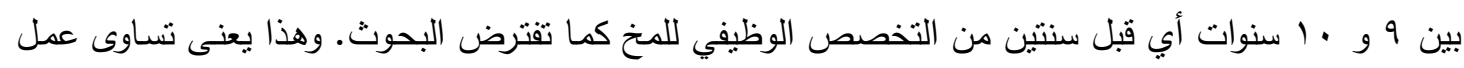

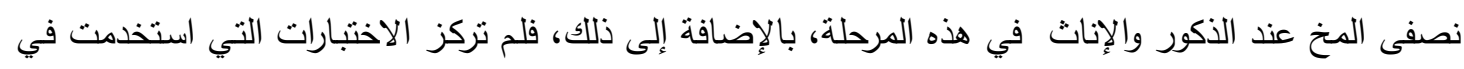
الدراسة الحالية (اختبار التحصيل المدرسي- الاختبار الفرعي للاستدلال الحسابي من مقياس وكسلر لقياس ذكاء لإصاء الأطفال أو مقياس تقدير الأطفال ذوى صعوبات تعلم الرياضيات) على المهام المكانية التي تتيح ظهور الفروق بين الجنسين كما تفترض البحوث والدراسات الأجنبية.

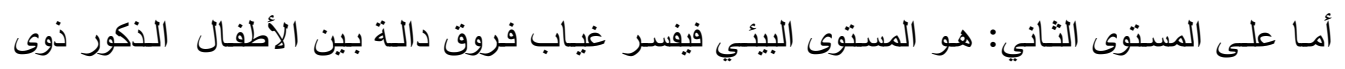

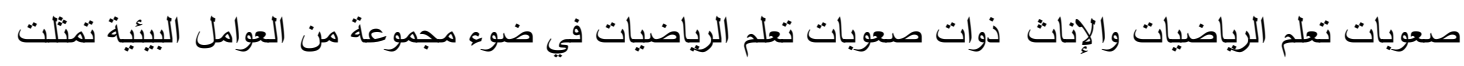


في إتاحة الفرص المتسـاوية للذكور والإنـاث في تعلم الرياضيات، وتسـاوى خبرات الأولاد والبنـات في أثناء حصص الرياضيات. ففي مرحلة الددرسة الابتدائية (موضع الدراسة الحالية) يعطى المدرسين اهتماماً منساوياً

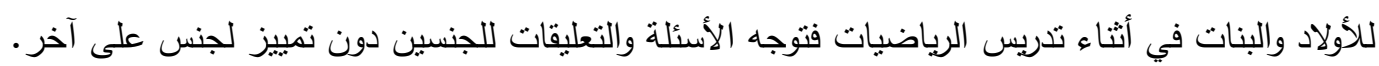

دراسات مقترحة :

فى ضوء نتائج الدراسة الحالية يمكن التوجه بمزيد من الدراسات الخاصة على :

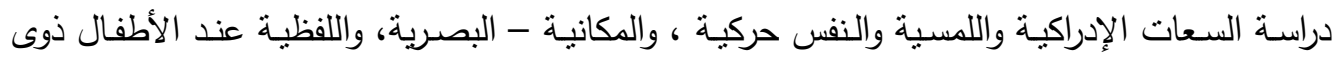

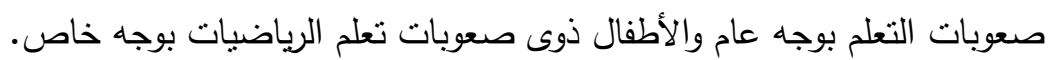

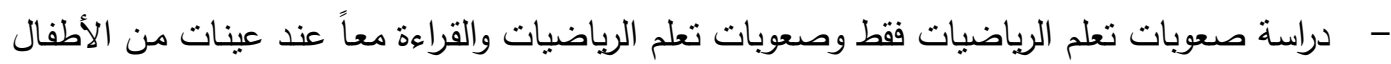

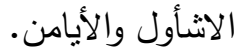
- - دراسة طولية للأطفال ذوى صعوبات تعلم الرياضيات.

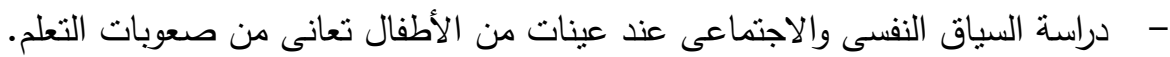
توصيات الاراسة فى ضوء النتائج الدراسة الحالية توصى الدراسة 1- إعداد البرامج التشخيصية والعلاجية للأطفال ذوى صعوبات تعلم الرياضيات فقط.

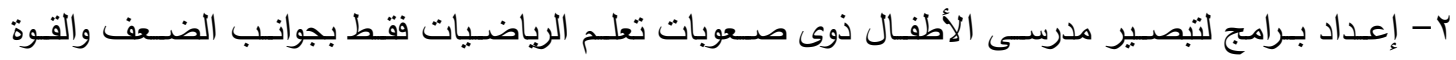

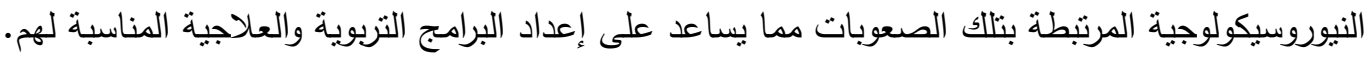
r- تقديم مناهج نظرية لتفسير صعوبات تعلم الرياضيات فقط فى ضوء النموذج النيوروسيكولوجى.

المراجع

1- إسماعيل، محمد عماد الدين ومليكه، لويس كامل (ب99 (1). مقياس وكسلر لذكاء الأطفال. القاهرة: دارالنهضة العربية.

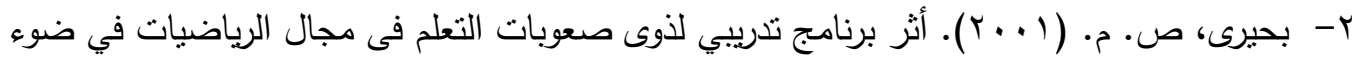
نظرية تجهيز المعلومات ـ رسالة دكتوراه - غير منشورة - معهد الدراسات التربوية، جامعة القاهرة.

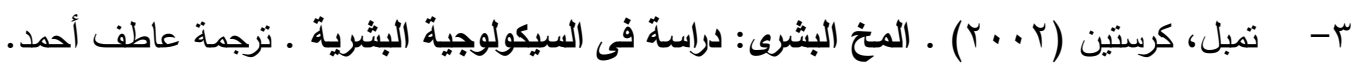

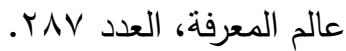

ع - حنفي، هويدا. (1999 (1). برنامج لعلاج صعوبات تعلم القراءة والكتابة والرياضيات لدى تلاميذ

الصف الرابع من التعليم الأساسي. رسالة دكتوراه- غير منشورة- كلية التربية، جامعة إسكندرية. 0- راجح، أحمد عزت (ب99 (199). أصول علم النفس. القاهرة: مكتبة الأنجلو المصرية.

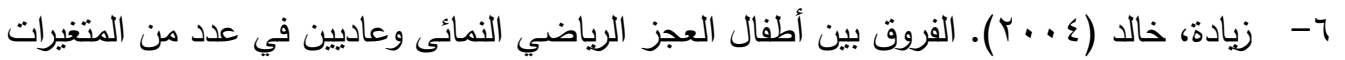

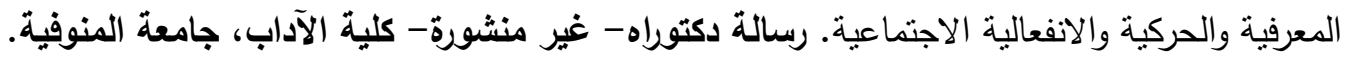

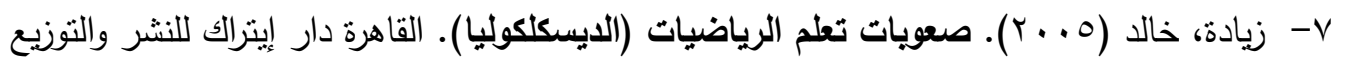

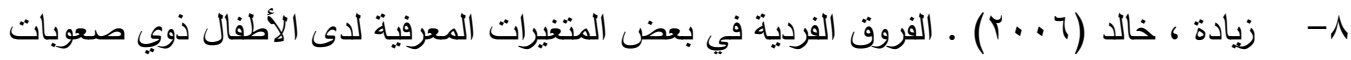

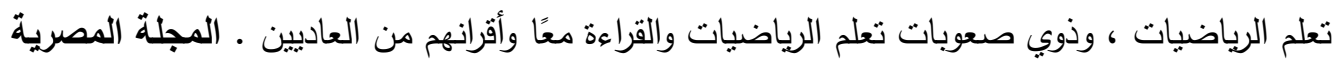

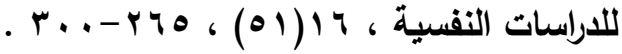

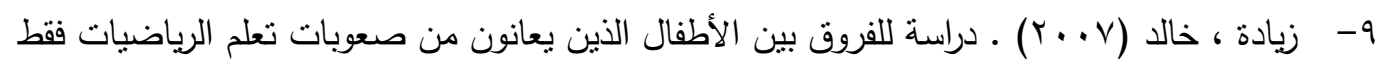

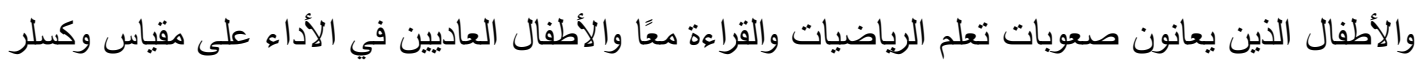

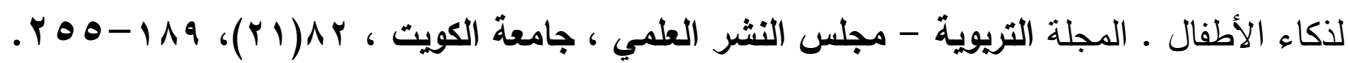




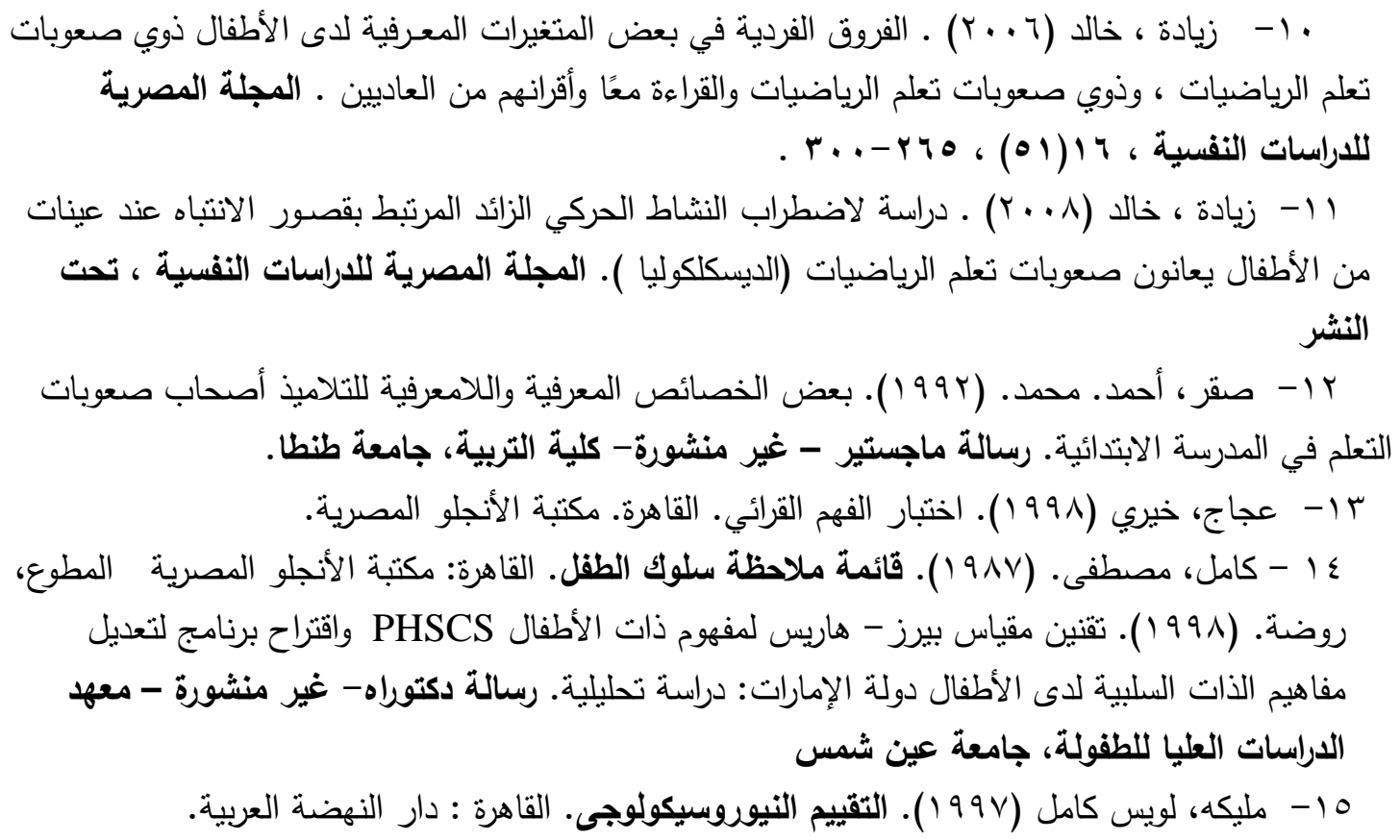

16- American Psychiatric Association (1994). Diagnostic criteria from DSM-IV, Washington, DC.

17 - American Psychiatric Association (2004). Diagnostic criteria from DSM-IV$\mathbf{T R}^{\mathrm{TM}}$, Washington, DC.

18- Badian, N.A. (1999). Persistent arithmetic, reading or arithmetic and reading disability. Annals of Dyslexia, 49, 45-70.

19-Barton,B.\& North,K.(2007).The self- concept of children and adolescents with neurofibromatosis type 1 . Child Care,Health and Development, 33(4),401

20- Bee, H. (1998). Life span development (2nd ed).New York: Longman.

21- Bracken, B.A. (1996). Hand book of self concept: developmental, social, and clinical consideration. New York: Joh Wiley \& Sons. INC.

22- Butterworth, B. (2005). Dyslexia and dyscalculia: a review and programme of research, from www.amthematicalbrain.com.

23- Corsini, R.J. (1999). The dictionary of psychology. United States of America. Toyler \& Francis Group.

24- Cosden, M.A.; Elliott, K.D. \& Noble, S. (1999). Self-understanding and selfesteem in children with learning disabilities. Learning Disability Quarterly, 22(4), 279-290.

(http://195.246.41.29/?sp.nextform=Print.htm\&sp.usernumber.P=73861\&sp.Search.d bid=03/11/22

25- $\quad$ Fuerst, D.R.; Fisk, J.L. \& Rourke, B.P. (1990). Psychosocial functioning of learning disabled children: Relations between WISC verbal Vs IQ Performance IQ discrepancies and Personality Subtypes. Journal of Consulting \& Clinical Psychology. 58(5) 657-660.

26- Gans, A.M.: Kenny , C.M .\& Ghany ,D.(2003) . Comparing the self concept of students with and without learning disabilities . Journal of Learning Disabilities ,36(3),287

27- Geary, C.D. (1993). Mathematical disabilities: Cognitive, neuropsychological and genetic component. Psychological Bullietin, 114 (2), 345-362.

28- Grolnick, W.S. \& Ryan, R.M.(1990). Self-Perceptions, motivation, and adjustment in children with learning disabilities: A multiple group comparison study. Journal of Learning Disabilities, 23(3), 177-184. 
29- Gross-Tsur, V.; Auerbach, J.; Manor, O. \& Shalev, R.S. (1996). Developmental dyscalculia: Cognitive, emotional and behavior manifestations. Approche-Neurochologique-des Apprentessage Chez L'En Fant, 8(4-5): 132-136.

30- Gross-Tsur, V.; Mannor, O., \& Amir, N. (1995). Developmental right hemisphere syndrome: clinical prospective of nonverbal disabilities. Journal of Learning Disabilities, 28 (2), 80-88.

31- Hamilton, I.S. (1996). Dictionary of psychological testing: Assessment and treatment. London: Jessica Kingsley Publishers.

32- Juvonen, J. \& Bear, G. (1992). Social adjustment of children with and without learning disabilities in integrated classrooms. Journal of Educational Psychology, 84(3) 322-330.

33- Kershner, R.J. (1990). Self-concept and IQ as predictors of remedial success in children with learning disabilities. Journal of Learning Disabilities, 23(6), 368-374.

34- Kirk, A.s. \& Gallagher, J.J. (1989). Educating exceptional children $\left(6^{\text {th }}\right.$ ed). $^{\text {d }}$ Boston: Hovghton Mifflin company.

35-Kloomok, S. (1991). Self- concept in children with learning disabilities. Dissertation Abstracts international, 53(5):

36- Lewis, C.; Hitch, G.J. \& Walker, P. (1994). The prevalence of specific arithmetic difficulties and specific reading difficulties in 9-10 years old boys and girls. Journal of Child Psychology and Psychiatry, 35(2), 283-292.

37- Lindsay, R.L.; Tomazic, T.; Mossouri; Levine, M.D. \& Accordo, P.J. (2001). Attentional Function as measured by a continuous performance task in children with dyscalculia. Journal of Developmental Behavior Pediatrics, 22(5): 287-292. (http//www.findarticles.com/cf_0/m0HVD/5_22/80493788/print.jhtml).

38- Mash, E.J. \& Wolfe, D.A. (2002). Abnormal Child Psychology.(2nd ed). United States: Wadsworth.

39-Miller, S.P. \& Mercer, C.D. (1997). Educational aspect of mathematics disabilities. Journal of Learning Disabilities, 30 (1), 47-56.

40- Montgomery, M.S. (1994). Self- concept and children with learning disabilities: Observer-child Concordance across six context-dependent domains. Journal of Learning Disabilities, 27(4), 254-262.

41- Monuteaux, M.C.; Faraone, S.V.; Herzig, K. \& Navsaria, N. (2005). ADHD and dyscalculia: Evidence for independent familial transmission. Journal of Learning Disabilities, 38 (1), 86-93.

42- Nass, R.D. (1993). Sex difference in learning ability and disability. Annals of Dyslexia, 43,61-77. (Psyclnfo).

43-Newman, M.R. (1998). The dyscalculia syndrome. Master of science. Special Education Thesis. (htlp://www.dyscalculia-org/Thesis.html).

44- Reid, D.K. \& Hresko, P.W. (1981). A cognitive approach to learning disabilities. New York: McGraw-Hill Book Company.

45- Revera, D.P. (1997). Mathematical education and students with learning disabilities: Introduction to special special series. Journal of Learning Disabilities, 30 (1), 2-19.

46- Rosenberg, P.B. (1989). Perceptual- motor and attentional correlates of developmental dyscalculia. Annals Neurology. 26(2): 216-220.

47-Rourke, B.P. (1993). Arithmetic disabilities, specific and otherwise: Aneuropsychological perspective. Journal of learning Disabilities, 26 (4): 214-226.

48- Rourke, B.P., \& Conway, J. (1997). Disabilities of arithmetic and mathematical reasoning: perspective from neurology and neuropsychology. Journal of Learning Disabilities, 30 (1), 34-46.

49- Shalev, R.S.; Auerbach, J. \& Gross-Tsur, V. (1995). Developmental dyscalculia behavioral and attentional aspects: A research note. Journal of Child Psychology and Psychiatry, 36(7), 1261-1268.

50- Shalev, R.S.; Manor, O., \& Gross-Tsur, V. (1997). Neuropsychological aspects of developmental dyscalculia. Mathematical Cognition, 3(2); 5-20. 
51- Shalev, R.S.; Manor, O., \& Kerem, B. (2001). Developmental dyscalculia is a familia learning disability. Journal of Learning Disabilities, 34 (1), 59-65.

52- Shalev, R.S.; Manor, O.; Auerbach, J.\& Gross-Tsur, V.(1998). Persistence of developmental dyscalculia: What Counts? Results From a 3 year Prospective follow-up study. Journal of Pediatrics,133(3),358-382.(http://195.246.41.29/? sp. nextform $=$ print. htm $\&$ sp. usernumber.p $=362586 \&$ sp. sear $)$.

53- Share, D.L.; Moffitt, T.E \& Silva, P.A. (1988). Factors associated with arithmetic and reading and specific arithmetic disabilities. Journal of Learning Disabilities, 21(51), 313-320.

54- Vaughn, S; Haager, D.; Hogan, A. \& Kouzekanani, K. (1992). Selfconcept and Peer acceptance in students with learning disabilities: A four-to five year prospective study. Journal of Educational Psychology, 84(1) 43-50. (http://www. Psycinfo.com/Psycarticels/index-cfm?fuseaction=Process Search\&Stai).

55- Wenz, G. M. \& Siparstein, G. N. (1998). Students with learning problems at risk in middle school: stress, social support and adjustment Educational \& Psychological measurements, 58 (5): 832- 835 (Psychinfo).

56- Wong, B.Y.L. (1996). The ABCs of learning disabilities. San Diego: Academic Press. 